\title{
High Performance Cold Climate Heat Pump (CCHP) - Final Report
}

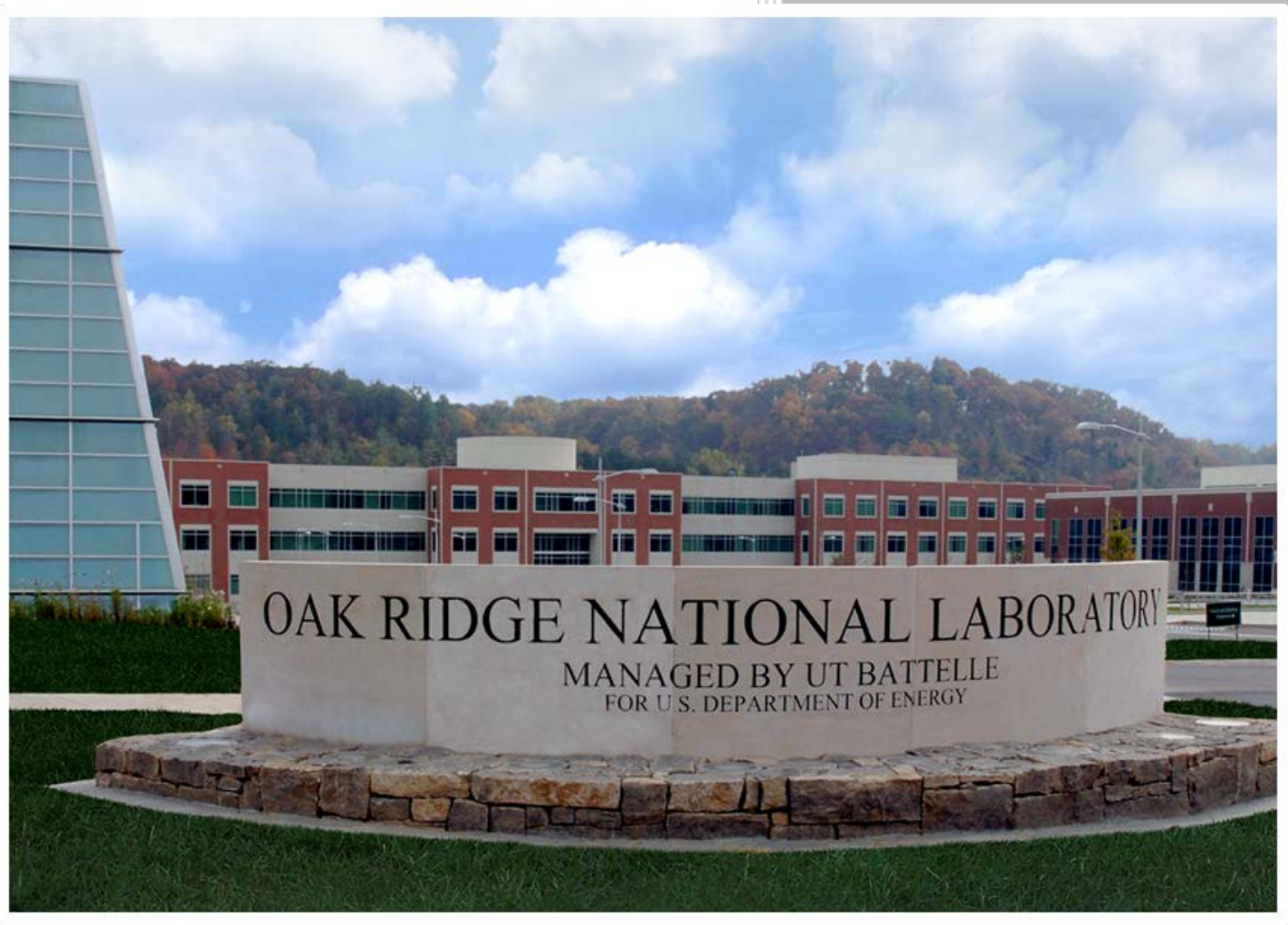

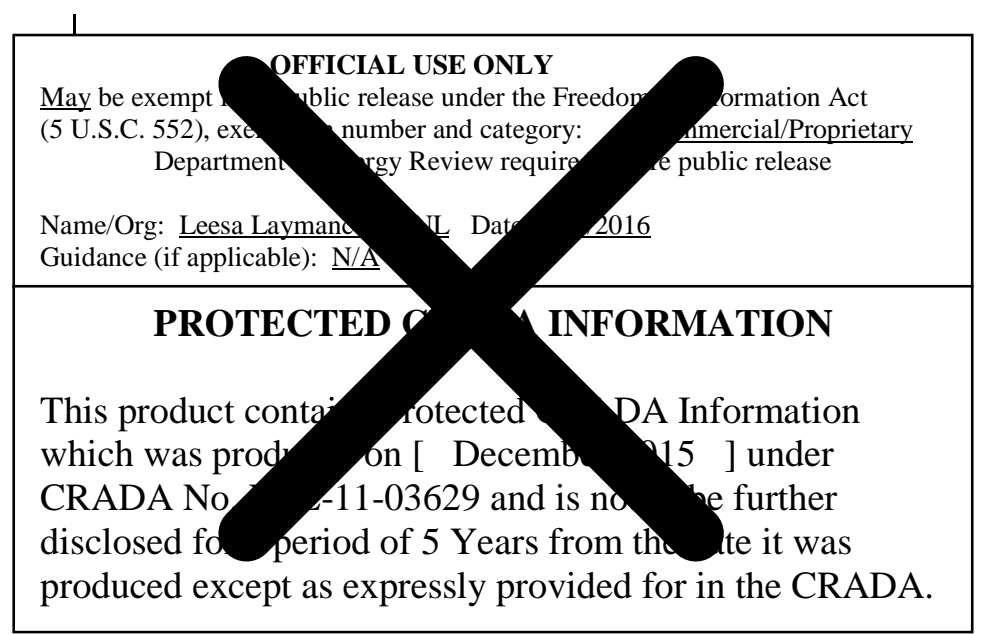

OAK RIDGE NATIONAL LABORATORY MANAGED BY UT-BATTELLE FOR THE US DEPARTMENT OF ENERGY
Bo Shen

Omar Abdelaziz

Van Baxter

C. Keith Rice

December 30, 2015

This document has been reviewed and is determined to be
APPROVED FOR PUBLIC RELEASE.
Name/Title: $\underline{\text { Tammy Claiborne/ORNL TIO }}$
Date: $\underline{03 / 25 / 2021}$




\section{DOCUMENT AVAILABILITY}

Reports produced after January 1, 1996, are generally available free via US Department of Energy (DOE) SciTech Connect.

Website http://www.osti.gov/scitech/

Reports produced before January 1, 1996, may be purchased by members of the public from the following source:

National Technical Information Service

5285 Port Royal Road

Springfield, VA 22161

Telephone 703-605-6000 (1-800-553-6847)

TDD 703-487-4639

Fax 703-605-6900

E-mail info@ntis.gov

Website http://www.ntis.gov/help/ordermethods.aspx

Reports are available to DOE employees, DOE contractors, Energy Technology Data Exchange representatives, and International Nuclear Information System representatives from the following source:

Office of Scientific and Technical Information

PO Box 62

Oak Ridge, TN 37831

Telephone 865-576-8401

Fax 865-576-5728

E-mail reports@osti.gov

Website http://www.osti.gov/contact.html

This report was prepared as an account of work sponsored by an agency of the United States Government. Neither the United States Government nor any agency thereof, nor any of their employees, makes any warranty, express or implied, or assumes any legal liability or responsibility for the accuracy, completeness, or usefulness of any information, apparatus, product, or process disclosed, or represents that its use would not infringe privately owned rights. Reference herein to any specific commercial product, process, or service by trade name, trademark, manufacturer, or otherwise, does not necessarily constitute or imply its endorsement, recommendation, or favoring by the United States Government or any agency thereof. The views and opinions of authors expressed herein do not necessarily state or reflect those of the United States Government or any agency thereof. 
Emerson CRADA final report, December 30, 2015

ORNL/TM-2015/784

CRADA/ NFE-11-03629

Energy and Transportation Science Division

\title{
High Performance Cold Climate Heat Pump (CCHP) - Final Report
}

\author{
Bo Shen \\ Omar Abdelaziz \\ Van Baxter \\ C. Keith Rice
}

Date Published: 02/09/2016

\author{
Prepared by \\ OAK RIDGE NATIONAL LABORATORY \\ Oak Ridge, Tennessee 37831-6283 \\ managed by \\ UT-BATTELLE, LLC \\ for the \\ US DEPARTMENT OF ENERGY \\ under contract DE-AC05-00OR22725
}

Protected CRADA Information

This report contains protected CRADA information which was produced on December, 2015, under CRADA No.NFE-11-03629 and is not to be further disclosed for a period of five years from the date it was produced except as expressly provided for in the CRADA. 


\section{CRADA NFE-11-03629 with Emerson Climate Technologies High Performance Cold Climate Heat Pump (CCHP) - Final Report}

\section{Executive Summary}

In the U. S., there are approximately 2.6 million dwellings that use electricity for heating in very cold and cold regions with an annual energy consumption of 0.16 quads. A high performance cold climate heat pump (CCHP) would result in significant savings over current technologies (> 70\% compared to strip heating). It can result in an annual primary energy savings of 0.1 Quads when fully deployed, which is equivalent to 5.9 million tons of annual $\mathrm{CO}_{2}$ emissions reduction.

The outcome of this project is the development of a split system, cold climate heat pump (CCHP) providing 36,000 Btu/hr $(10.6 \mathrm{~kW})$ heating capacity with a COP $>4.0$ (at the $47^{\circ} \mathrm{F}\left(8.3^{\circ} \mathrm{C}\right) \mathrm{AHRI}$ rating condition) and maximum efficiency degradation of $50 \%$ and capacity loss of $25 \%$ at $-13^{\circ} \mathrm{F}\left(-25^{\circ} \mathrm{C}\right)$ ambient conditions.

Between 2012 and 2015, Oak Ridge National Laboratory (ORNL) and Emerson Climate Technologies engaged in a Cooperative Research and Development Agreement (CRADA) to develop a high efficiency, cold climate heat pump for the US residential market. We went through an exhaustive technologies survey to select energy efficient and cost-effective components. We conducted in-depth engineering design and building energy modeling, based on the ORNL Heat Pump Design Model (HPDM) and EnergyPlus, by which we made the final choices. We selected a cost-effective option, which uses tandem compressors, with a single compressor rated for the building design cooling load, and running two compressors to meet the $75 \%$ capacity goal at $-13^{\circ} \mathrm{F}(-$ $25^{\circ} \mathrm{C}$ ). The tandem compressors, i.e. two parallel, equal-size, single-speed compressors, provided by Emerson Climate Technologies, were optimized for heating operation and are able to tolerate discharge temperature up to $280^{\circ} \mathrm{F}\left(137.8^{\circ} \mathrm{C}\right)$.

We developed lab and field prototypes and successfully met DOE's performance targets. The lab prototype using the tandem single-speed compressors reached $4.24 \mathrm{COP}$ at $47^{\circ} \mathrm{F}$ $\left(8.3^{\circ} \mathrm{C}\right)$; $76 \%$ heating capacity and $1.9 \mathrm{COP}$ at $-13^{\circ} \mathrm{F}\left(-25^{\circ} \mathrm{C}\right)$, and $2.9 \mathrm{COP}$ at $17^{\circ} \mathrm{F}(-$ $8.3^{\circ} \mathrm{C}$ ), having a rated HSPF (HSPF is heating seasonal performance factor $[\mathrm{Btu} / \mathrm{h} / \mathrm{W}]$, defined in AHRI 210/240) of 11.21. Using the same tandem compressors in a breadboard HP, a field investigation was conducted in the past year, in an occupied home in Ohio. The field HP operated successfully for 10 months. During the heating season, the seasonal COP was 3.16, and the HP was able to operate down to $-13^{\circ} \mathrm{F}\left(-25^{\circ} \mathrm{C}\right)$ and eliminate resistance heat use. The HP maintained an acceptable comfort level through the heating season. During the cooling season, the seasonal EER was 17.7, by running a single compressor only. 
Emerson CRADA final report, December 30, 2015

Further efforts were made to increase the HP COPs at low ambient temperatures. We developed a "premium" version using tandem VI compressors. The "premium" prototype reached $4.4 \mathrm{COP}$ at $47^{\circ} \mathrm{F}\left(8^{\circ} \mathrm{C}\right) ; 88 \%$ heating capacity and $2.0 \mathrm{COP}$ at $-13^{\circ} \mathrm{F}\left(-25^{\circ} \mathrm{C}\right)$, and $3.1 \mathrm{COP}$ at $17^{\circ} \mathrm{F}\left(-8.3^{\circ} \mathrm{C}\right)$, having a rated HSPF of 11.84 . The 'premium" prototype performance is uniformly $5 \%$ higher than the option of using tandem, single-speed compressors.

Having achieved the performance goal, Emerson Climate Technologies is actively promoting the design features developed in this project to the US OEMs that use Copeland compressors. 


\section{TABLE OF CONTENTS}

1. Introduction

Page

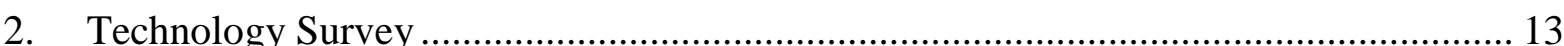

2.1 PRODUCTS MADE BY JAPANESE OEMS …………........................................ 13

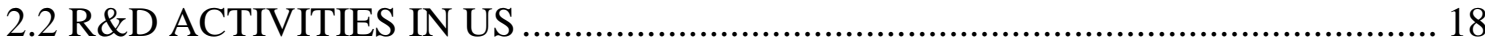

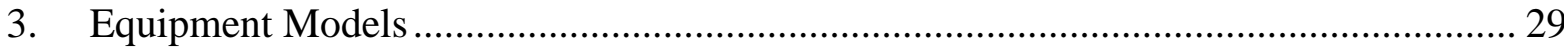

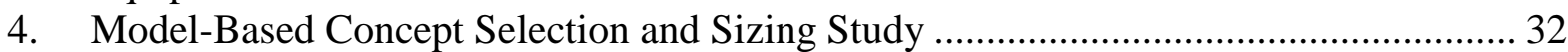

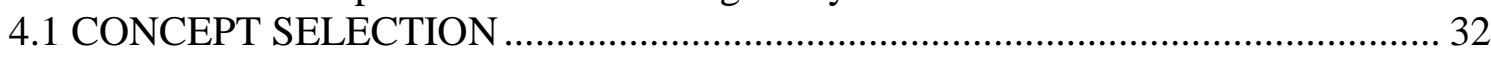

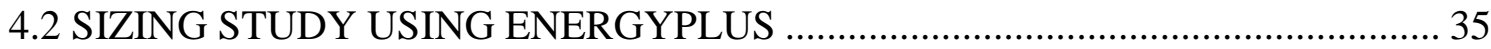

5. Laboratory Investigations ......................................................................................... 46

5.1 'MOST COST-EFFECTIVE' OPTION - EQUAL TANDEM, SINGLE-SPEED

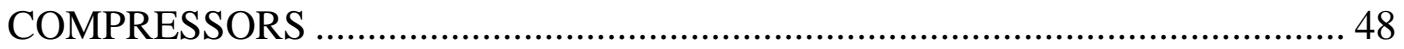

5.2 'PREMIUM’ OPTION - EQUAL TANDEM, VAPOR INJECTION

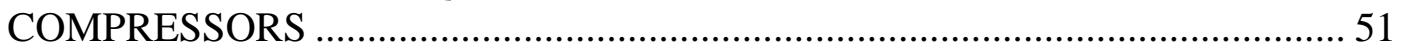

5.3 EJECTOR CYCLE INVESTIGATIONS .......................................................... 55

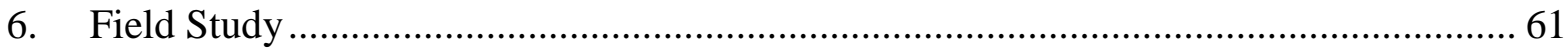

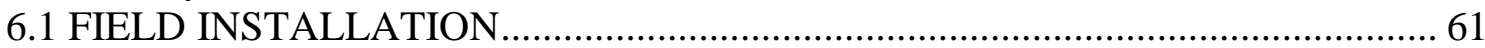

6.2 DATA ACQUISITION AND MEASUREMENT SYSTEM ..................................... 64

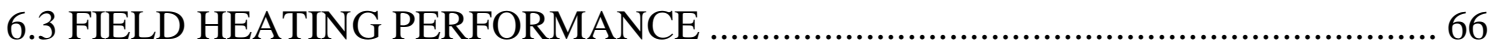

6.4 FIELD COOLING PERFORMANCE ………………......................................... 70

6.5 COMPARE THE ELECTRICITY BILLS BEFORE AND AFTER

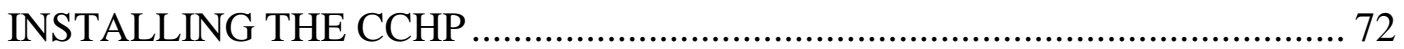
6.6 SENSITIVITY STUDY USING THE HEATING SEASONAL DATA IN 2016 ... 73

7. Comparison to NEEP's Cold Climate Air-Source Heat Pump Listing.............................. 76

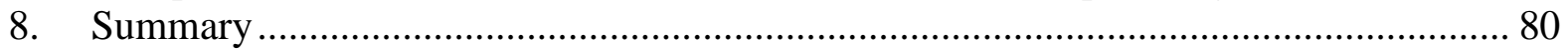

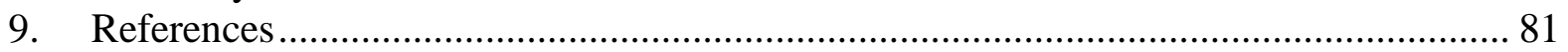




\section{List of Figures}

Figure 1a: Estimates for the Cold Climate HP Shipment, Energy Savings, and Emission

Reduction.

Figure 1b: Building heating load in Region V (DHRmin) compared to heating capacity of a typical ASHP with 7.5 HSPF and a target CCHP having equivalent nominal heating

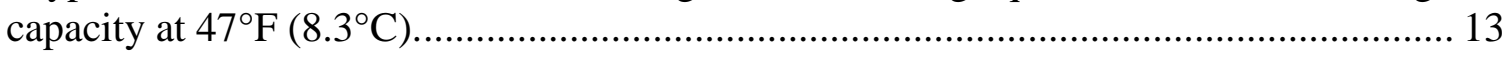

Figure 2: MEC “ZUBADAN” system refrigeration cycle schematic (Katsuta, 2013b)... 14

Figure 3: ZUBADAN heating capacity vs. previous product (Katsuta, 2013b) .............. 14

Figure 4: Hitachi LI system refrigeration cycle schematic (Katsuta, 2013b) ................... 15

Figure 5: Hitachi LI system heating capacity vs. OD wet bulb (Katsuta, 2013b) ............ 15

Figure 6: Daikin VRV two-stage compressor system cycle schematic (Katsuta, 2013b) 17

Figure 7: Two-stage VRV system heating capacity and COP vs. single-stage system

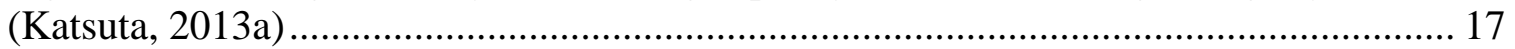

Figure 8: Denso CO2 ejector cycle HPWH cycle schematic (Katsuta, 2013a) ................ 18

Figure 9: Heat pump schematic - Intercooler (Left) - Economizer (Middle) - Cascade

(Right) (Bertsch et al., 2006) .................................................................................... 19

Figure 10: Comparison of the COP for the three technologies with a $50 \%$ second law

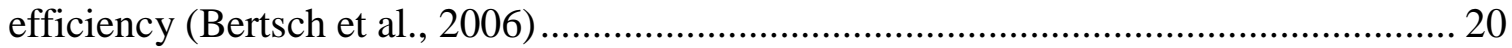
Figure 11: Comparison of the heating capacity for the three technologies (Bertsch et al., 2006)

Figure 12: Schematic of two VI cycles with (a) flash tank (b) economizer heat exchanger

(Abdelaziz et al., 2011).................................................................................................. 22

Figure 13: P-H Diagram of Vapor Injection Cycle....................................................... 22

Figure 14: Flash tank VI cycle (FTC) compared to conventional (baseline) heat pump

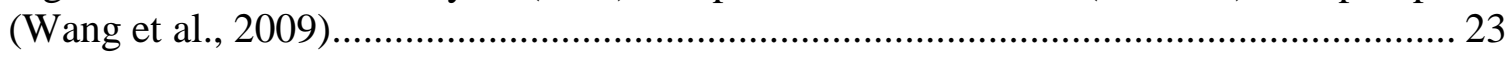

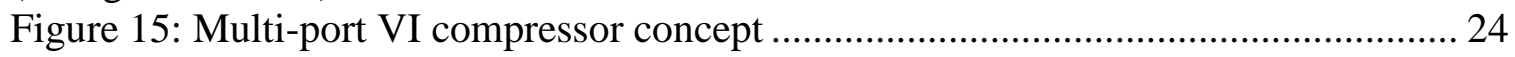

Figure 16: COP compared against the normalized pressure of two-stage heat pump

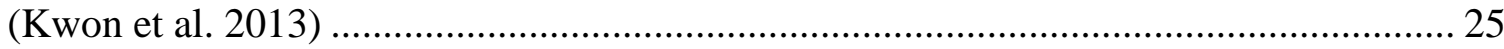

Figure 17: Experimental results of two-stage heat pump compared to simulation results;

manufacturer's data was used to indicate performance of conventional HP (Bertsch et al.

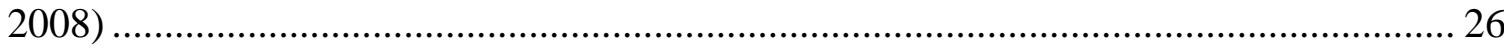

Figure 18: Schematic (left) and p-h cycle diagram (right) of flooded compressor cycle

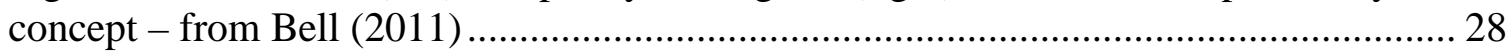

Figure 19: System schematic for oil-flooded heat pump .............................................. 28

Figure 20: GenOpt Optimization Wrapper to a Vapor Compression System Model ....... 32

Figure 21: Ratios of heating capacity relative to $47^{\circ} \mathrm{F}$, COP at $47^{\circ} \mathrm{F}$ and integrated COP

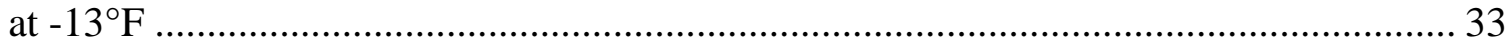

Figure 22: Pressure Ratios Changing with Indoor and Ambient Air Temperatures......... 35 Figure 23: Discharge Temperature Changing with Indoor and Ambient Air Temperatures

Figure 24: Supplemental Electric Resistance Heat Uses, Relative to Annual Heating Energy Consumption, in Commercial, Small Lodging Building................................... 41 
Figure 25: Supplemental Electric Resistance Heat Uses, Relative to Annual Heating Energy Consumption, in Residential, Single-Family Detached House with Heated Basement.

Figure 26: Comparisons of Annual, Average HSPFs (EnergyPlus Simulations) to Calculated HSPFs (AHRI 210/240) in Region V

Figure 27: Ratios of Heating Energy Consumption, Compared to 100\% Electric

Resistance Heating in Commercial, Small Lodging Building

Figure 28: Ratios of Heating Energy Consumption, Compared to 100\% Electric

Resistance Heating in Residential, Single-Family Detached House

Figure 29: Ratios of Heating Energy Consumption, Compared to Baseline 9.6 HSPF,

Single-Speed Heat Pump, in Commercial, Small Lodging Building....

Figure 30: Ratios of Heating Energy Consumption, Compared to Baseline 9.6 HSPF, Single-Speed Heat Pump, in Residential, Single-Family Detached House....

Figure 31: Heating Energy Reductions per Ton of Building Design Cooling Capacity, in Commercial, Small Lodging Building, Compared to 100\% Electric Resistance Heating 44 Figure 32: Comparing Heating Energy Reductions per Ton of Building Design Cooling Capacity, between Commercial, Small Lodging Building and Residential, Single-Family Detached House, Compared to 100\% Electric Resistance Heating... 44 Figure 33: Total Source Energy Consumption Percentages Relative to Baseline 90\% AFUE Gas Heating in Residential, Single-Family Detached House ............................. 45 Figure 34: Lab Prototype - Outdoor Unit (setup for investigating an ejector) ................. 47 Figure 35: Lab Prototype - Indoor Air Handler ............................................................ 47 Figure 36: CCHP using tandem, single-speed compressors and an EXV for discharge temperature control in heating mode 49

Figure 37: Insulated Copeland Tandem Compressors. ................................................ 49

Figure 38: Comparison of Air-Side COPs of New and Previous Tandems at $-13^{\circ} \mathrm{F}$........ 51 Figure 39: Comparison of Air-Side Heating Capacities of New and Previous Tandems at $-13^{\circ} \mathrm{F}$ 51

Figure 40: CCHP using tandem VI compressors and an EXV for discharge temperature

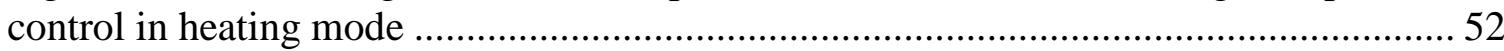
Figure 41: CCHP using tandem VI compressors and suction line heat exchanger .......... 52 Figure 42: Heating capacity vs. ambient temperature, for tandem single-speed compressors and tandem VI compressors.....

Figure 43: Heating COP vs. ambient temperature, for tandem single-speed compressors and tandem VI compressors. 53

Figure 44: Supply Air Temperature vs. ambient temperature, for tandem single-speed compressors and tandem VI compressors.

Figure 45: Heating capacity vs. ambient temperature, for tandem single-speed

compressors and Mitsubishi Hyper Heat (H2i) Series P ............................................ 55

Figure 46: An Ejector and P-H diagram of the ejector cycle....................................... 56

Figure 47: CCHP laboratory system, for comparing Ejector to EXV . .......................... 56

Figure 48: Ejector parts and assembly ................................................................ 57

Figure 49: Scenario A: Temperature Profiles with a Properly Sized Ejector ................... 58

Figure 50: Scenario B: Temperature Profiles with an Over-Sized Ejector...................... 58

Figure 51: Scenarios C and D: Evaporator Temperature Profiles with an Undersized

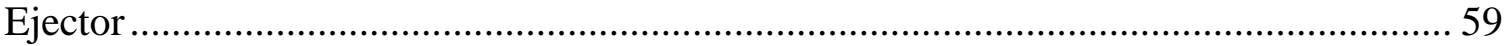




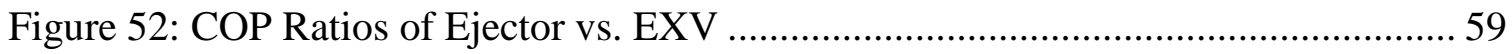

Figure 53: COP Enhancements by Using Pump(s) to Boost Ejector Flow ....................... 60

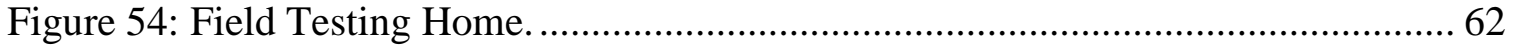

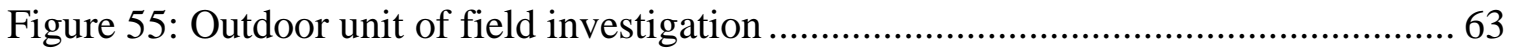

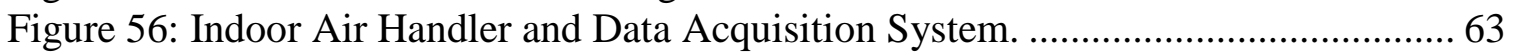

Figure 57: Data acquisition system schematic for CCHP field test................................ 64

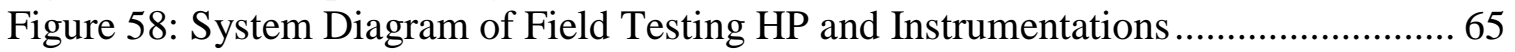

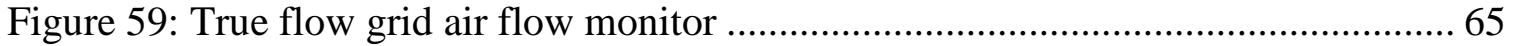

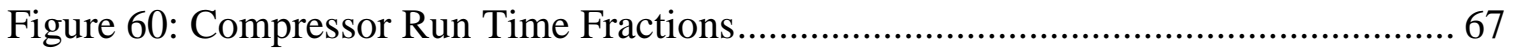

Figure 61: Delivered Heat Capacities and Measured Building Heating Load Line ......... 67

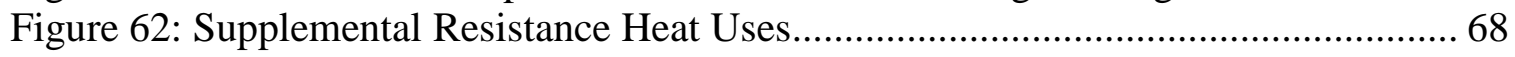

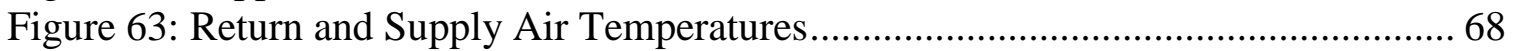

Figure 64: Defrost time ratio and load relative to capacity delivered in each bin ............ 69

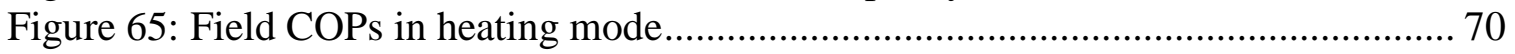

Figure 66: Percentages of Heat Energy Delivered by Bins in 2015 .............................. 70

Figure 67: Return and supply air temperatures in cooling mode................................. 71

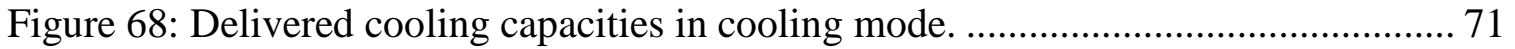

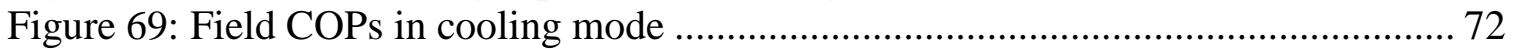

Figure 70: Comparing electric bills of the field testing home before/after installing the

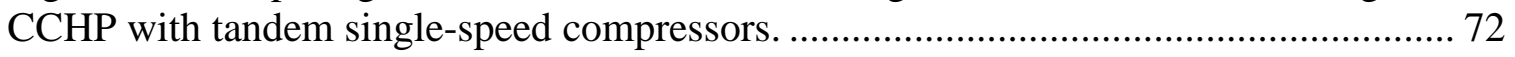

Figure 71: Overlay the field testing data with the electricity bills................................. 73

Figure 72: Return air temperatures in 2015 and 2016 heating seasons ........................... 74

Figure 73: Supply air temperatures in 2015 and 2016 heating seasons ........................... 74

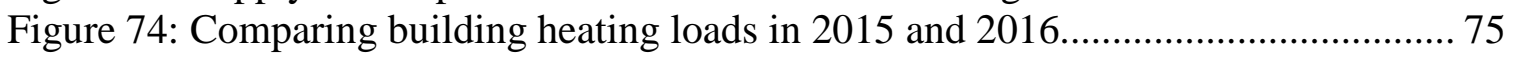

Figure 75: Compressor running time fractions in the 2016 heating season..................... 75

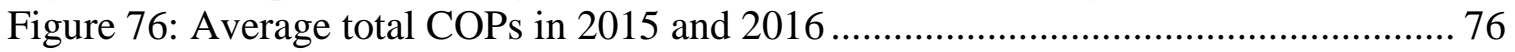

Figure 77: Percentages of Heat Energy Delivered by Bins in 2016 .............................. 76

Figure 78: Rated Capacity Ratios at $17^{\circ} \mathrm{F}$ vs Rated Heating Capacity.............................. 77

Figure 79: COPs at $47^{\circ} \mathrm{F}$ vs. Rated Heating Capacity .................................................... 77

Figure 80: COPs at $17^{\circ} \mathrm{F}$ vs. Rated Heating Capacity ................................................ 78

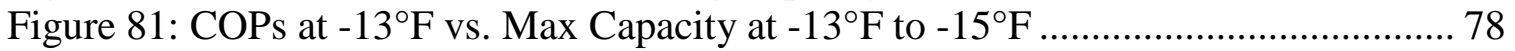

Figure 82: CCHP Net COPs Matching Min and Max Load Lines in Region IV ............ 79

Figure 83: CCHP Net COPs Matching Min and Max Load Lines in Region V ............... 80 
Emerson CRADA final report, December 30, 2015

\section{LIST OF TABLES}

Table 1: Heating capacity specifications for cold climate Toshiba Carrier.... 16

Table 2: Comparing different heat pump technologies to a single-stage baseline (Bertsch et al., 2006)

Table 3: ESTCP project performance objectives of the cold climate heat pump ............. 27

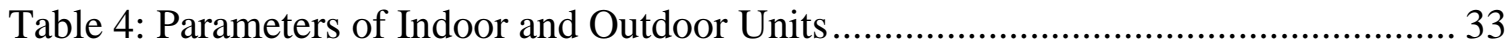

Table 5: Heat Pump Design and Sizing Options

Table 6: System Indices Predicted by HPDM and HSPF Calculations by AHRI 210/240

Table 7: Performance indices of CCHPs using tandem single-speed compressors.......... 50

Table 8: Heating Seasonal Performance Factors of CCHPs using tandem single-speed compressors. 50

Table 9: Heating Seasonal Performance Factors of CCHPs using tandem VI compressors

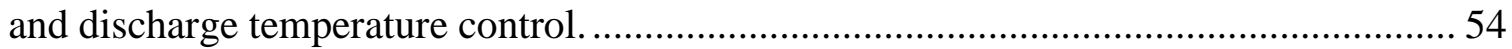

Table 10: Previous Single-Speed Heat Pump in the Testing Home ................................ 73 


\section{Introduction}

As described by Khowailed et al. (2011), Cold climate heat pump (HP) technology is relevant to a substantial portion of the U.S. population, especially with more than onethird of U.S. housing stock concentrated in colder regions of the country and another $31 \%$ in the mixed-humid climate region. The findings of this report can be summarized as shown in Figure 1a below. The study showed that the cold climate heat pumps should be considered as alternative to electric furnaces and heat pumps with auxiliary heating in the mixed humid climate region. The cold climate heat pump technology is estimated to have an annual shipment of 275,500 units to supplant electric furnaces, electric heat pumps, and gas furnaces. Assuming that the cold climate HP technology fulfills this estimated market penetration, an annual estimated national site energy savings of 0.0037 quads, and a carbon emission reduction of 0.47 million Ton are expected to be realized.

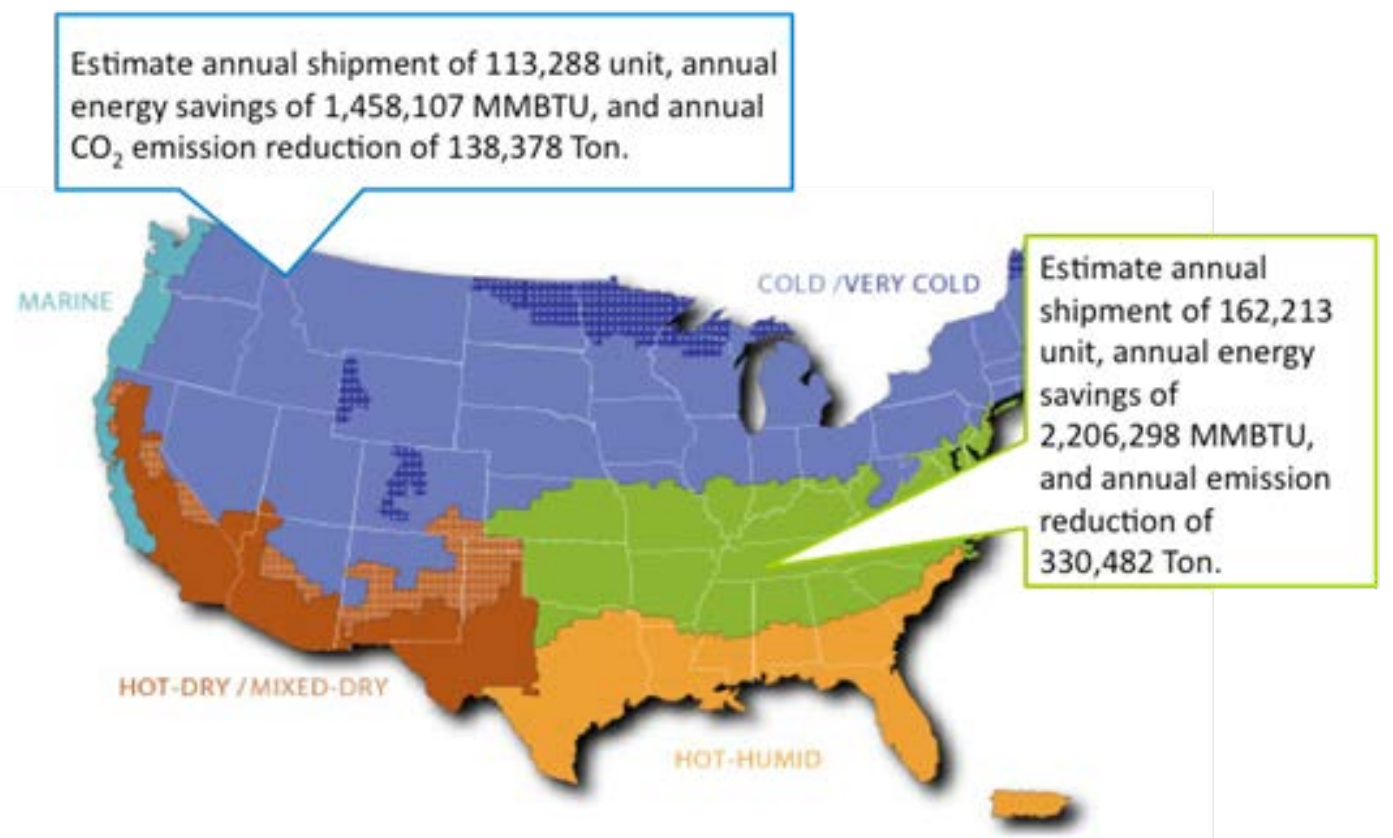

Figure 1a: Estimates for the Cold Climate HP Shipment, Energy Savings, and Emission Reduction.

A look at the heating fuel and equipment currently being used in the housing stock provides an insight into the competing equipment that cold climate HPs hope to replace. The primary target market for the cold climate HP (CCHP) is the 2.6 million U.S. homes using electric furnaces and HPs in the cold/very cold region. It is estimated that $4.75 \%$ of these homeowners either replace or buy new heating equipment in a given year. Accordingly, the project team could infer that the cold climate HP primary market is composed of 123,500 replacements of electric furnaces and conventional air-to-air HPs annually. A secondary housing market for the cold climate HP comprises homes in the mixed-humid region of the country that are using electric furnaces. The cold climate HP could also target as a secondary market homes across both the cold/very cold and mixed- 
humid regions that use propane and fuel oil as their primary heating fuel. Homes using gas furnaces across both the cold/very cold and mixed-humid regions represent another, albeit more challenging, secondary market for the cold climate HP. The combined total of homes in these three secondary markets is 46 million, and we can also infer that about 2.2 million of these systems are replaced annually.

When comparing heating equipment stock in 2001, 2005, and 2009 in the cold/very cold region of the country, it appears that gas furnaces are slowly losing market share and that electric furnaces and HPs are making gains. The fact that electricity-dependent heating equipment is rising in preference among homeowners in the colder regions of the country suggests that future penetration of the cold climate HP holds promise. Accordingly, cold climate HP technology could achieve an attractive position, given certain favorable market conditions such as reaching a competitive cost point, strong federal incentives, a consistent level of reliable performance and competitive, and a product rollout by a credible market leader.

A typical single-speed, air-source heat pump (ASHP) having a HSPF of 7.7 (HSPF is heating seasonal performance factor [Btu/h/W], defined in AHRI 210/240), as shown in Figure 1b, doesn't work well under cold outdoor temperature conditions typical of cold climate locations for three major reasons:

1. Too high discharge temperature: low suction pressure and high pressure ratio at low ambient temperatures cause significantly high compressor discharge temperatures, in excess of the maximum limit for many of the current compressors on the market. Furthermore, system charge of a heat pump is usually optimized in cooling mode, which leads to overcharge conditions in heating mode, further increasing the discharge temperature.

2. Insufficient heating capacity: heating capacity of a single-speed heat pump decreases with ambient temperature. As illustrated in Figure 1b, the heating capacity at $-13^{\circ} \mathrm{F}(-$ $\left.25^{\circ} \mathrm{C}\right)$ typically decreases to $20 \%$ to $40 \%$ of the rated heating capacity at $47^{\circ} \mathrm{F}\left(8.3^{\circ} \mathrm{C}\right)$ ( equivalent to the rated cooling capacity at $95^{\circ} \mathrm{F}\left(35^{\circ} \mathrm{C}\right)$ ). As such, a single-speed heat pump, sized to match the building cooling load, is not able to provide adequate heating capacity to match the building heating load at low ambient temperatures, and supplemental resistance heat has to be used.

3. Low COP: heating COP degrades significantly at low ambient temperatures, due to the elevated temperature difference between the source side and demand side. 


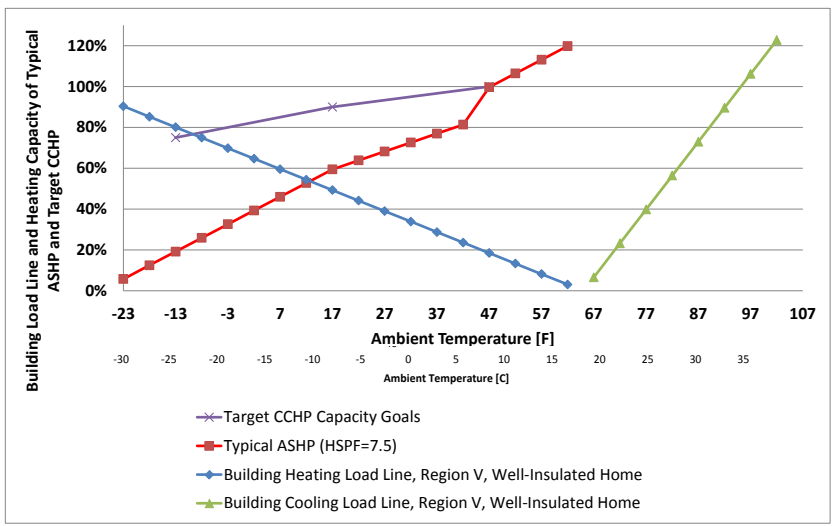

Figure 1b: Building heating load in Region V (DHRmin) compared to heating capacity of a typical ASHP with 7.5 HSPF and a target CCHP having equivalent nominal heating capacity at $47^{\circ} \mathrm{F}\left(8.3^{\circ} \mathrm{C}\right)$.

For the CCHP development, cost-effective solutions should be identified to tackle the above three issues. DOE's performance targets for CCHPs are 1) to maintain heating capacity at $-13^{\circ} \mathrm{F}\left(-25^{\circ} \mathrm{C}\right)$ greater than $75 \%$ of the rated heating capacity at $47^{\circ} \mathrm{F}\left(8.3^{\circ} \mathrm{C}\right)$, and 2) heating $\mathrm{COP}$ at $47^{\circ} \mathrm{F}\left(8.3^{\circ} \mathrm{C}\right)$ greater than 4.0 . The $75 \%$ capacity criterion would result in a heat pump capacity approximately equal to the building heating load for a well-insulated home at $-13^{\circ} \mathrm{F}\left(-25^{\circ} \mathrm{C}\right)$ in Region $\mathrm{V}$ (assumed to be the minimum design heating requirement-DHRmin load condition as defined by AHRI Standard 210/240 for Region $\mathrm{V}$ ), where the building heating load at $-13^{\circ} \mathrm{F}\left(-25^{\circ} \mathrm{C}\right)$ is $80 \%$ of the building cooling design load at $95^{\circ} \mathrm{F}\left(35^{\circ} \mathrm{C}\right)$ ambient temperature.

\section{Technology Survey}

\subsection{Products Made by Japanese OEMs}

Mitsubishi Electric Corporation (MEC) developed a system called ZUBADAN featuring a 'FLASH injection cycle' (Vapor Injection - VI refrigeration cycle) as illustrated schematically in Figure 2. The maximum heating capacity was increased by $20 \%$ under the condition of ambient temperature at $5^{\circ} \mathrm{F}\left(-15^{\circ} \mathrm{C}\right)$. In order to achieve its high heating mode performance, intracycle heat recovery via a heat inter changer (HIC) was applied to subcool refrigerant using the VI flow stream before entering the expansion valve and thus increasing the heat gain from ambient by the evaporator (outdoor) heat exchanger (HEX or $\mathrm{HX}$ ). The VI flow stream controls the discharge temperature of the compressor, allowing it to run at maximum speed even under the high compression ratios experienced during low ambient temperature operation. Figure 3 shows the cycle performance capacity ratio at $-13^{\circ} \mathrm{F}\left(-25^{\circ} \mathrm{C}\right)$ ranges from $\sim 71-75 \%$ of rated heating capacity. 


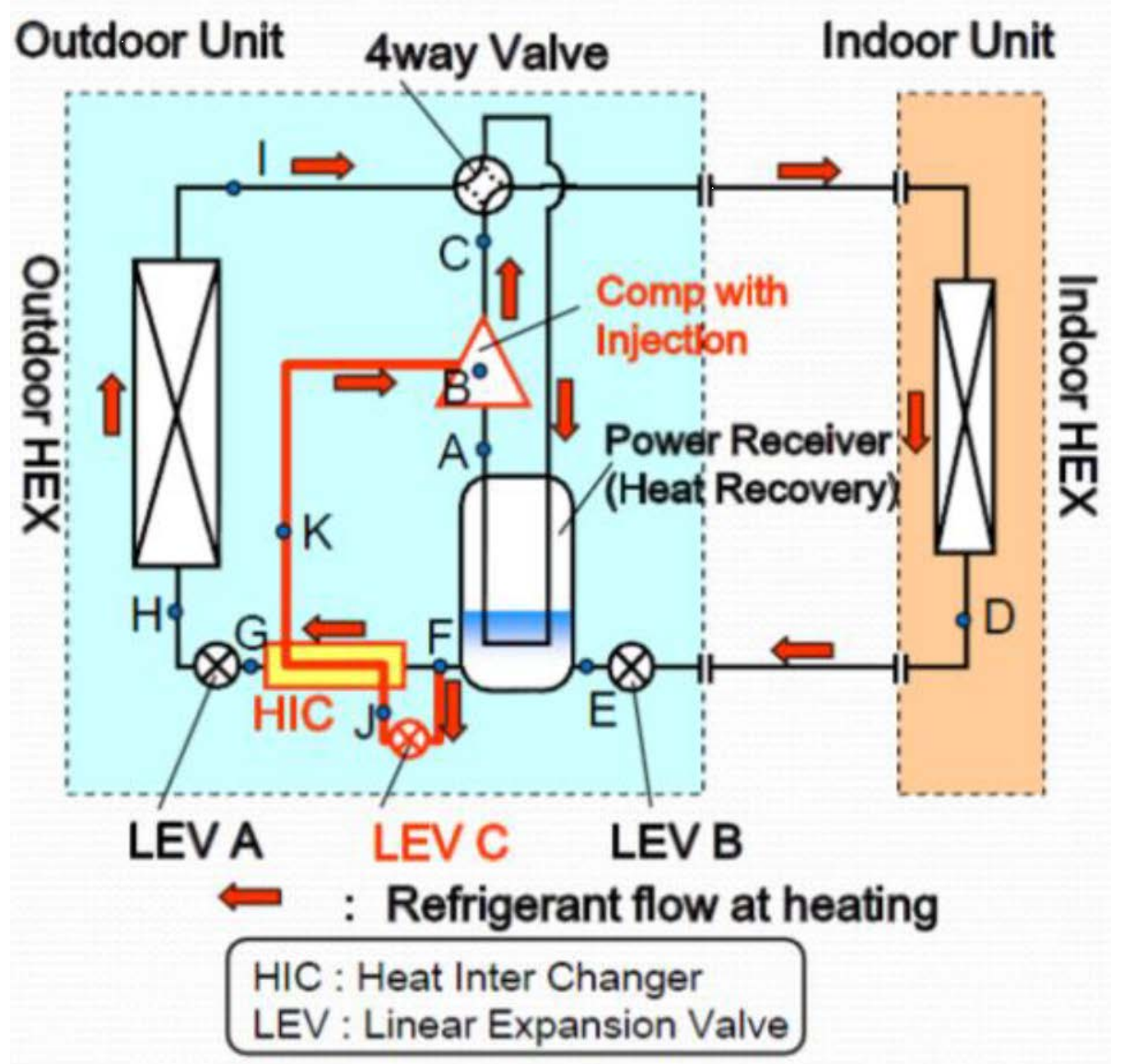

Figure 2: MEC "ZUBADAN" system refrigeration cycle schematic (Katsuta, 2013b)

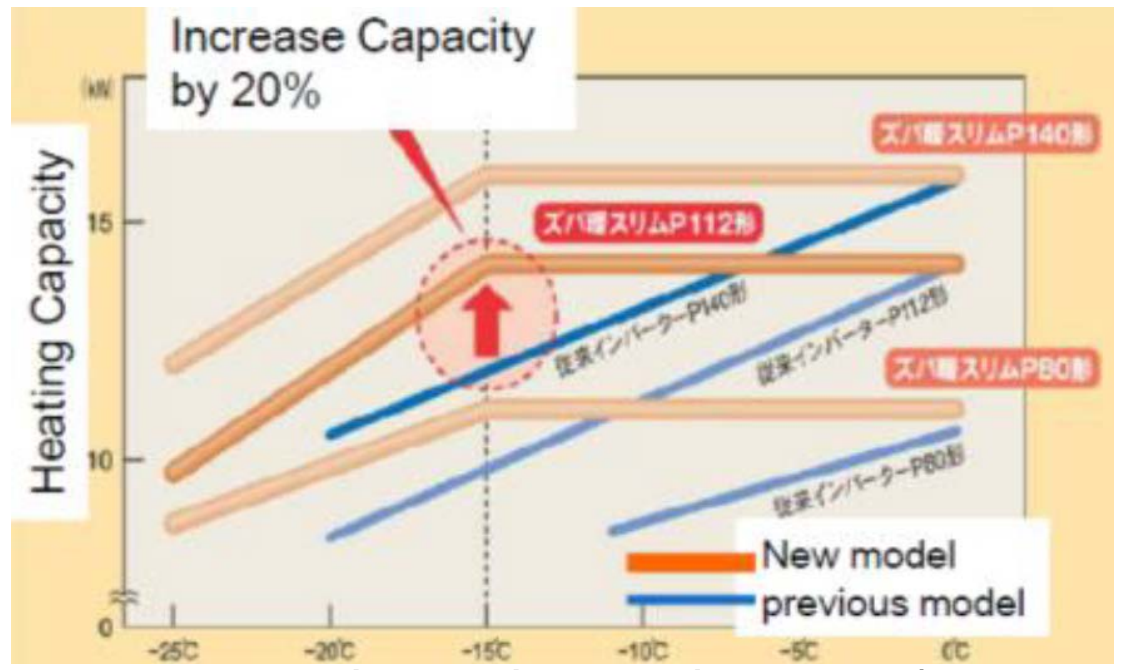

Figure 3: ZUBADAN heating capacity vs. previous product (Katsuta, 2013b)

Hitachi developed an A/C product using a liquid injection (LI) refrigeration cycle for cold regions, illustrated in Figure 4 . Figure 5 shows that the system capacity ratio at $13^{\circ} \mathrm{F}\left(-25^{\circ} \mathrm{C}\right)$ outdoor temperatures ranges from $\sim 75 \%$ to $80 \%$ vs. rated capacity. 


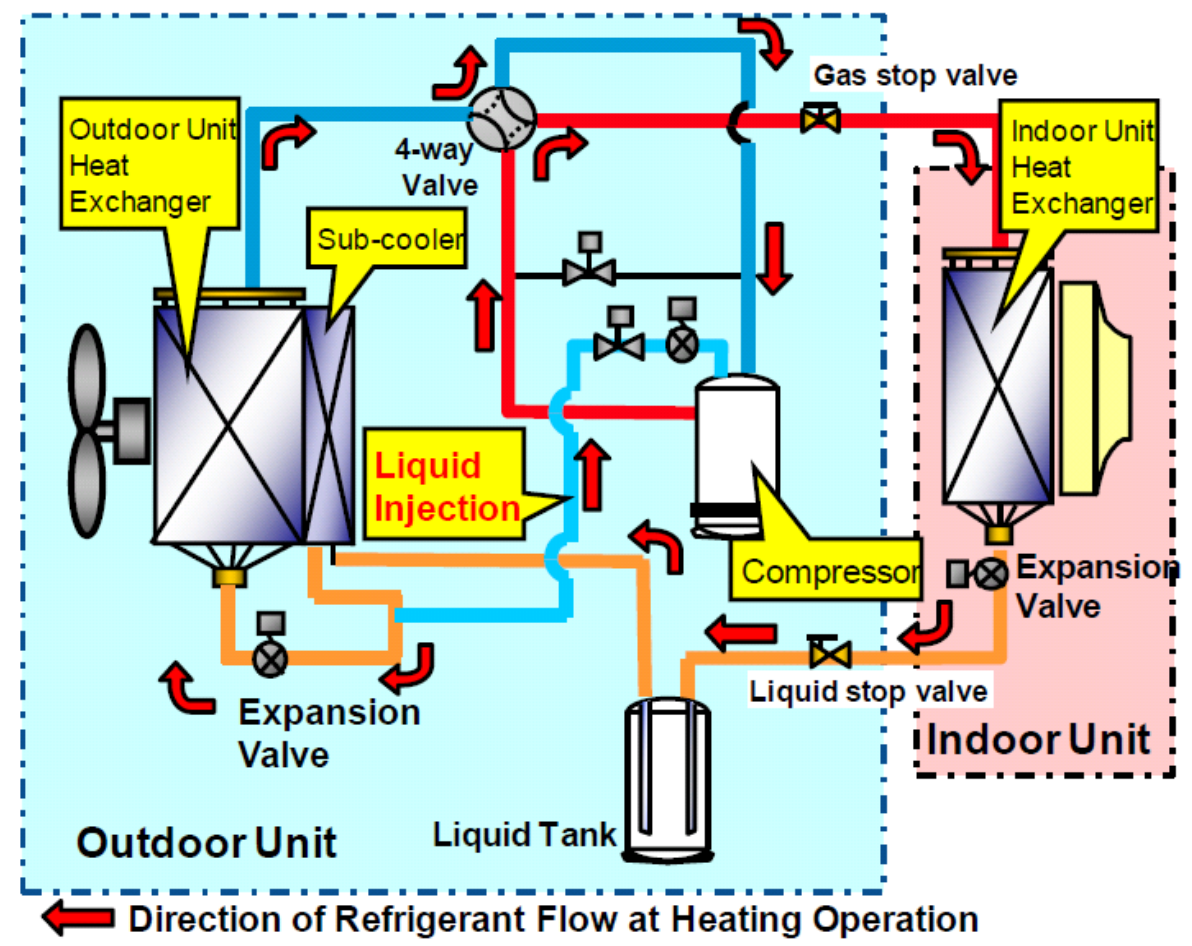

Figure 4: Hitachi LI system refrigeration cycle schematic (Katsuta, 2013b)

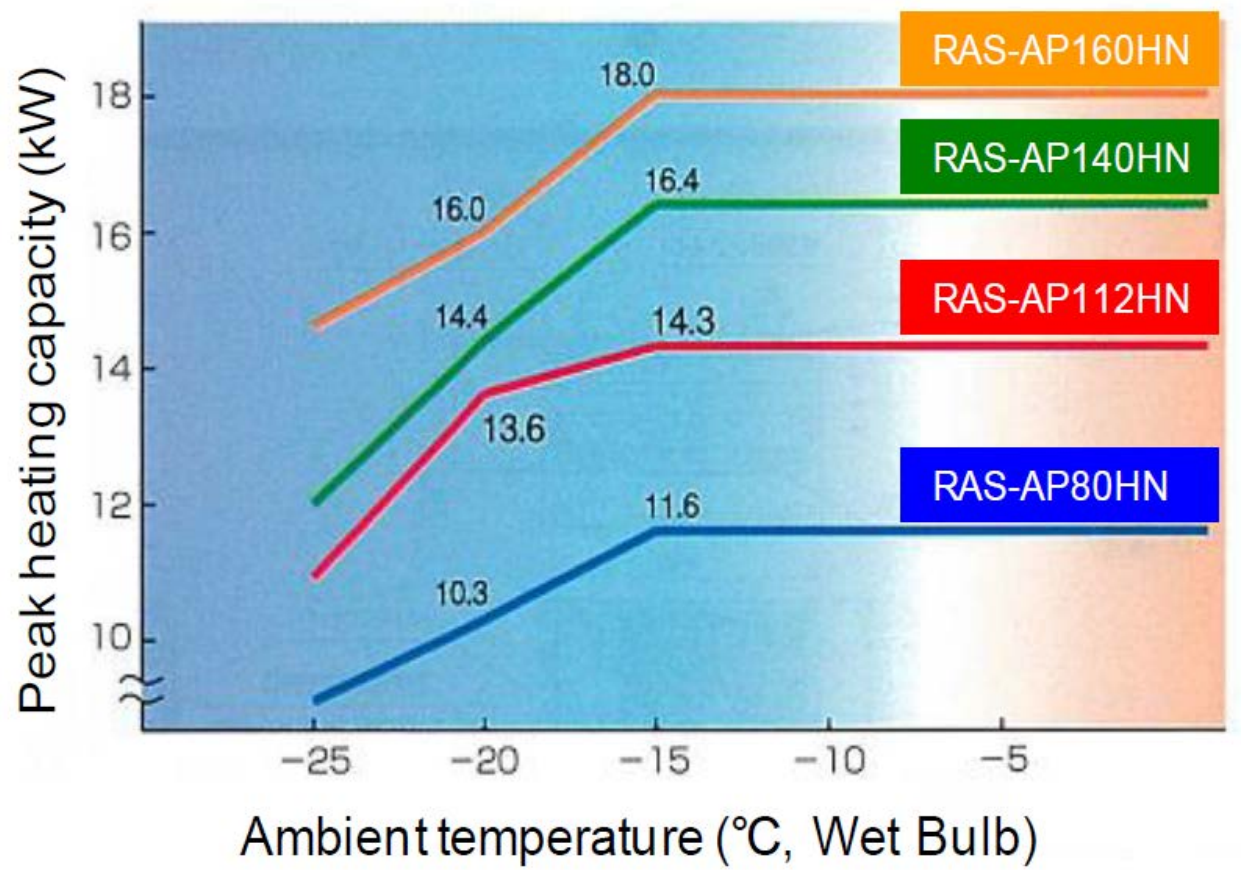

Figure 5: Hitachi LI system heating capacity vs. OD wet bulb (Katsuta, 2013b)

Toshiba Carrier developed a heat pump for stores and offices in cold climates. Several features have been incorporated across this entire product line to enhance cold climate 
Emerson CRADA final report, December 30, 2015

performance. These include an optimized outdoor HX design, a defrost circuit that bypasses the indoor $\mathrm{HX}$ during defrost cycles to speed defrost times, and a refrigerant subcooling loop installed in the outdoor HX drain pan to ensure defrost water does not refreeze during extended cold ambient operation. The heating capacity specifications for each size system in the product line are summarized in Table 1 . The heating capacity of the system remains constant down to $5^{\circ} \mathrm{F}\left(-15^{\circ} \mathrm{C}\right)$ by controlling the maximum compressor speed according to outside temperature. The heating capacity ratio at $4^{\circ} \mathrm{F}$ ($\left.20^{\circ} \mathrm{C}\right)$ vs. low temperature $35.6^{\circ} \mathrm{F}\left(2^{\circ} \mathrm{C}\right)$ rated capacity ranges from about $85-90 \%$ for these products. Compared to the rated capacity, the capacity ratio at $4^{\circ} \mathrm{F}\left(-20^{\circ} \mathrm{C}\right)$ ranges from about $90-130 \%$.

Table 1: Heating capacity specifications for cold climate Toshiba Carrier

\begin{tabular}{|c|c|c|c|c|c|}
\hline & & $3 \mathrm{HP}$ & $4 \mathrm{HP}$ & $5 \mathrm{HP}$ & $6 \mathrm{HP}$ \\
\hline Rated heating capacity & $(\mathrm{kW})$ & 8.0 & 11.2 & 14.0 & 16.0 \\
\hline Rated heating COP & & 4.42 & 4.36 & 4.47 & 4.00 \\
\hline $\begin{array}{l}\text { Rated heating capacity at low } \\
\text { temperature } \\
\text { (outside temperature: } 2^{\circ} \mathrm{C} \text { ) }\end{array}$ & $(\mathrm{kW})$ & 11.5 & 14.2 & 16.3 & 16.8 \\
\hline $\begin{array}{l}\text { Heating capacity at low } \\
\text { temperature } \\
\text { (outside temperature: }-15^{\circ} \mathrm{C}^{\star} \text { ) }\end{array}$ & $(\mathrm{kW})$ & 11.5 & 14.2 & 16.3 & 16.8 \\
\hline $\begin{array}{l}\text { Heating capacity at low } \\
\text { temperature } \\
\text { (outside temperature: }-20^{\circ} \mathrm{C}^{*} \text { ) }\end{array}$ & $(\mathrm{kW})$ & 10.3 & 12.0 & 14.3 & 14.8 \\
\hline Outdoor unit dimensions & $(\mathrm{mm})$ & \multicolumn{2}{|c|}{$1340 \mathrm{H} \times 900 \mathrm{~W} \times 320 \mathrm{D}$} & \multicolumn{2}{|c|}{$1540 \mathrm{H} \times 900 \mathrm{~W} \times 320 \mathrm{D}$} \\
\hline Outdoor unit weight & $(\mathrm{kg})$ & \multicolumn{2}{|c|}{95} & \multicolumn{2}{|c|}{116} \\
\hline
\end{tabular}

${ }^{*}$ Conditions were set by the manufacturer. Heating capacities are peak values and do not include defrost functions.

Daikin Industries introduced a variable refrigerant volume (VRV) product for cold climates featuring two-stage compression with a flash tank intercooler economizer cycle. Figure 6 is a schematic of the system refrigeration cycle. Heating capacity and COP of the system is summarized in Figure 7 - note that the capacity data in the graph do not include any degradation due to frosting. The capacity ratio at $-14^{\circ} \mathrm{C}\left(-10^{\circ} \mathrm{F}\right)$ vs. rated capacity at $41^{\circ} \mathrm{F}\left(5^{\circ} \mathrm{C}\right)$ is $90 \%$. Adding two-stage cycle with intercooler economizer to the system achieves $\sim 10 \%$ higher COP than for a similar size single-stage system. 


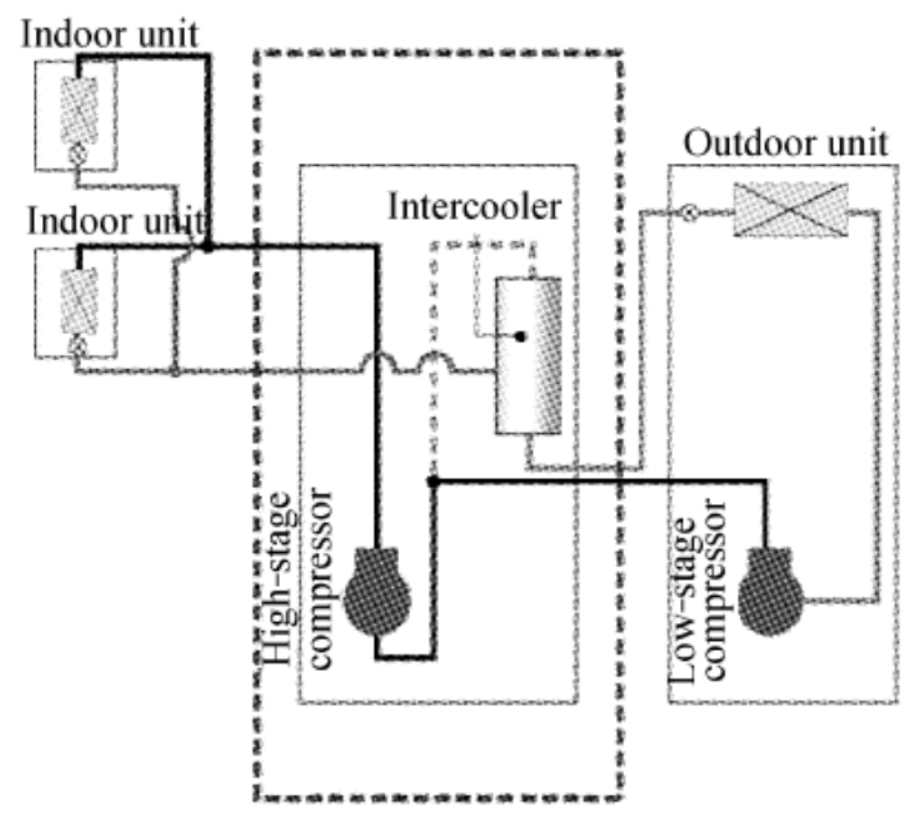

Figure 6: Daikin VRV two-stage compressor system cycle schematic (Katsuta, 2013b)
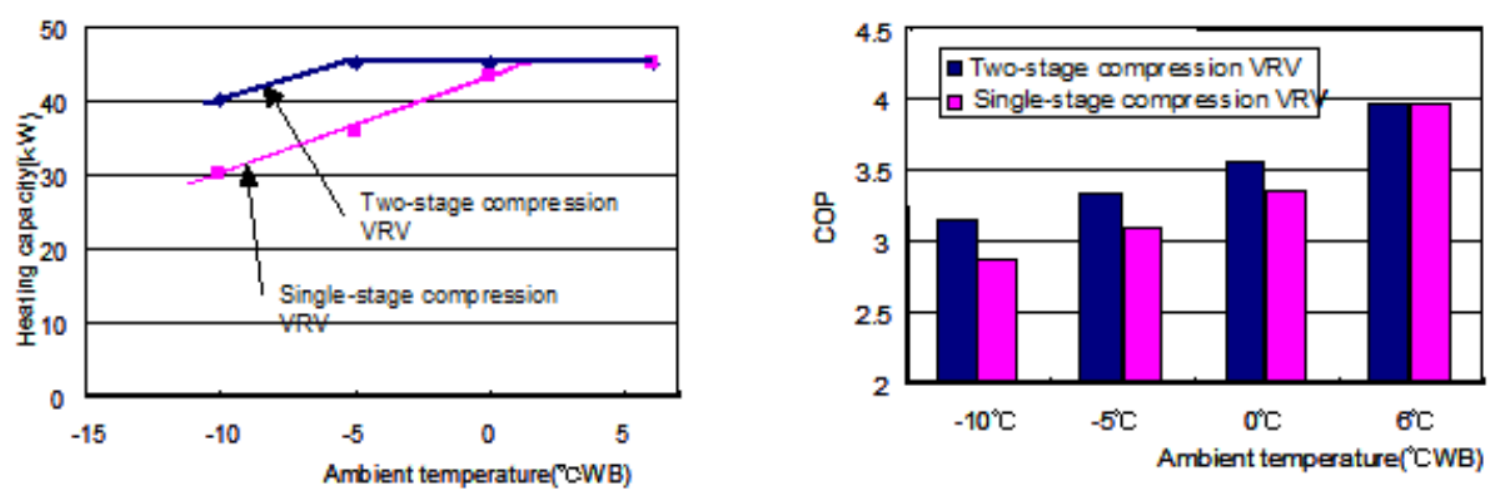

Figure 7: Two-stage VRV system heating capacity and COP vs. single-stage system (Katsuta, 2013a)

Denso has developed an enhanced "EcoCute" type heat pump water heater (HPWH) using R-744 $\left(\mathrm{CO}_{2}\right)$ employing a variable ejector refrigeration cycle technology. The system design features two key points. First is to maintain a discharge temperature of the refrigerant that will ensure the required heating capacity in the water heating HX (gas cooler). In an ejector refrigeration cycle, the heating capacity tends to drop because the refrigerant discharge temperature decreases as the compressor suction pressure rises. Increasing the refrigerant pressure at the compressor discharge port is one way to maintain the required discharge temperature, but this tends to negate the efficiency advantages of the ejector. The Denso development employs an external HX and internal HX downstream from the accumulator to ensure that the discharge temperature from the water heating $\mathrm{HX}$ is maintained at desired levels (Figure 8). The external HX absorbs heat in the air whereas the internal (intracycle) HX exchanges heat with the refrigerant 
exiting the water heating HX. The external HX functions most effectively when the feed water temperature (water temperature entering the water heating $\mathrm{HX}$ ) is low, whereas the internal HX is more effective for high temperature feed water.

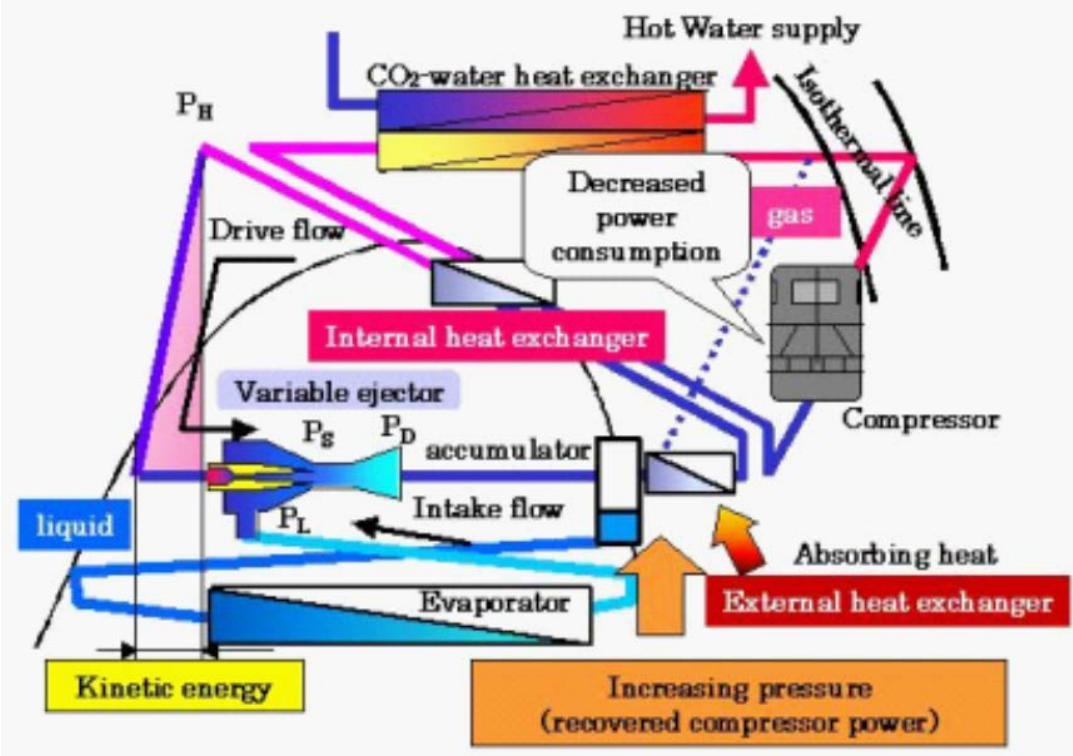

Figure 8: Denso CO2 ejector cycle HPWH cycle schematic (Katsuta, 2013a)

The second point is to maintain a high COP. The Denso team has developed an ejector design with a flow restriction mechanism to optimally control the cross-sectional areas of the throat and exit simultaneously. This enables the system high side pressure to be controlled at optimal levels to maximize ejector efficiency and system COP.

The ejector cycle HPWH has 30\% higher capacity and 20\% improved COP compared to conventional EcoCute systems. This technology enables more efficient and larger capacity water heating systems that can supply hot water for floor heating and other purposes as well as water heating systems.

\subsection{R\&D Activities in US}

A conference paper by Bertsch et al. (2006) investigated in detail three heat pump technologies for use in cold climates. The authors first identified the four principle problem areas faced by ASHPs when operating at low outdoor temperatures. The first issue is a lack of heating capacity caused by lower refrigerant flow rates at the low temperatures when the heating load is the largest - which leads to significant need for a backup heating source, usually provided by electric resistance heaters, to supplement the heat pump output. The second issue is that the discharge temperature of the compressor reaches high levels due to the low suction pressures and high compressor pressure ratio experienced at low ambient temperature operation due to the high pressure ratio. The third issue is that the heat pump COP decreases quickly under low outdoor temperature operation. The last main problem involves sizing the heat pump capacity. If the heat pump capacity is sized to meet house design heating loads at a very low outdoor 
temperature, this leads to oversizing for cooling, resulting in frequent cycling and degraded cooling seasonal performance.

Six different heat pump technologies were identified by Bertsch et al. (2006) that have the potential to solve some of these issues in varying degrees. Table 2 provides a side-byside comparison between these six technologies and a conventional heat pump and shows the number of heating modes, efficiency, heat output and discharge temperature of each technology.

Table 2: Comparing different heat pump technologies to a single-stage baseline (Bertsch et al., 2006)

\begin{tabular}{|c|c|c|c|c|c|c|}
\hline \multirow{2}{*}{$\#$} & Concept & $\begin{array}{c}\text { Preferred } \\
\text { Compressor }^{*}\end{array}$ & $\begin{array}{c}\text { Number heat } \\
\text { output steps }\end{array}$ & $\begin{array}{c}\text { Relative } \\
\text { Efficiency }\end{array}$ & $\begin{array}{c}\text { Relative } \\
\text { Heat output }\end{array}$ & $\begin{array}{c}\text { Discharge } \\
\text { temperature }\end{array}$ \\
\hline 1 & 1-stage cycle & LT & 1 & $100 \%$ & $100 \%$ & High \\
\hline \multirow{2}{*}{2} & \multirow{2}{*}{ 2-stage w. intercooler } & 2-stage & 1 & $130 \%$ & $100 \%$ & Acceptable \\
\cline { 3 - 7 } & \multirow{2}{*}{3} & Sc, Recip, Rot & 3 & $130 \%$ & $140 \%$ & Acceptable \\
\hline 4 & 2-stage w. economizer & 2-stage & 1 & $130 \%$ & $100 \%$ & Low \\
\cline { 3 - 7 } & Cascade cycle & Sc, Recip, Rot & 3 & $130 \%$ & $150 \%$ & Low \\
\hline 5 & Refrigerant injection & Sc, Screw & 2 & Comparable & $115 \%$ & Low \\
\hline 6 & Oil cooling & Recip, Rot & 1 & Comparable & Comparable & Acceptable \\
\hline 7 & Mechanical subcooling & LT + Sc & 2 & $110 \%$ & $120 \%$ & High \\
\hline
\end{tabular}

*) Sc...Scroll, Recip...Reciprocating, Rot...Rotary, LT...Low temperature

Three of these technology options were selected for detailed comparison - the two-stage using an intercooler, the two-stage using an economizer and the cascade cycle. It can be seen from Table 2 that these three technologies have the highest relative efficiency and relative heat output with low or acceptable discharge temperatures. The schematic for each of these three technologies is shown in Figure 9.
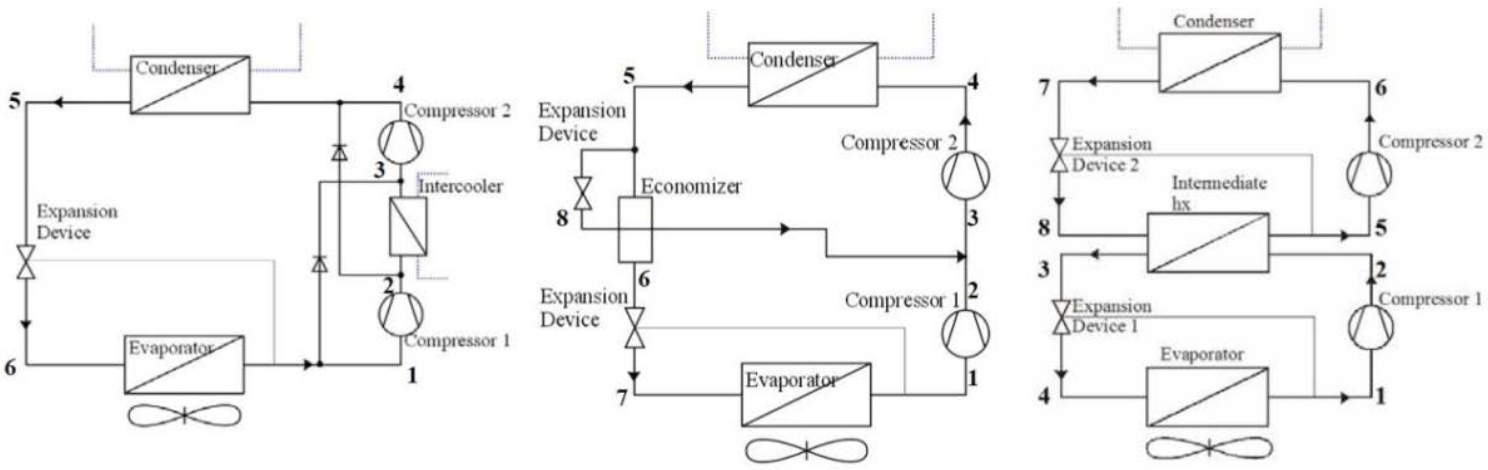

Figure 9: Heat pump schematic - Intercooler (Left) - Economizer (Middle) - Cascade (Right) (Bertsch et al., 2006)

System simulation models were created for each of the three technologies to simulate the heating capacity and performance for comparison. The supply temperature for each was fixed to $122{ }^{\circ} \mathrm{F}\left(50^{\circ} \mathrm{C}\right)$. A plot of the COP versus outdoor temperature for each heat pump technology is shown in Figure 10 and is compared to a second law efficiency of $50 \%$. The intercooler and economizer cycles show similar performance at temperatures 
above $32^{\circ} \mathrm{F}\left(0^{\circ} \mathrm{C}\right)$ while the cascade cycle performs relatively better at colder temperatures. All cycles show COPs above 2 at the low outdoor temperatures indicating reasonably good efficiency during these extremes.

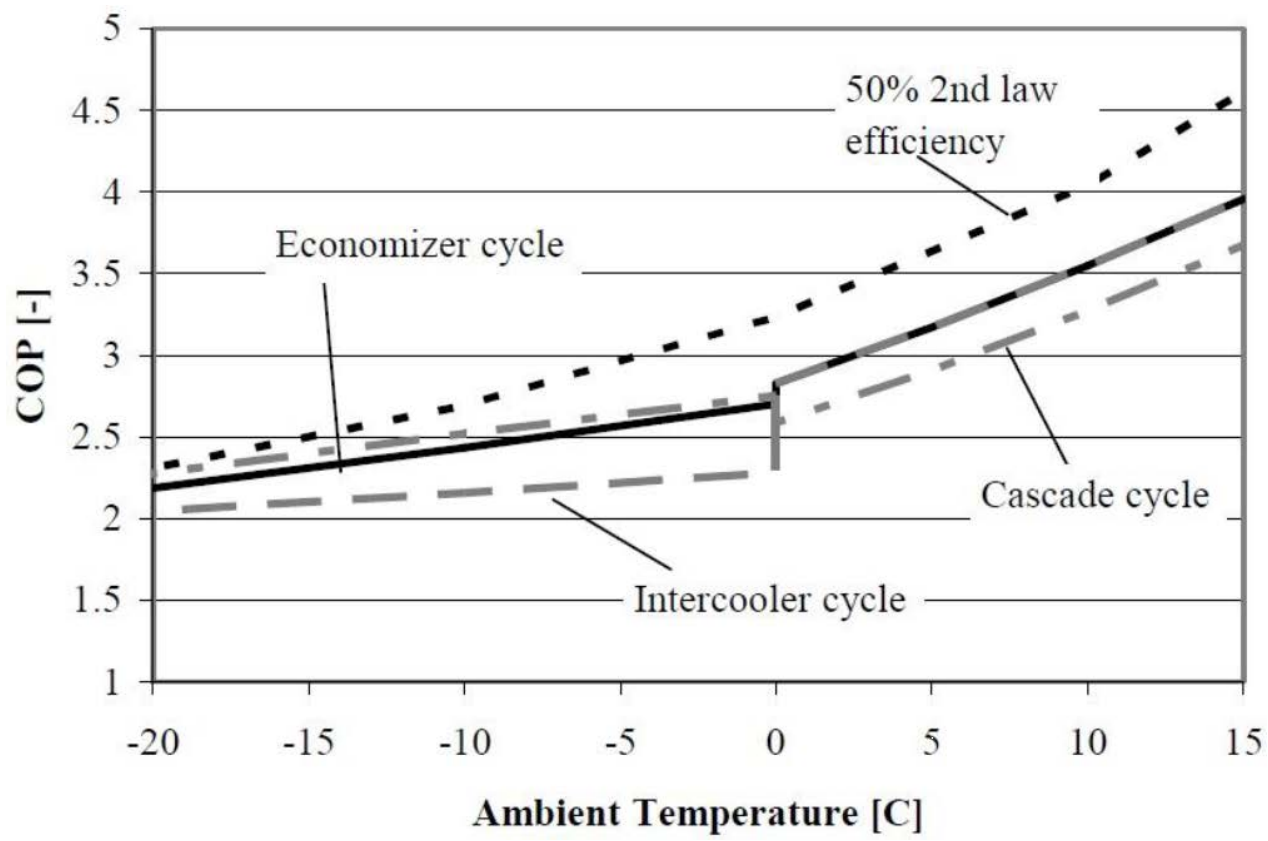

Figure 10: Comparison of the COP for the three technologies with a $50 \%$ second law efficiency (Bertsch et al., 2006)

The heating capacity compared to a linear heating demand of a building is plotted versus the outdoor temperature for all three technologies as shown in Figure 11. All three cycles have similar capacities at the low ambient temperatures. The only noticeable difference between these technologies is at the warmer ambient temperatures. The cascade cycle COP is considerably lower than that of the economizer and intercooler cycles, and this is most likely due to the sizing selected for the high stage cycle. Bertsch et al. assumed the cascade cycle has an additional outdoor heat exchanger to allow for the high side cycle to operate without the low side cycle. Overall, all three cycles are predicted to be able to satisfy the heating load. The conclusion made from these results and the equipment required is that the two-stage economizer cycle would be the best choice for an ASHP in colder climates. 


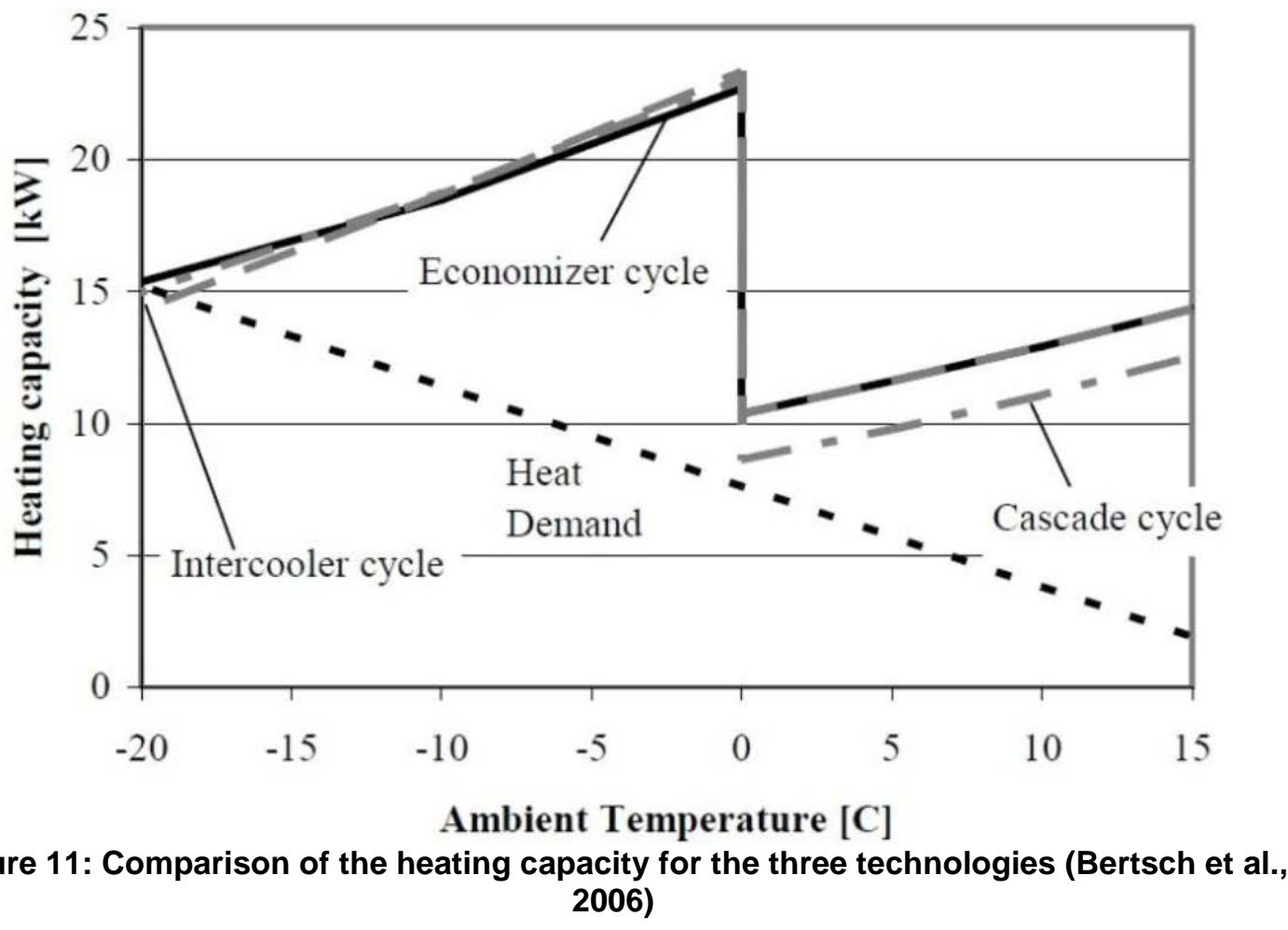

\subsubsection{Vapor Injection (VI) Heat Pump}

Heat pumps with compressor vapor injection (VI) can be classified into two fundamental configurations. One utilizes a flash tank also known as an open economizer and the other uses a heat exchanger economizer or closed economizer. Figure 12 shows a schematic of each system. Figure 13 shows a Pressure-Enthalpy diagram of vapor injection cycle. The flash tank cycle uses an expansion valve before a fixed volume tank to separate the liquid and vapor refrigerant at an intermediate pressure. For the flash tank cycle, the saturated vapor is drawn from the top of the tank and enters an injection port on the compressor. The saturated liquid is expanded further to the evaporation pressure. For the economizing heat exchanger cycle, the subcooled liquid leaving the condenser is separated into two streams; one is expanded to an intermediate pressure and heated by subcooling the other refrigerant stream through the heat exchanger. The superheated refrigerant enters the injection port on the compressor. If the phase separation process in the flash tank was perfect and the superheat entering the injection port of the compressor from the economizer heat exchanger was zero, the ideal cycles of both systems would be thermodynamically identical (Wang et al., 2009). 


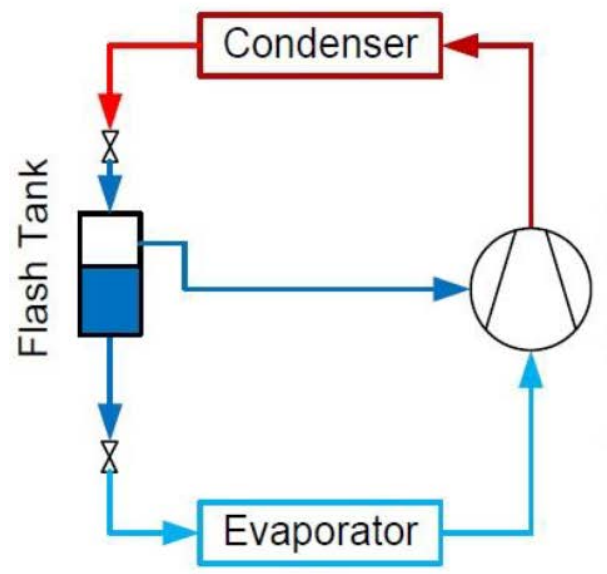

(a)

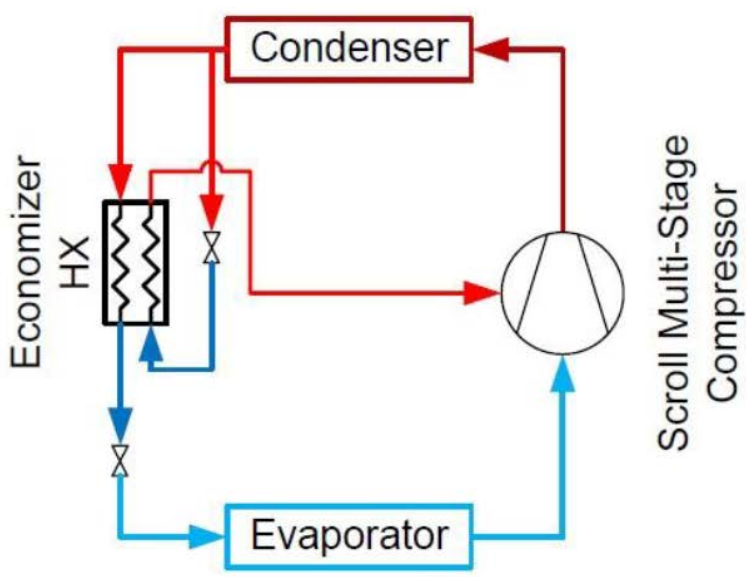

(b)

Figure 12: Schematic of two VI cycles with (a) flash tank (b) economizer heat exchanger (Abdelaziz et al., 2011)

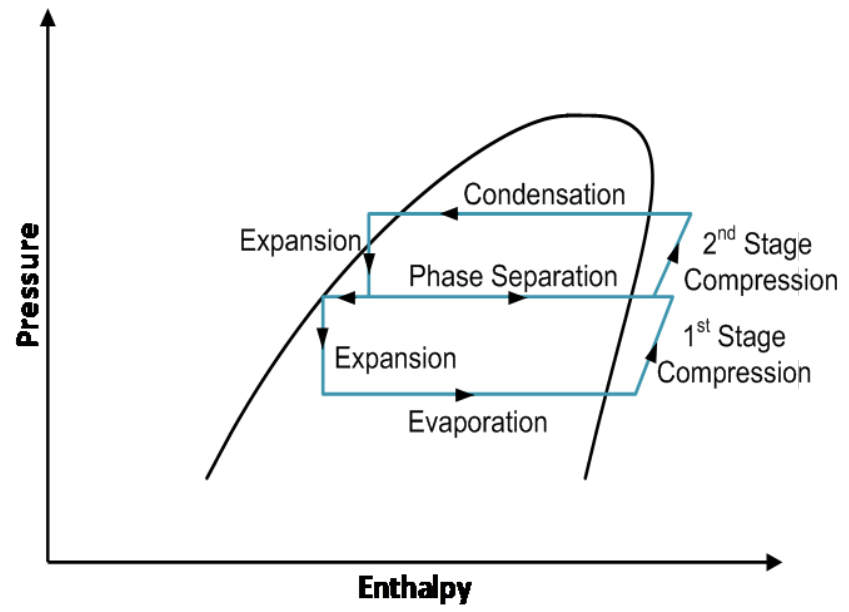

Figure 13: P-H Diagram of Vapor Injection Cycle

These systems create a multi-stage compression process within one compressor by mixing the superheated vapor in the compressor with saturated or a smaller degree of superheated vapor. As the number of injection ports is increased to approach continuous injection, the compression process will follow the refrigerant vapor saturation curve. One model predicts that continuous injection will improve the system COP between $18 \%$ and $51 \%$ for common air-conditioning and refrigeration applications, where higher temperature lift cycles benefit most significantly (Mathison et al., 2011). Abdelaziz and Shen (2012) conducted an optimization analysis of the two cycles in Figure 12. Optimizations were conducted to 1) minimize heat exchanger ( $\mathrm{HX}$ ) area subject to prescribed capacity and COP at rating conditions $\left(47^{\circ} \mathrm{F}\right.$ or $\left.8.3^{\circ} \mathrm{C}\right)$ followed by 2$)$ analysis to maximize system efficiency subject to a minimum capacity constraint at a low temperature operation condition $\left(-15^{\circ} \mathrm{F}\right.$ or $\left.-26.1^{\circ} \mathrm{C}\right)$. Their result suggested that the flash tank cycle of Figure 12(a) offers both lower system HX sizes and better performance at the low ambient condition. 
Experimental results on an 36,000 Btu/hr (10.6 kW) R-410A heat pump with flash tank VI showed about $30 \%$ heating capacity improvement with $20 \%$ COP gain at the ambient temperature of $0^{\circ} \mathrm{F}\left(-17.8^{\circ} \mathrm{C}\right)$ when compared to a conventional system having the same compressor displacement volume (Wang et al., 2009). The system capacity for both heating and cooling compared to the conventional system is shown in Figure 14 as a function of the outdoor temperature. The system heating and cooling capacity increases when vapor injection is used compared to the conventional system.

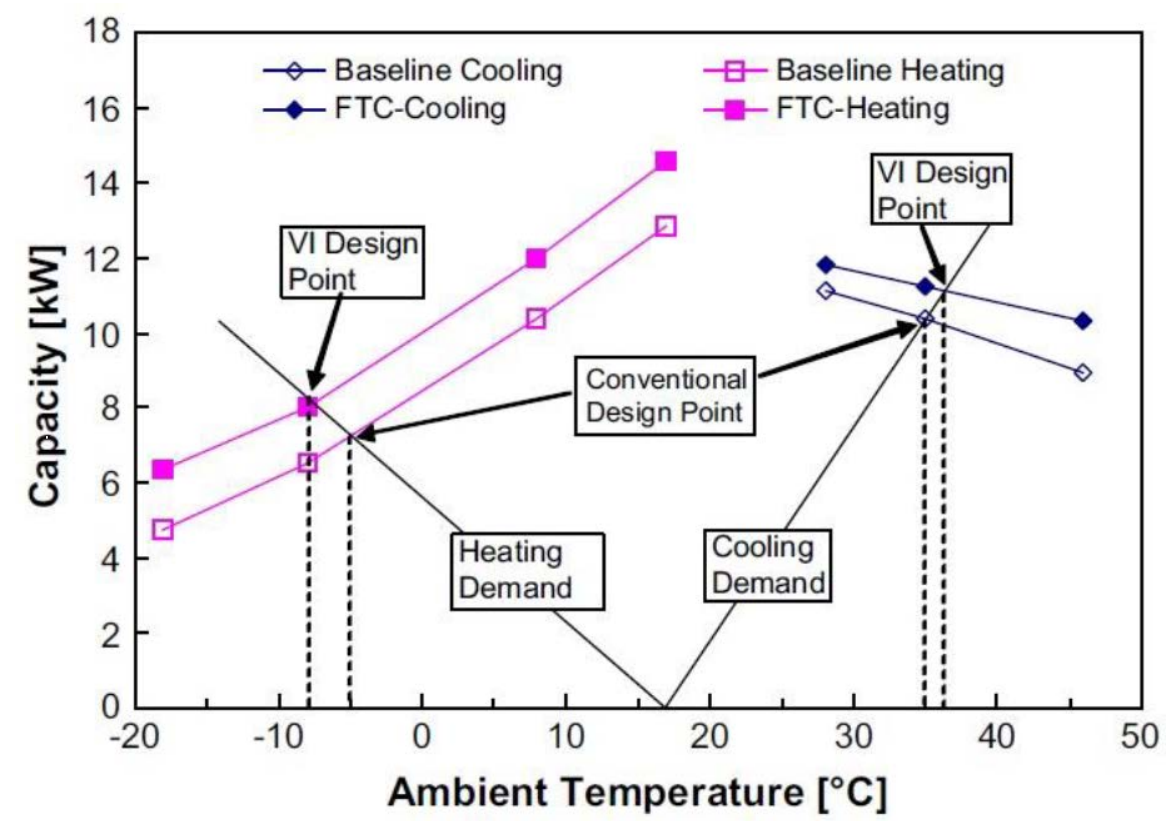

Figure 14: Flash tank VI cycle (FTC) compared to conventional (baseline) heat pump (Wang et al., 2009)

When comparing the two types of VI cycles, experimental results have shown the flash tank cycle to have a heating capacity and COP of $10.5 \%$ and $4.3 \%$ higher, respectively, than the economizing heat exchanger cycle (Ma and Zhao, 2008). A literature review of VI cycles concluded that the flash tank cycle is more favorable in terms of the performance improvement and cost while the economizing heat exchanger has the advantage of wider VI operating range (Xu et al., 2011). For R-410A, there have been some experimental and theoretical investigations of the air-source, vapor injection heat pump, but additional experimental results are needed to fully understand the various VI cycle options (Rohm et al., 2011).

VI cycle concepts utilizing multi-port compressors (one implementation of multi-stage VI compression) have also been investigated (Song, 2013; Ramaraj, 2012; Mathison et al., 2011). Figure 15 illustrates the cycle concept (a) and an example implementation in a scroll compressor (b). Previous theoretical and experimental work has shown that economizing holds significant potential to improve the performance of vapor compression equipment. Mathison et al. (2011) predicted that the maximum performance improvement with economizing can be achieved by continuously injecting two-phase 
refrigerant to maintain a saturated vapor state in the compressor. For an R-410A cycle evaporating at $41^{\circ} \mathrm{C}\left(5^{\circ} \mathrm{C}\right)$ and condensing at $104^{\circ} \mathrm{F}\left(40^{\circ} \mathrm{C}\right)$, the cycle model predicts that economizing will improve the COP by approximately $18 \%$ in this limiting case. The benefits are even greater for a larger temperature lift application, such as a cold climate heat pumps; the model predicts that economizing can provide up to a $51 \%$ improvement in COP for a cycle using R-404A with an evaporation temperature of $-22^{\circ} \mathrm{C}\left(-30^{\circ} \mathrm{C}\right)$ and a condensing temperature of $104^{\circ} \mathrm{F}\left(40^{\circ} \mathrm{C}\right)$. However, continuously injecting refrigerant is not only beyond the capabilities of current compressors, but also requires the development of equipment to continuously supply refrigerant to the compressor at the desired pressure and quality. In addition, injecting a two-phase mixture introduces the possibility for damage to the compressor if the evaporation process within the compressor is not well-understood.

Mathison (2011) demonstrated that using a finite number of injection ports and saturated vapor in place of a two-phase mixture provides a practical means for approaching the limiting cycle performance. For the R-410A cycle evaporating at $41^{\circ} \mathrm{F}\left(5^{\circ} \mathrm{C}\right.$ and condensing at $104^{\circ} \mathrm{F}\left(40^{\circ} \mathrm{C}\right)$, the model predicted that injecting saturated vapor through three ports will provide a $12 \%$ improvement in COP, which is approximately $69 \%$ of the maximum benefit provided by economizing with continuous injection of two-phase refrigerant. Therefore, the development of the economized cycle currently focuses on using saturated vapor injection with two or three ports.
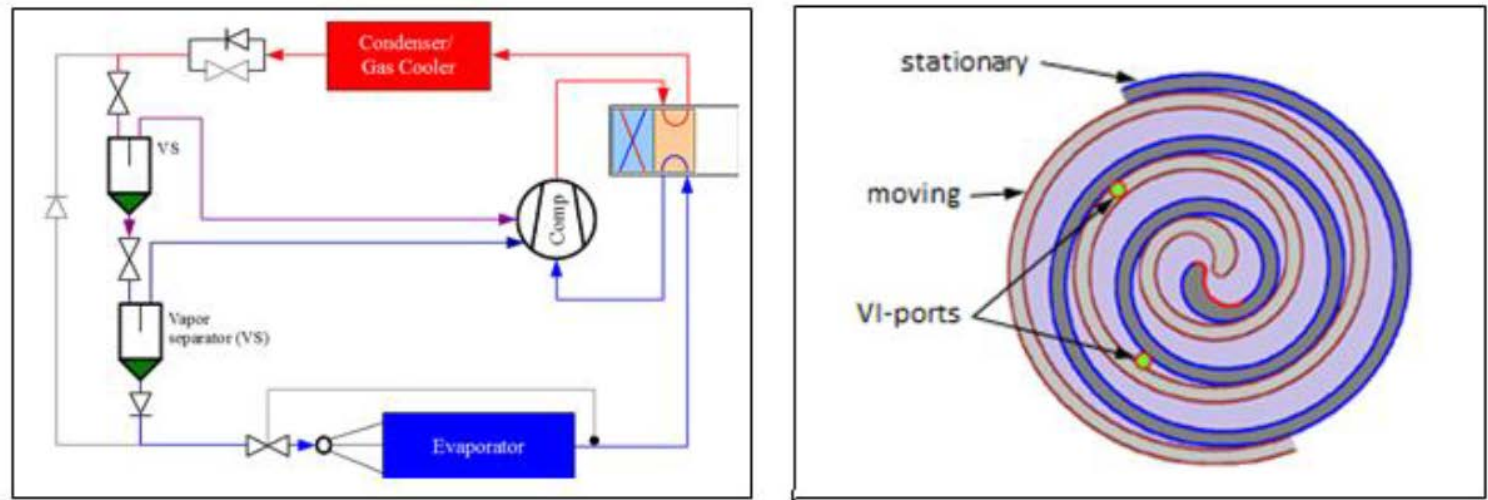

Figure 15: Multi-port VI compressor concept

\subsubsection{Two-Stage ASHPs with economizing}

The only difference between a two-stage economizer (see schematic in Figure 9 (middle)) and VI cycle is two individual compressors are used with a mixing chamber in between instead of directly injecting vapor into a compressor chamber of the compressor. By compressing the refrigerant in stages, a second-law-based thermodynamic analysis shows the increase in irreversible losses at high-temperature differences can be minimized. A two-stage R-134a refrigeration system operating at $-22^{\circ} \mathrm{F}\left(-30^{\circ} \mathrm{C}\right)$ evaporating and $140^{\circ} \mathrm{F}$ $\left(60^{\circ} \mathrm{C}\right)$ condensing has a $24 \%$ improvement in performance compared to a single-stage system (Zubair et al., 1996). Analysis on a cascade system highlights the reduction of entropy generation when compressing in stages. Going from 1 to 2 stages reduced the superheat losses significantly from $94 \mathrm{~kJ} / \mathrm{K}-\mathrm{hr}$ to $0.106 \mathrm{~kJ} / \mathrm{K}-\mathrm{hr}$ to reach an overall reduction of entropy generation by $78 \%$ (Ratts et al., 2000). 
An R-134a two-stage heat pump with both an economizing heat exchanger and a flash tank was used for heating water from a waste energy source. In spite of the higher source temperatures used, the experimental results demonstrated the frequency control of the high-stage compressor to control the intermediate pressure resulted in an ability to improve the performance by as much as $5.2 \%$ as compared to the single-stage system without economizing under identical heat source conditions (Kwon et al., 2013). A normalized pressure is calculated using the three system pressures to identify the optimal operating point for fixed heat source temperatures. A plot of three different source temperatures for COP versus the normalized pressure is shown in Figure 16.

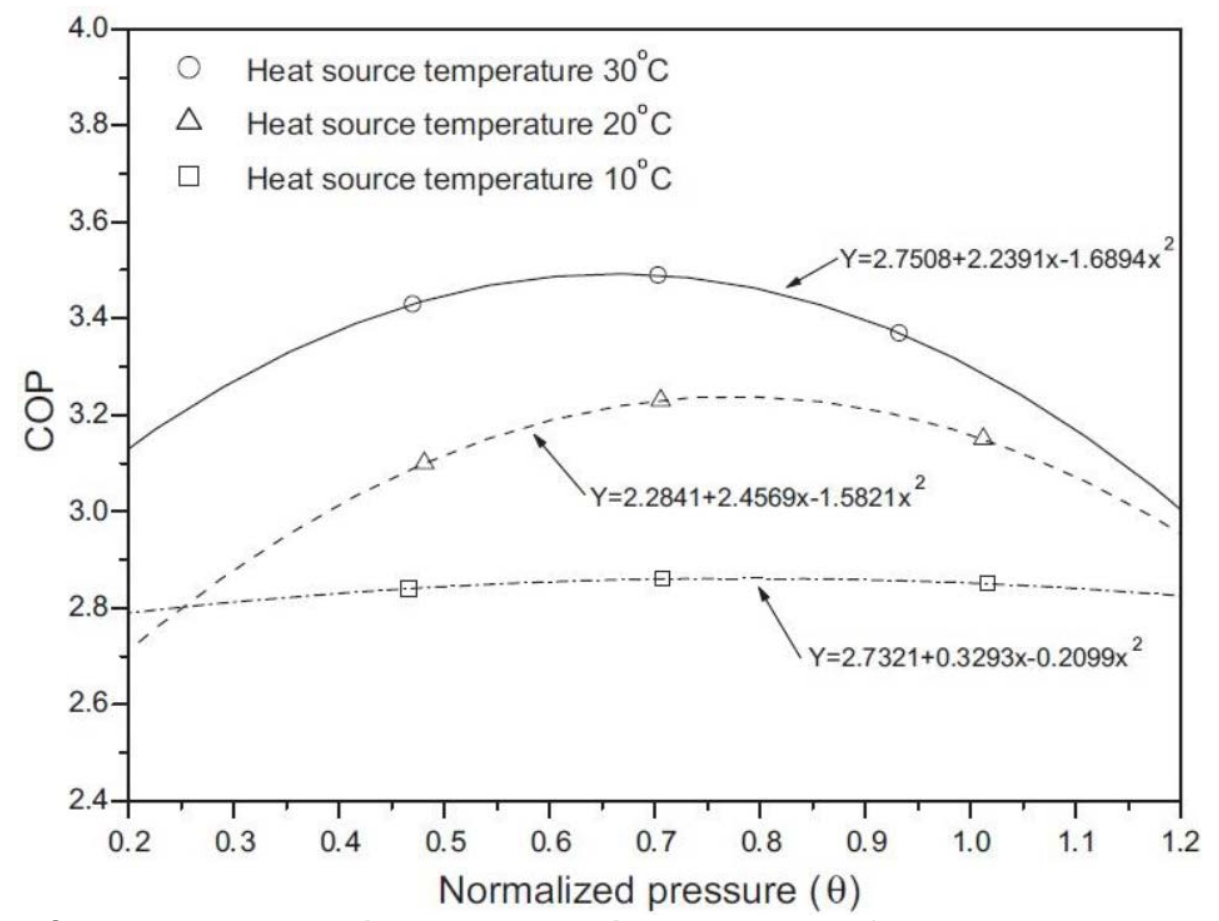

Figure 16: COP compared against the normalized pressure of two-stage heat pump (Kwon et al. 2013)

An R-410A two-stage heat pump with an economizing heat exchanger was experimental tested down to ambient temperatures of $-22^{\circ} \mathrm{F}\left(-30^{\circ} \mathrm{C}\right)$, achieving a heating capacity and COP of roughly 36,000 Btu/hr (11 kW) and 2.1 respectively (Bertsch et al., 2008). The plots of the experimental results compared to the simulation of the system heating capacity and COP are shown in Figure 17. The two-stage heat pump is shown to have much larger heating capacities than a conventional heat pump at low outdoor temperatures. The system could also be easily built from off-the-shelf components with little modifications which suggest the commercialization potential of a two-stage heat pump with economizing heat exchanger. 

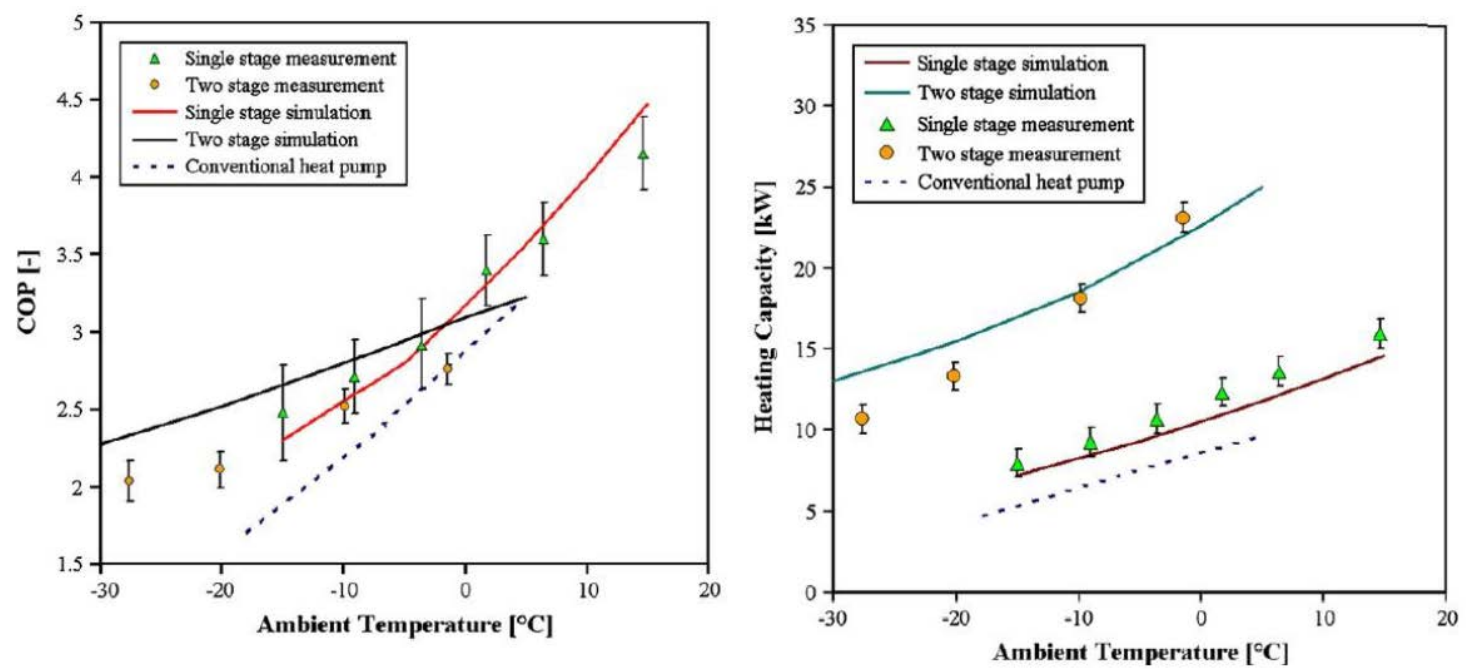

Figure 17: Experimental results of two-stage heat pump compared to simulation results; manufacturer's data was used to indicate performance of conventional HP (Bertsch et al. 2008)

A field test of an advanced ASHP designed for cold climate operation has been completed at Camp Atterbury Army base in Indiana (Caskey et al., 2013). The heat pump is a two-compressor (two-stage) system with an economizer VI loop, similar to the concept analyzed by Bertsch, et al. (2008). It features a large tandem scroll compressor for low ambient temperature capacity boosting and a VS scroll for cooling operation and moderate ambient heating. The test is being conducted under the DOD's Energy Security Technology Certification Program (ESTCP). Two, identical military barracks from available buildings located at Camp Atterbury, outside Edinburgh, Indiana, were selected for the field demonstration. The originally installed HVAC system was a natural gas furnace with a split system air conditioner. A side-by-side performance comparison between the originally installed HVAC system and the two pre-commercial heat pump units developed at Purdue University was conducted during the 2012-2013 heating season. Only commercially available components were selected for all parts of the heat pump units with help from three industrial partners, namely Ingersoll Rand - The Trane Company, Emerson Climate Technology, and Danfoss. The heat pump units had a design heating capacity of $62,580 \mathrm{BTU} / \mathrm{h}(18.34 \mathrm{~kW})$ at an ambient temperature of $4^{\circ} \mathrm{F}\left(-20^{\circ} \mathrm{C}\right)$.

The heat pump performance was compared to the existing HVAC system using six performance objectives that are listed in Table 3. The objective of the project is to reach or surpass the success criteria listed for each performance objective. 
Emerson CRADA final report, December 30, 2015

Table 3: ESTCP project performance objectives of the cold climate heat pump

\begin{tabular}{|c|c|c|c|}
\hline $\begin{array}{l}\text { Performance } \\
\text { Objective }\end{array}$ & Metric & Data Requirements & Success Criteria \\
\hline \multicolumn{4}{|c|}{ Quantitative Performance Objectives } \\
\hline $\begin{array}{l}\text { 1. Reduce primary } \\
\text { energy for heating } \\
\text { (Energy) }\end{array}$ & Therms or kW-hr & $\begin{array}{l}\text { Electric and gas use } \\
\text { metered }\end{array}$ & $\begin{array}{l}\text { Reduce primary } \\
\text { energy use by } 25 \%\end{array}$ \\
\hline $\begin{array}{l}\text { 2. Reduce costs } \\
\text { (Finances) }\end{array}$ & $\$$ & $\begin{array}{l}\text { Base rates for } \\
\text { electricity and fuel }\end{array}$ & $\begin{array}{l}10 \% \text { reduction in } \\
\text { heating costs }\end{array}$ \\
\hline $\begin{array}{l}\text { 3. Reduce } \\
\text { emissions } \\
\text { (Environment) }\end{array}$ & $\begin{array}{l}\text { Metric ton } \mathrm{CO}_{2} \\
\text { equivalent }\end{array}$ & Conversions for fuels & $\begin{array}{l}\text { Reduce } \mathrm{CO}_{2} \\
\text { emissions by } 15 \%\end{array}$ \\
\hline \multicolumn{4}{|c|}{ Qualitative Performance Objectives } \\
\hline $\begin{array}{l}\text { 4. Ease of } \\
\text { installation }\end{array}$ & $\begin{array}{l}\text { Ability of a technician- } \\
\text { level individual to install } \\
\text { the heat pump }\end{array}$ & $\begin{array}{l}\text { Feedback from the } \\
\text { technicians on } \\
\text { installation time }\end{array}$ & $\begin{array}{c}\text { A field technician } \\
\text { team is able to install } \\
\text { the system }\end{array}$ \\
\hline 5. Maintenance & $\begin{array}{l}\text { Ability of a technician- } \\
\text { level individual to } \\
\text { maintain the heat pump }\end{array}$ & $\begin{array}{l}\text { Feedback from the } \\
\text { technicians on } \\
\text { maintenance calls }\end{array}$ & $\begin{array}{l}\text { A field technician } \\
\text { team is able to } \\
\text { operate the system }\end{array}$ \\
\hline 6. Comfort & $\begin{array}{l}\text { Maintain temperature } \\
\text { within comfort range of } \\
\text { building occupants }\end{array}$ & $\begin{array}{l}\text { Indoor temperature } \\
\text { readings and survey of } \\
\text { occupants }\end{array}$ & $\begin{array}{c}80 \% \text { of occupants } \\
\text { satisfied with indoor } \\
\text { conditions }\end{array}$ \\
\hline
\end{tabular}

Caskey et al. (2013) discussed results of the field test from the 2012-2013 heating season in general comparison with the criteria listed in Table 3. For the monitored period at the Army site the ASHP system achieved about 19\% source energy savings vs. the baseline gas furnace system but utility costs were higher due to the low price the Army pays for natural gas at the site. Using average Indiana residential electricity and gas prices the utility costs for the ASHP and baseline furnace would have been about the same. The ASHP used no electric back up heating during the test period. Using ASHRAE Standard 55 (ASHRAE, 2010) to evaluate the thermal comfort indicated that the heat pump was able to maintain comfort levels throughout the heating season. Furthermore, the installation and maintenance cost and complexity of the heat pump is comparable to those of conventional air-source heat pumps.

\subsubsection{Flooded compressor concept investigation}

The oil flooding concept utilizes oil injection into the compressor suction port(s) to absorb the heat of compression (reducing discharge temperature) and approach an isothermal compression process (Bell, 2011). Figure 18 illustrates a cycle schematic and p-h diagram of the concept. The addition of compressor flooding with regeneration in vapor compression systems results in a more isothermal compression process that can have a significant beneficial impact on system efficiency for large temperature lifts. For refrigerants with large pressure differences across the compressor, the use of a hydraulic expander can also help to recapture some of the work of compression of the flooding liquid. The engineering challenges in implementation of this technology are reasonable, which suggests that it could be applied readily in new construction. Analyses indicate this concept has both capacity and efficiency advantages over VI cycles for low-temperature applications (Bell et al., 2011). In particular, the injection of oil results in an increase in 
refrigerant mass flow rate and overall isentropic efficiency and a decrease in the compressor discharge temperature. The analyses conducted so far clearly suggest that designing an efficient scroll compressor with oil injection for application to a low-sourcetemperature ASHP application will be possible with respect to energy performance and manufacturability.
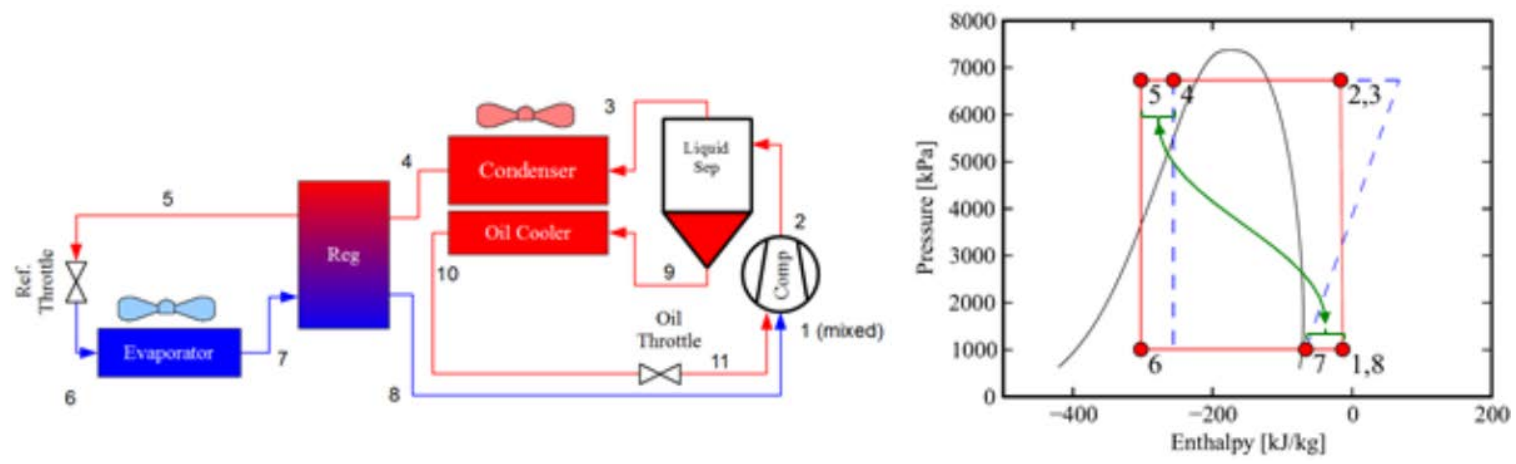

Figure 18: Schematic (left) and p-h cycle diagram (right) of flooded compressor cycle concept - from Bell (2011)

Laboratory testing of systems incorporating VI and oil-flooded compressors were performed at Herrick Laboratory in Purdue University (Bach et al., 2013). Figure 19 shows the schematic of the oil-flooded system. In HP mode, the internal heat exchanger and oil cooler are active and oil injection is used. For AC mode, both heat exchangers are bypassed and the compressor is run without oil injection.

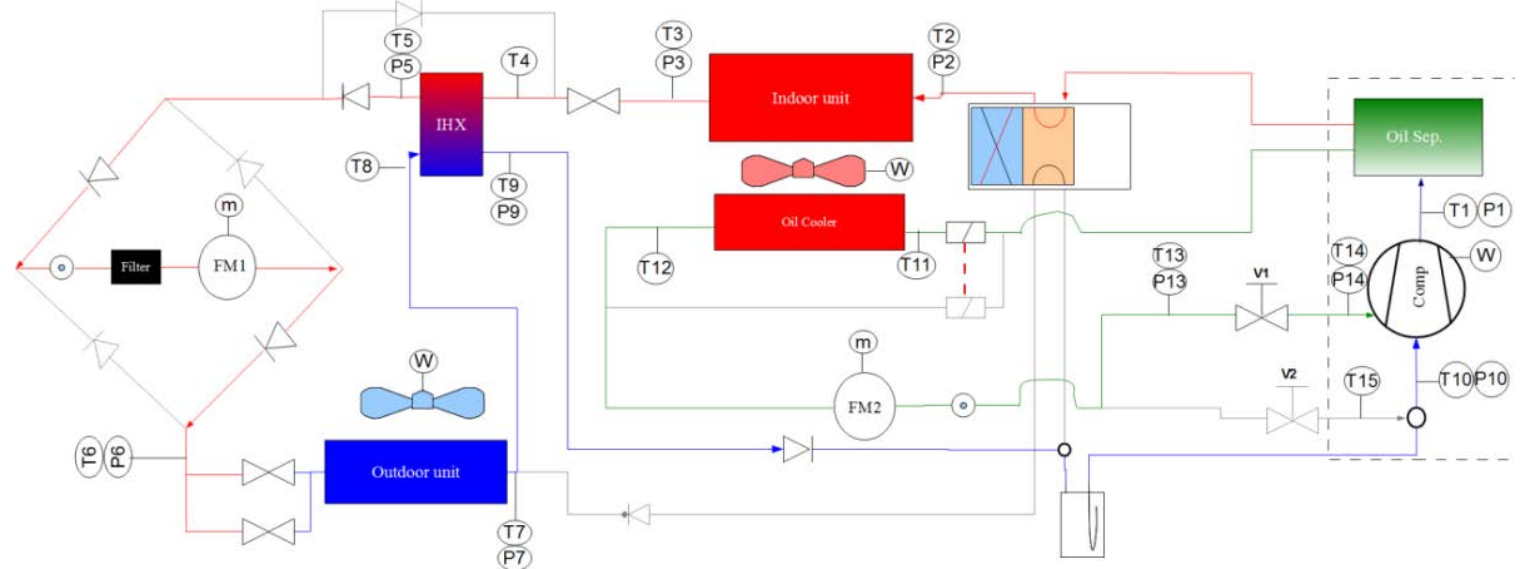

Figure 19: System schematic for oil-flooded heat pump

The oil-flooded system was operated at the standard AHRI 210/240 (2008) testing conditions with 6 different oil injection rates, ranging from 0 to $30 \%$ of the total compressor flow rate. In addition to the standard ASHP heating testing conditions (AHRI, 2008), a low ambient temperature condition $\left(0^{\circ} \mathrm{F}\right)$ was tested. Cooling or airconditioning (AC) mode tests will be conducted to determine possible system efficiency penalties due to the system changes in that operating mode. The final results were documented in (Yang et al. 2014). Oil flooded compressor system design resulted in 10\% seasonal heating performance and slightly higher heating capacity. 


\section{Equipment Models}

The DOE/ORNL Heat Pump Design Model (HPDM) is a hardware-based equipment design and modeling tool. HPDM is used as the major base of our design work, to compare system configurations, select components and size heat exchangers.

The ORNL Building Equipment Research team has over thirty years' experience in thermal system and component modeling. We have developed in-house steady-state simulation models covering most categories of residential and light commercial space cooling, space heating and water heating components, like compressors, heat exchangers, pumps, fans, etc. These models have been extensively used and validated through our research projects. Being different from the performance curves used in EnergyPlus and other building energy simulation software, our models are fundamentally based, can simulate detailed heat exchanger geometry and circuitry, and accept real air side and refrigerant side boundary conditions. These models are actually equipment design tools, which can do performance prediction, component sizing, and system optimization at specified efficiency levels and cost.

Our in-house heat exchanger models have different complexity levels, falling under three categories, i.e. bulk models, phase-to-phase models, and discretized models. The bulk models are usually based on Effectiveness-NTU or UA-LMTD approach, to simulate the component as a whole. The phase-to-phase models separate the refrigerant side to vapor, two-phase and liquid regions, and each region has individual air side and refrigerant side entering states. The discretized models use segment-to-segment modeling approach, which divide a heat exchanger into to numerous mini-segments; each segment has individual refrigerant and air entering parameters, and considers possible phase separation; the mini segments are basic building blocks, which are used to build up heat exchangers having arbitrary circuitry, geometry, and represent any boundary conditions. All our phase-to-phase and segment-to-segment heat exchanger models are able to calculate refrigerant charge inventory. Some component models and features, in the HPDM library, are introduced as below:

\section{Compressors:}

Single-speed Compressor: We use AHRI 10-coefficient compressor maps (ANSI/AHRI $540-99,2010$ ) to calculate mass flow rate and power consumption, and enable calculation of the refrigerant-side vs. air-side energy balance from inlet to outlet. We also consider the actual suction state to correct the map mass flow prediction using the method of Dabiri and Rice (1981) as given in Equation (1).

$$
\dot{m}_{\text {ref ,actual }}=\left[1+F_{\text {mass }}\left(\frac{v_{\text {ARI-map }}}{v_{\text {act }}}-1\right)\right] \dot{m}_{\text {ref,ARI-map }}
$$


where $F_{\text {mass }}$ is an empirical correction factor assigned a value of $0.75, \dot{m}_{\text {ref,ARI-map }}$ and $\dot{m}_{\text {ref, actual }}$ are the mass flow rates at the standard (compressor map) and actual suction superheat, and $v_{\text {ARI-map }}$ and $v_{\text {act }}$ are the specific volumes at the standard and actual superheat.

Variable-speed compressor: The model accepts multiple sets of mass flow and power curves, and does linear interpolation between speed levels.

\section{Heat Exchangers:}

Segment-to-segment fin-\&-tube condenser: It uses a segment-to-segment modeling approach; each tube segment has individual air side and refrigerant side entering states, and considers possible phase transition; An $\varepsilon$-NTU approach is used for heat transfer calculations within each segment. Air-side fin is simplified as an equivalent annular fin. Both refrigerant and air-side heat transfer and pressure drop are considered; the coil model can simulate arbitrary tube and fin geometries and circuitries, any refrigerant side entering and exit states, misdistribution, and accept two-dimensional air side temperature, humidity and velocity local inputs; the tube circuitry and 2-D boundary conditions are provided by an input file.

Segment-to-segment fin-\&-tube evaporator: In addition to the functionalities of the segment-to-segment fin-tube condenser, the evaporator model is capable of simulating dehumidification process. The method of Braun et al. (1989) is used to simulate cases of water condensing on an evaporating coil, where the driving potential for heat and mass transfer is the difference between enthalpies of the inlet air and saturated air at the refrigerant temperature.

\section{Expansion Devices:}

Idealized TXV: The compressor suction superheat degree is explicitly specified.

Fans and Blowers:

Single-speed fan: Given airflow rate, the model uses a fan curve to simulate static head, power consumption, and calculate air-side temperature increment from inlet to outlet.

Variable-speed fan: The model accepts multiple sets of fan curves, and does linear interpolation between speed levels.

\section{Refrigerant Properties:}

Interface to Refprop 9.0: We programmed interface functions to call Refprop 9.0 directly; our models accept all the refrigerant types in the Refprop 9.0 database, and also we can simulate new refrigerant by making the refrigerant definition file according to the Refprop 9.0 format.

Hybrid look-up tables with Refprop 9.0: Refprop 9.0 can be fairly slow for some refrigerant mixtures. To speed up the calculation, we have an option to generate property look-up tables, based on Refprop 9.0; our program uses 1-D and 2-D cubic spline algorithms to calculate refrigerant properties via reading the look-up tables, this would 
greatly boost the calculation speed, given the same accuracy; however, the cubic spline algorithms are less accurate when approaching to the critical region, in the case, we switch back to the Refprop 9.0 functions.

\section{Optimization:}

HPDM has embedded optimization capability, which uses GenOpt, an open source optimization program published by Wetter (2009). A wrapper program was developed to communicate between GenOpt and HPDM by exchanging text input and output files. The GenOpt optimization wrapper is shown in Figure 20. GenOpt automatically generates input files for the simulation program based on predefined templates that include keywords describing the problem variables.

As shown in Figure 20, the problem domain is defined in two parts, One part defines required inputs for the GenOpt program (in the GenOpt command file), which selects the optimization algorithm and regulates design spaces for the iterative variables; the other part (in the wrapper template file) defines attributes and design spaces for the selected objectives. The wrapper program accepts three kinds (attributes) of objectives: optimization objectives, target objectives (equality constraints), and bound objectives (inequality constraints). An optimization objective is to maximize or minimize an output variable, a target objective intends to match the output variable to a given value, and a bound objective is to define upper and lower bounds for an output variable.

GenOpt produces guess values for the iterative variables through a text file to the wrapper program. The wrapper program interprets the input file to provide the required inputs for the vapor compression system model, and then executes the model to get performance outputs. Then, the wrapper program provides the outputs in the form shown in Equation (2).

$$
\begin{aligned}
& f(x)=\sum\left(W_{i} * \text { OptObj }_{i}\right)+\sum\left[T_{j} *\left(\text { TgtObj }_{j}-\text { Goal }_{j}\right)\right]^{2} \\
& +\sum\left[P_{k} *\left(\text { BndObj }_{k}-\text { Bound }_{k}\right)\right]^{2}
\end{aligned}
$$

where $f(x)$ is the integrated function to be minimized by the GenOpt algorithm, $x$ is a vector of the model variables to be iterated, and $\mathrm{Wi}$ is the weighting factor for an optimization objective. OptObji is a variable for optimization, it will be maximized by giving a negative weighting factor, and minimized by giving a positive weighting factor. TgtObjj is a variable intended to match a given target value, and $\mathrm{Tj}$ is a weighting factor to be multiplied with the residual. Goalj is a given target value. BndObjk is an output variable having either upper or lower bound. Boundk is a given boundary value. Pk is a penalty factor, which is zero when the output variable is within the given bounds; on the other hand, it becomes a quite large multiplier when the output variable goes beyond the bounds.

Next, GenOpt evaluates the result of the output function, and updates the guesses for the iterative variables. The interaction process between GenOpt and the wrapper program is repeated until the minimum of the output function is found. For the analyses below, the 
optimization algorithm applied was Generalized Pattern Search algorithm (Hooke-Jeeves and Coordinate Search algorithm).

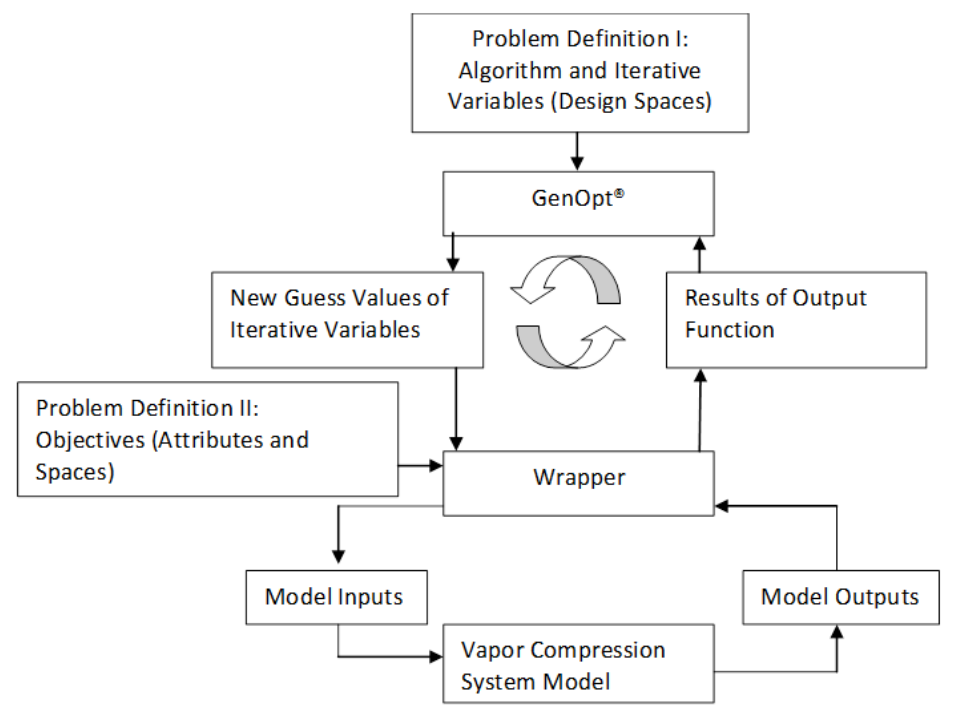

Figure 20: GenOpt Optimization Wrapper to a Vapor Compression System Model

\section{Model-Based Concept Selection and Sizing Study}

\subsection{Concept Selection}

Based on the technology survey, the DOE/ORNL heat pump design model (HPDM) was used for analytical evaluations. A number of candidate system technologies were simulated, including a baseline single-speed heat pump, multi-capacity compressor(s) options, and vapor injection compressor option with inter-stage economizer (VI+EcHX) or flash tank (VI+FlashTank). The single-speed heat pump uses a compressor having a nominal cooling capacity of 5-ton/17.6 kW. The VI+EcHX and VI+FlashTank options also use a VI compressor having a nominal cooling capacity of 5-ton/17.6 kW. Two multi-capacity compressor(s) options were evaluated. One included a VS compressor, with its speed ranging from 800 to 7200 RPM and having a nominal cooling capacity of 5-ton/17.6 kW rated at $4500 \mathrm{RPM}$. The other featured a tandem compressor pair having two equal size, single-speed compressors, or two equal size, VI compressors. Each compressor in the tandem systems has a nominal cooling capacity of 2.5-ton/8.8 kW. All the compressor technologies were simulated with the same set of indoor and outdoor units, which were originally used for a 5-ton heat pump, as given in Table 4. For the system modeling in heating mode, the condenser exit subcooling degree was set at $10 \mathrm{R}$ (5.6 K), i.e. assuming optimized charge control; the evaporator exit was assumed to be saturated vapor, i.e. from use of a suction line accumulator. When using a VI compressor with an economizer, the economizer exit superheat degree was set at $10 \mathrm{R}(5.6 \mathrm{~K})$ and its heat transfer effectiveness was assumed as 70\%. The indoor return air temperature was 
Emerson CRADA final report, December 30, 2015

always set at $70^{\circ} \mathrm{F}\left(21 \cdot 1^{\circ} \mathrm{C}\right)$.

Table 4: Parameters of Indoor and Outdoor Units

\begin{tabular}{ccc}
\hline Parameters (heating mode) & Indoor Fin-\&-Tube Coil & Outdoor Fin-\&-Tube Coil \\
\hline Face area, $\mathrm{ft}^{2}\left(\mathrm{~m}^{2}\right)$ & $3.30(0.307)$ & $22.3(2.07)$ \\
\hline Total Tube Number & 84 & 64 \\
\hline Number of rows & 3 (cross counter-flow) & 2 (cross counter-flow) \\
\hline Number of parallel circuits & 9 & 6 \\
\hline Fin density, fins $/ \mathrm{ft}(\mathrm{fins} / \mathrm{m})$ & $168(551)$ & $264(866)$ \\
\hline Flow Rate, $\mathrm{cfm}\left(\mathrm{m}^{3} / \mathrm{s}\right)$ & Indoor Blower $\left(\right.$ High/Low $\left.{ }^{1}\right)$ & Outdoor Fan \\
\hline Power $[\mathrm{W}]$ & $1670 / 1380(0.790 / 0.653)$ & $3500(1.652)$ \\
\hline
\end{tabular}

1. The indoor blower has two speed levels. For $\leq 50 \%$ compressor capacity or at $-13^{\circ} \mathrm{F} /-25^{\circ} \mathrm{C}$ ambient temperature, the lower indoor air flow rate and blower power were used; otherwise, the higher air flow rate and blower power were used.

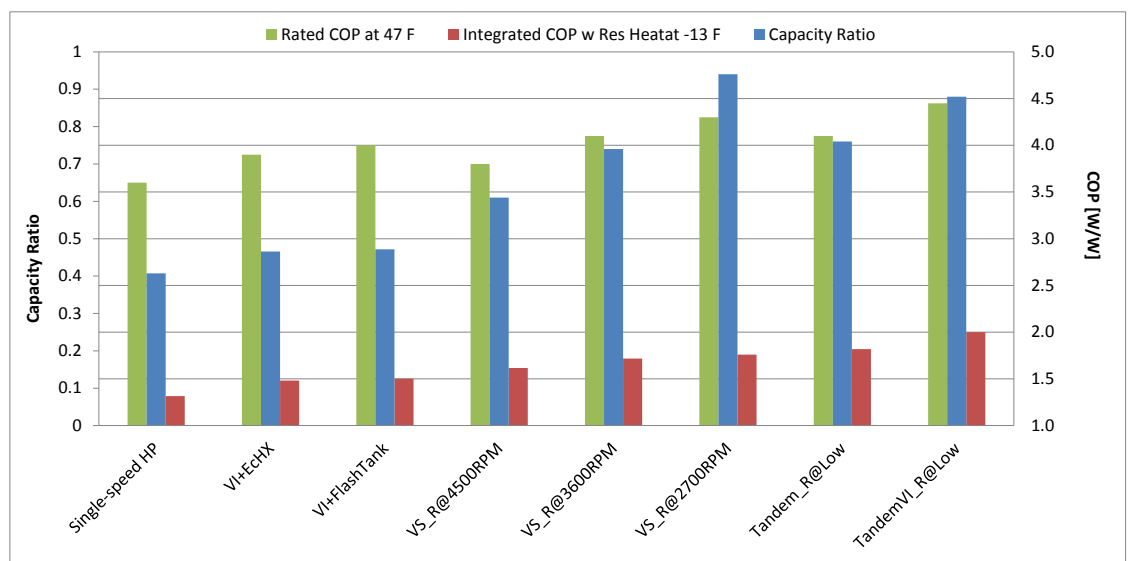

Figure 21: Ratios of heating capacity relative to $47^{\circ} \mathrm{F}, \mathrm{COP}$ at $47^{\circ} \mathrm{F}$ and integrated COP at $13^{\circ} \mathrm{F}$

The heat pump rated capacity at $47^{\circ} \mathrm{F}\left(8.3^{\circ} \mathrm{C}\right)$, approximately the rated cooling capacity at $95^{\circ} \mathrm{F}\left(35^{\circ} \mathrm{C}\right)$ is usually the value used to match a building cooling design load for the sizing selection. Regarding the multi-capacity compressor(s), VS_R@4500RPM, 3600RPM, and 2700RPM mean obtaining the rated heating capacity at $47^{\circ} \mathrm{F}\left(8.3^{\circ} \mathrm{C}\right)$ by running the VS compressor speed at 4500, 3600, and 2700 RPM, respectively. Tandem_R@Low means achieving the rated heating capacity at $47^{\circ} \mathrm{F}\left(8.3^{\circ} \mathrm{C}\right)$, by running a single compressor. The simulation results in Figure 21 compare heating COPs at $47^{\circ} \mathrm{F}$ $\left(8.3^{\circ} \mathrm{C}\right)$, integrated COPs at $-13^{\circ} \mathrm{F}\left(-25^{\circ} \mathrm{C}\right)$, and ratios of heat pump heating capacity at $13^{\circ} \mathrm{F}$ vs. $47^{\circ} \mathrm{F}$ rating point. The ratios of heating capacity were defined as heat pump capacity running at full speed at $-13^{\circ} \mathrm{F}$ vs. the rated capacity at $47^{\circ} \mathrm{F}$. The integrated COPs at $-13^{\circ} \mathrm{F}\left(-25^{\circ} \mathrm{C}\right)$ were calculated by including the supplemental resistance heat needed to match $80 \%$ rated heating capacity at $47^{\circ} \mathrm{F}\left(8.3^{\circ} \mathrm{C}\right)$, i.e. the building heating load for a well-insulated home at $-13^{\circ} \mathrm{F}\left(-25^{\circ} \mathrm{C}\right)$ in Region $\mathrm{V}$. If no resistance heat was needed, the heat pump COP was used as the integrated COP. It can be seen that overcapacity is the key to match the $75 \%$ capacity goal at $-13^{\circ} \mathrm{F}\left(-25^{\circ} \mathrm{C}\right)$ and provide higher 
integrated COP due to the elimination of resistance heat use. Four options in Figure 21 are able to reach the DOE capacity goal at $-13^{\circ} \mathrm{F}\left(-25^{\circ} \mathrm{C}\right)$, i.e. $>75 \%$ relative to the rated capacity at 47 $\mathrm{F}\left(8.3^{\circ} \mathrm{C}\right)$ (VS_R@4500RPM, 3600RPM, Tandem_R@Low and TandemVI_R@Low). Tandem_R@Low has a higher integrated COP than the VS options, since the VS compressor has an efficiency drop when running at the top speed of 7200 RPM. The tandem compressors with vapor injection and inter-stage economizing result in the highest integrated COP and the second highest capacity.

The VI compressor(s) with inter-stage economizing (illustrated in Figure 21) are able to boost heating capacity and COP at low ambient temperatures. However, a single VI compressor alone is not sufficient to meet the capacity target $(<25 \%$ capacity reduction from nominal. If the supplemental resistance heat (COP $<=1.0)$ is required to meet the building heating load, the integrated COP degrades dramatically. Thus, for CCHPs using VI, tandem or variable speed VI compressors have to be applied. This will accordingly increase the cost, in comparison to using tandem single-speed compressors.

A HP usually has its charge optimized for cooling mode. When switching to heating mode, the system tends to be overcharged, which causes high pressure ratio and discharge temperature. In order to meet the $75 \%$ capacity goal at $-13^{\circ} \mathrm{F}$, it is necessary to over-speed or over-capacity of the compressor(s) as compared to the rated condition at $47^{\circ} \mathrm{F}$. This will cause even higher pressure ratios and discharge temperatures than a typical single-stage HP. Too high discharge temperatures will shut off the compressor (a typical shut off temperature is $230^{\circ} \mathrm{F}$ ). Also, high pressure ratios will accelerate leakage from the high side to low side inside the compressor, which drastically decreases the compressor volumetric and isentropic efficiencies.

Figures 22 and 23 illustrate two charge control scenarios. Scenario I uses a TXV to control the evaporator exit superheat degree at $10^{\circ} \mathrm{R}$, with the system charge optimized for cooling mode. Scenario II uses a suction line accumulator and maintains the condenser subcooling degree at $10^{\circ} \mathrm{R}$. Both scenarios run a variable-speed compressor at 7200 RPM, with the HP running 4500 RPM to get the rated capacity at $47^{\circ} \mathrm{F}$. Figure 22 shows pressure ratio as a function of the ambient and indoor air temperatures. Figure 23 shows the compressor discharge temperature contours. It can be seen, at $-13^{\circ} \mathrm{F}$, Scenario I leads to pressure ratio ranging from 8 to 9 , and discharge temperature ranging from 280 to $300^{\circ} \mathrm{F}$; Scenario II leads to pressure ratio from 7 to 8 , and discharge temperature from 210 to $220^{\circ} \mathrm{F}$. Consequently, a proper charge and discharge temperature control is necessary to enable a CCHP working at extremely low ambient temperatures with overspeeding. 

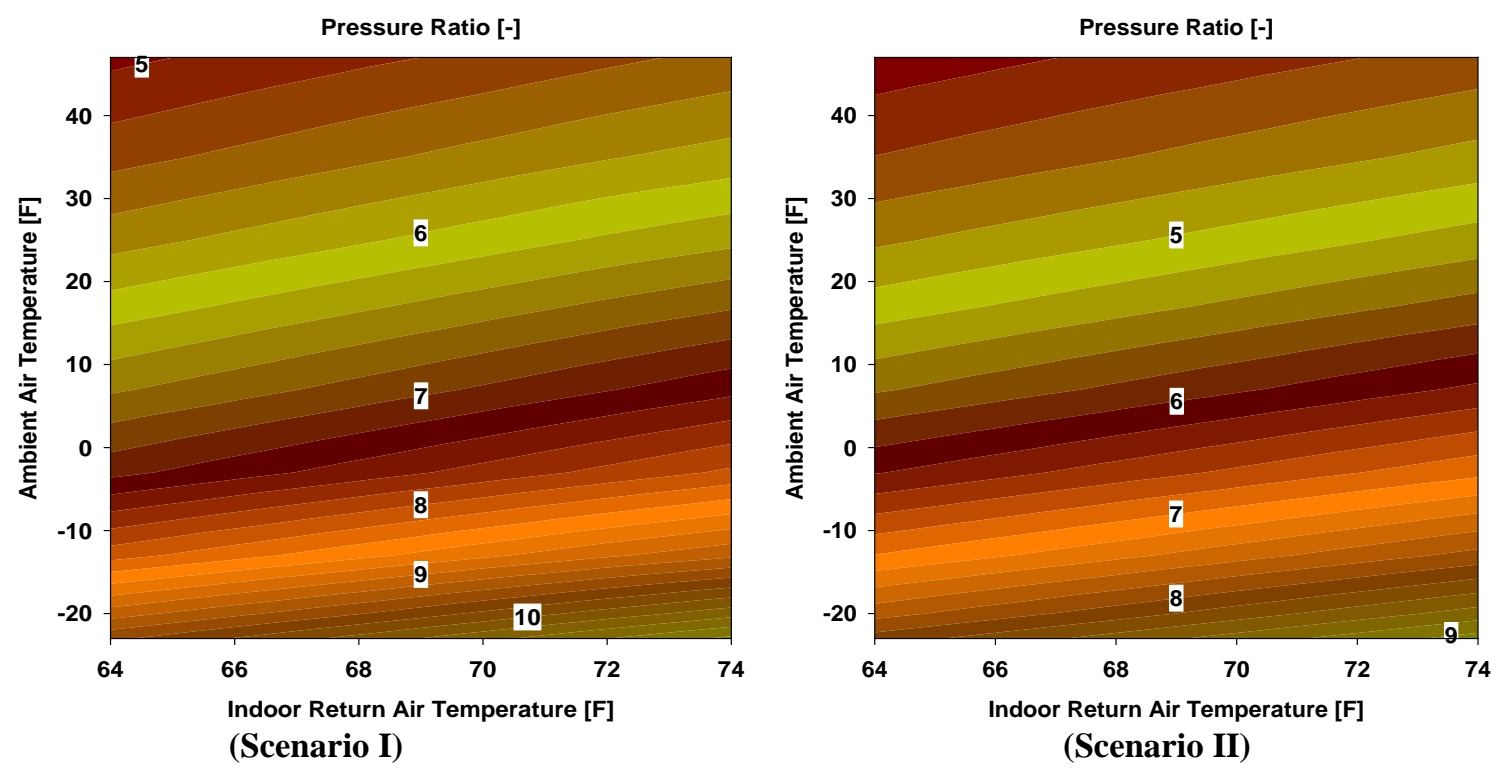

Figure 22: Pressure Ratios Changing with Indoor and Ambient Air Temperatures
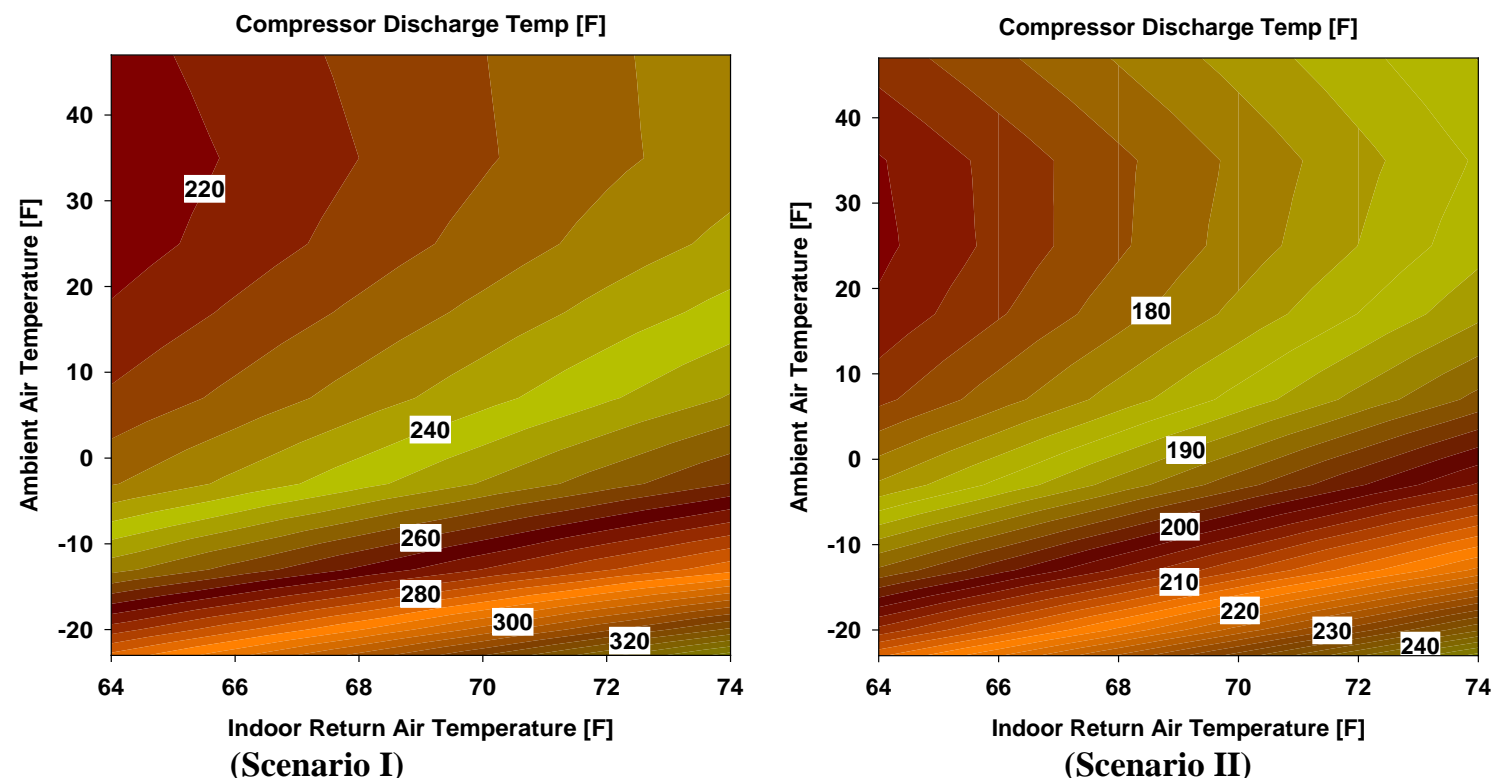

Figure 23: Discharge Temperature Changing with Indoor and Ambient Air Temperatures

\subsection{Sizing Study Using EnergyPlus}

EnergyPlus 7.2 (2013) is used for the building energy simulations discussed in this report. EnergyPlus uses off-design performance curves to correct heat pump capacities and power consumptions from the design condition at one speed level (i.e. Cooling: $80^{\circ} \mathrm{F}\left(26.7^{\circ} \mathrm{C}\right)$ indoor dry bulb $/ 67^{\circ} \mathrm{F}\left(19.4^{\circ} \mathrm{C}\right)$ indoor wet bulb, $95^{\circ} \mathrm{F}\left(35^{\circ} \mathrm{C}\right)$ outdoor dry bulb temperature; Heating: at the outdoor temperatures of $47^{\circ} \mathrm{F}\left(8.3^{\circ} \mathrm{C}\right) \mathrm{DB} / 43^{\circ} \mathrm{F}$ $\left(6.1^{\circ} \mathrm{C}\right) \mathrm{WB}$ and indoor temperature of $70^{\circ} \mathrm{F}\left(21.1^{\circ} \mathrm{C}\right)$ ), to account for impacts of offdesign temperatures. The curves are normalized to the heat pump rating point performance. To facilitate variable speed modeling capability, EnergyPlus 7.2 requires 
inputting normalized performance curves at individual speed levels, and linearly interpolates performance between two neighboring speed levels. The real-time operating speed is chosen by the model, matching the coil capacity to the building load.

Our analyses are based on compressor maps provided by Emerson Climate Technologies, and calibrated system and heat exchanger models of HPDM. HPDM is used to generate off-design performance curves by running steady-state simulations in an extensive working range. The performance curves were used in EnergyPlus for building energy simulations.

The base air source heat pump unit we selected for the analyses is a 5-ton, split heat pump, using a single-speed, 5-ton (17.6 kW) scroll compressor, having rated SEER (seasonal energy efficiency ratio) of $13.0 \mathrm{Btu} / \mathrm{WH}$ (cooling seasonal performance factor, $\mathrm{CSPF}$, of $3.8 \mathrm{~W} / \mathrm{W})$ and HSPF of 9.6 Btu/Wh (2.8 W/W). The unit information, i.e. heat exchangers, lines, fans, etc. was provided by our industry partner. We used HPDM to model the equipment and calibrated the model against the manufacturer's published performance data. After this was done, we kept the same heat exchangers, indoor blower and outdoor fan, and refrigerant connection lines, and evaluated different compressor options including: a 2-stage 5-ton scroll compressor (the top speed provides 5-ton cooling capacity at the rated condition, and ratio of capacity between the low and high stage is $67 \% / 100 \%)$; a 2-stage 6-ton scroll compressor (67\%/100\% capacity ratio); a tandem 8ton scroll compressor (consisting of two identical 4-ton compressors); a variable speed (VS) scroll compressor (having 5-ton nominal cooling capacity at $4500 \mathrm{RPM}$ ); a larger size variable speed scroll compressor (20\% more mass flow rate and power consumption than the 5-ton VS at each speed); a smaller size, 5-ton tandem scroll compressor (consisting of two identical 2.5-ton compressors); and a 5-ton single-speed vapor injection (VI) scroll compressor. It should be noted that the variable speed compressors investigated have speed ranges of 1800 RPM to 7200 RPM.

In order to design a cold climate heat pump, we want to optimize the heating performance, rather than the cooling performance. In addition, for a modulated system with significant refrigerant mass flow rate variation, we need an adjustable expansion device. At low ambient temperature, we want to minimize the evaporator superheat degree to elevate the suction saturation temperature for better efficiency. Considering these, we use a suction line accumulator to maintain the evaporator exit at saturated state, and an electronic or thermostatic expansion valve (EXV or TXV) refrigerant flow control device to control the condenser exit subcooling to $10^{\circ} \mathrm{R}\left(5.6^{\circ} \mathrm{K}\right)$. These two measures improve the heating efficiency as well as keeping the discharge temperature below the high limit, with the heat pump running down to the ambient temperature of $-13^{\circ} \mathrm{F}$ ($\left.25^{\circ} \mathrm{C}\right)$.

The next step involved studying the interaction of the building envelope and operating schedule with the equipment and ambient conditions. This involved sizing strategies, i.e. determining which speed level to match the heat pump cooling capacity to the building design cooling load. In Table 5, we list sixteen equipment design and sizing options. The 
Emerson CRADA final report, December 30, 2015

table also describes hardware information and the particular sizing strategy used to set up the equipment model for each option.

Each design and sizing option is assigned a unique name using the following naming convention:

\section{CMPTYPE_SIZINGRATIO_HEXSCALE_CMPSCALE}

Where,

$\rightarrow$ CMPTYPE compressor type: 1S means single-stage compressor; 2S means two-stage compressor; 2T means tandem compressor; VS means variable-speed compressor; VI means single-speed, vapor injection compressor.

$\rightarrow$ SIZINGRATIO = ratio of "total" cooling capacity to match the building design cooling load, The "total" capacity is obtained at the high speed for the 1S, 2S, 2T and VI compressors, and at 4500 RPM for the VS compressors (allowing reserving overspeeding capability for heating mode, from 4500 RPM to 7200 RPM). For an air source heat pump unit with a $1 \mathrm{~S}$ compressor the rated cooling capacity at standard rating conditions (i.e. $95^{\circ} \mathrm{F} / 35^{\circ} \mathrm{C}$ outdoor; and $80^{\circ} \mathrm{F}\left(26.7^{\circ} \mathrm{C}\right) \mathrm{DB} / 67^{\circ} \mathrm{F}\left(19.4^{\circ} \mathrm{C}\right) \mathrm{WB}$ indoor) is approximately equal to the rated heating capacity rated at outdoor temperatures of $47^{\circ} \mathrm{F}$ $\left(8.3^{\circ} \mathrm{C}\right) \mathrm{DB} / 43^{\circ} \mathrm{F}\left(6.1^{\circ} \mathrm{C}\right) \mathrm{WB}$ and indoor temperature of $70^{\circ} \mathrm{F}\left(21.1^{\circ} \mathrm{C}\right)$.

$\rightarrow$ HEXSCALE = scaling factor of indoor and outdoor heat exchangers, in comparison to the heat exchangers used in the 5-ton baseline heat pump.

$\rightarrow$ CMPSCALE = scaling factor of the compressor "total" cooling capacity, in comparison to the single-speed 5-ton scroll compressor used in the baseline heat pump.

For building energy simulations, normalized performance of the design options were scaled to match the same building design cooling load. i.e.

(Compressor Capacity@100\% × SIZINGRATIO) ${ }_{\text {option-n }} \times$ UnitScale $_{\text {option-n }}=$ Design Load (Eq. 3)

Here the design capacity is the EnergyPlus autosized Nominal Cooling Capacity for a single-speed unit at standard rating conditions (ambient: $95^{\circ} \mathrm{F}$; indoor: $80^{\circ} \mathrm{F} \mathrm{DB} / 67^{\circ} \mathrm{F}$ WB). The Design capacity is determined for the unit to match the peak cooling demand in a cooling design day, specific to each city, as regulated by ASHRAE 90.1-2007 (ASHRAE 2007). The UnitScale is the scaling factor for a unit, which is used to uniformly multiply the compressor size and heat exchanger area, to match the building cooling demand. 
Emerson CRADA final report, December 30, 2015

Table 5: Heat Pump Design and Sizing Options

\begin{tabular}{|c|c|c|}
\hline$\#$ & $\begin{array}{l}\text { Design and Sizing } \\
\text { Options }\end{array}$ & Practical Scenarios for Equipment Modeling \\
\hline 1 & $\begin{array}{l}\text { 1S-1.00R-1.0HX- } \\
\text { 1.0CMP }\end{array}$ & $\begin{array}{l}\text { Single speed heat pump having SEER of 13.0, HSPF of 9.6. Using a single-speed } \\
\text { 5-ton scroll compressor, and heat exchangers in the 5-ton HP. }\end{array}$ \\
\hline 2 & $\begin{array}{l}\text { 2S-1.00R-1.0HX- } \\
\text { 1.0CMP }\end{array}$ & $\begin{array}{l}\text { 5-ton HP, using a 2-stage, } 5 \text {-ton scroll compressor, rated at high speed to match a } \\
\text { building design cooling load of } 5 \text { ton. }\end{array}$ \\
\hline 3 & $\begin{array}{l}\text { 2S-0.73R-1.0HX- } \\
\text { 1.0CMP }\end{array}$ & $\begin{array}{l}\text { 5-ton HP, using a 2-stage, } 5 \text {-ton scroll compressor, rated at low speed to match a } \\
\text { building design cooling load of } 3.5 \text { ton. }\end{array}$ \\
\hline 4 & $\begin{array}{l}\text { 2S-0.73R-1.0HX- } \\
1.2 \mathrm{CMP}\end{array}$ & $\begin{array}{l}\text { 5-ton HP, using a 2-stage, } 6 \text {-ton scroll compressor, rated at low speed to match a } \\
\text { building design cooling load of } 4 \text { ton. }\end{array}$ \\
\hline 5 & $\begin{array}{l}\text { 2T-0.57R-1.0HX- } \\
1.6 \mathrm{CMP}\end{array}$ & $\begin{array}{l}\text { 5-ton HP, using a tandem, } 8 \text {-ton scroll compressor ( } 2 * 4 \text {-ton), rated at low speed to } \\
\text { match a building design cooling load of } 4 \text { ton. }\end{array}$ \\
\hline 6 & $\begin{array}{l}\text { VS-0.64R-1.0HX- } \\
\text { 1.2CMP }\end{array}$ & $\begin{array}{l}\text { 5-ton HP, using a 6-ton, variable-speed scroll compressor, rated at } 2700 \text { RPM to } \\
\text { match a building design cooling load of } 4 \text { ton. (working speed from } 1800 \text { RPM to } \\
7200 \text { RPM) }\end{array}$ \\
\hline 7 & $\begin{array}{l}\text { VS-0.82R-1.0HX- } \\
1.2 \mathrm{CMP}\end{array}$ & $\begin{array}{l}\text { 5-ton HP, using a 6-ton, variable-speed scroll compressor, rated at } 3600 \text { RPM to } \\
\text { match a building design cooling load of } 5 \text { ton. }\end{array}$ \\
\hline 8 & $\begin{array}{l}\text { VS-1.00R-1.0HX- } \\
\text { 1.2CMP }\end{array}$ & $\begin{array}{l}\text { 5-ton HP, using a } 6 \text {-ton, variable-speed scroll compressor, rated at } 4500 \text { RPM to } \\
\text { match a building design cooling load of } 6 \text { ton. }\end{array}$ \\
\hline 9 & $\begin{array}{l}\text { VS-0.64R-1.0HX- } \\
\text { 1.0CMP }\end{array}$ & $\begin{array}{l}\text { 5-ton HP, using a 5-ton, variable speed scroll compressor, rated at } 2700 \text { RPM to } \\
\text { match a building design cooling load of } 3 \text { ton. }\end{array}$ \\
\hline 10 & $\begin{array}{l}\text { VS-0.82R-1.0HX- } \\
\text { 1.0CMP }\end{array}$ & $\begin{array}{l}\text { 5-ton HP, using a 5-ton, variable speed scroll compressor, rated at } 3600 \text { RPM to } \\
\text { match a building design cooling load of } 4 \text { ton. }\end{array}$ \\
\hline 11 & $\begin{array}{l}\text { VS-1.00R-1.0HX- } \\
\text { 1.0CMP }\end{array}$ & $\begin{array}{l}\text { 5-ton HP, using a 5-ton, variable speed scroll compressor, rated at } 4500 \text { RPM to } \\
\text { match a building design cooling load of } 5 \text { ton. }\end{array}$ \\
\hline 12 & \begin{tabular}{|l|} 
2S-0.80R-1.0HX- \\
1.0CMP \\
\end{tabular} & $\begin{array}{l}\text { 5-ton HP, using a 2-stage, 5-ton scroll compressor, to match a building design } \\
\text { cooling load of } 4 \text { ton. }\end{array}$ \\
\hline 13 & $\begin{array}{l}\text { 2T-0.57R-1.0HX- } \\
\text { 1.0CMP } \\
\end{array}$ & $\begin{array}{l}\text { 5-ton HP, using a tandem, } 5 \text {-ton scroll compressor ( } 2 * 2.5 \text {-ton), rated at low speed } \\
\text { to match a building design cooling load of } 3 \text { ton. }\end{array}$ \\
\hline 14 & \begin{tabular}{|l|} 
2S-0.59R-1.0HX- \\
1.0CMP \\
\end{tabular} & $\begin{array}{l}\text { 5-ton HP, using a 2-stage, 5-ton scroll compressor, to match a building design } \\
\text { cooling load of } 3.0 \text { ton. }\end{array}$ \\
\hline 15 & $\begin{array}{l}\text { VI-1.00R-1.0HX- } \\
\text { 1.0CMP } \\
\end{array}$ & $\begin{array}{l}\text { 5-ton HP, using a 5-ton, single-speed VI scroll compressor, to match a building } \\
\text { design cooling load of } 5.0 \text { ton. }\end{array}$ \\
\hline 16 & $\begin{array}{l}\text { 1S-0.50R-2.0HX- } \\
\text { 2.0CMP }\end{array}$ & $\begin{array}{l}\text { Two identical single speed heat pumps, having SEER of 13.0, HSPF of 9.6: only } \\
\text { one unit used for cooling mode and one or both for heating mode based on the } \\
\text { building heating demand. }\end{array}$ \\
\hline
\end{tabular}

Table 6 lists nominal heating capacities at $47^{\circ} \mathrm{F}$, which are mostly obtained at low speed levels, and approximately equal to the selected nominal cooling capacity at $95^{\circ} \mathrm{F}$. We also list capacity degradations at $-13^{\circ} \mathrm{F}$, obtained using the maximum heating capacity (at the highest speed) of the system at $-13^{\circ} \mathrm{F}$, divided by the nominal heating capacity at $47^{\circ} \mathrm{F}$. The system heating COPs at $47^{\circ} \mathrm{F}$ are approximately around 4.0 , and the COPs at $-13^{\circ} \mathrm{F}$ are around 2.0 (50\% reduction). We also calculated HSPFs (Heating Seasonal Performance Factor), following AHRI 210/240 standard (AHRI 2010), respectively for region IV and $\mathrm{V}$ for minimum and maximum design heating requirements $\left(\mathrm{DHR}_{\min }\right.$ and $\left.\mathrm{DHR}_{\max }\right)$. When calculating the HSPFs, the degradation coefficient (Cd) of the $1 \mathrm{~S}$ and VI systems is assumed to be $0.1, \mathrm{Cd}$ of the $2 \mathrm{~S}$ systems is assumed to be $0.13, \mathrm{Cd}$ of the $2 \mathrm{~T}$ systems is assumed to be 0.17 , and Cd of the VS systems is assumed to be 0.20 , those are empirical numbers recommended by Emerson Climate Technologies. Equipment 
cyclic operation only occurs at the lowest speed, except for Option 16 (1S-0.50R-2.0HX2.0CMP) where cyclic losses of the two identical single-speed HP units are considered for both the capacity levels. Regarding frosting/defrosting (F/D) operations, we follow the recommendation of AHRI 210/240, i.e. neglecting F/D losses when the ambient temperature is higher than $42^{\circ} \mathrm{F}\left(8.3^{\circ} \mathrm{C}\right)$ and below $17^{\circ} \mathrm{F}\left(-8.3^{\circ} \mathrm{C}\right)$ (power and capacity correction factors being 1.0); assuming 0.9 capacity correction factor, 0.985 power correction factor, to the steady-state performance at $35^{\circ} \mathrm{F}\left(1.7^{\circ} \mathrm{C}\right)$ and linearly interpolating the capacity and power correction factors, respectively, from $35^{\circ} \mathrm{F}$ to $42^{\circ} \mathrm{F}$ $\left(1.7^{\circ} \mathrm{C}\right.$ to $\left.8.3^{\circ} \mathrm{C}\right)$ and from $35^{\circ} \mathrm{F}$ to $17^{\circ} \mathrm{F}\left(1.7^{\circ} \mathrm{C}\right.$ to $\left.8.3^{\circ} \mathrm{C}\right)$. Also, we ignore the power used for the crank-case heater. The same treatment for cyclic losses and F/D operations was used in EnergyPlus building simulations. Table 6 shows 8 options having capacity degradation at $-13^{\circ} \mathrm{F}\left(-25^{\circ} \mathrm{C}\right)$ smaller than $30 \%$, highlighted in green. They are four variable-speed systems (\#6: VS-0.64R-1.0HX-1.2CMP, \#7: VS-0.82R-1.0HX-1.2CMP, \#9: VS-0.64R-1.0HX-1.0CMP, and \#10: VS-0.82R-1.0HX-1.0CMP) sized to match building design cooling load at 2700 RPM or 3600 RPM, two tandem systems (\#5: 2T0.57R-1.0HX-1.6CMP, \#13: 2T-0.57R-1.0HX-1.0CMP) sized to match building design cooling load at the lowest speed, one two-speed system to match the design cooling load even below the system capacity at the low speed (\#14: 2S-0.59R-1.0HX-1.0CMP), and a system composed of two identical 9.6 HSPF heat pumps (\#16: 1S-0.50R-2.0HX2.0CMP). We call these 8 options as CCHPs.

Table 6: System Indices Predicted by HPDM and HSPF Calculations by AHRI 210/240

\begin{tabular}{|c|c|c|c|c|c|c|c|c|}
\hline $\begin{array}{l}\text { Design and Sizing } \\
\text { Options }\end{array}$ & $\begin{array}{l}\text { Nom } \\
\mathrm{COP} \\
\text { @4 } 47^{\circ} \mathrm{F}\end{array}$ & $\begin{array}{c}\text { Nom } \\
\text { Capacity } \\
@ 47^{\circ} \mathrm{F} \\
\text { (DHR) }\end{array}$ & $\begin{array}{c}\text { Capacity } \\
\text { Ratio @ } \\
-13^{\circ} \mathrm{F}\end{array}$ & $\begin{array}{c}\mathrm{COP} \\
@ \\
-13^{\circ} \mathrm{F}\end{array}$ & $\begin{array}{l}\text { HSPF - } \\
\mathrm{DHR}_{\text {min }}\end{array}$ & $\begin{array}{l}\text { HSPF - } \\
\mathrm{DHR}_{\text {max }}\end{array}$ & $\begin{array}{l}\mathrm{HSPF}- \\
\mathrm{DHR}_{\min }\end{array}$ & $\begin{array}{l}\text { HSPF - } \\
\mathrm{DHR}_{\text {max }}\end{array}$ \\
\hline & {$[-]$} & [kBtu/h] & {$[-]$} & {$[-]$} & $\begin{array}{l}\text { Region } \\
\text { IV }\end{array}$ & $\begin{array}{l}\text { Region } \\
\text { IV } \\
\end{array}$ & Region V & Region V \\
\hline $\begin{array}{l}\text { 1. 1S-1.00R-1.0HX- } \\
\text { 1.0CMP }\end{array}$ & 3.58 & 62.72 & $40 \%$ & 1.92 & 9.55 & 7.35 & 8.42 & 6.68 \\
\hline $\begin{array}{l}\text { 2. 2S-1.00R-1.0HX- } \\
\text { 1.0CMP }\end{array}$ & 3.79 & 58.06 & $42 \%$ & 2.09 & 9.96 & 8.08 & 8.66 & 6.72 \\
\hline $\begin{array}{l}\text { 3. 2S-0.73R-1.0HX- } \\
\text { 1.0CMP }\end{array}$ & 3.78 & 42.55 & $57 \%$ & 2.09 & 9.98 & 7.83 & 8.92 & 7.87 \\
\hline $\begin{array}{l}\text { 4. 2S-0.73R-1.0HX- } \\
\text { 1.2CMP }\end{array}$ & 3.45 & 49.31 & $58 \%$ & 1.91 & 9.28 & 8.64 & 8.37 & 7.42 \\
\hline $\begin{array}{l}\text { 5. 2T-0.57R-1.0HX- } \\
\text { 1.6CMP }\end{array}$ & 3.89 & 47.82 & $77 \%$ & 1.85 & 10.43 & 9.41 & 9.44 & 8.09 \\
\hline $\begin{array}{l}\text { 6. VS-0.64R-1.0HX- } \\
\text { 1.2CMP }\end{array}$ & 4.06 & 43.70 & $94 \%$ & 1.80 & 11.41 & 10.56 & 10.44 & 8.88 \\
\hline $\begin{array}{l}\text { 7. VS-0.82R-1.0HX- } \\
\text { 1.2CMP }\end{array}$ & 3.90 & 55.89 & $74 \%$ & 1.80 & 11.48 & 9.77 & 10.14 & 8.00 \\
\hline $\begin{array}{l}\text { 8. VS-1.00R-1.0HX- } \\
\text { 1.2CMP }\end{array}$ & 3.51 & 68.01 & $61 \%$ & 1.80 & 11.26 & 8.97 & 9.86 & 8.00 \\
\hline $\begin{array}{l}\text { 9. VS-0.64R-1.0HX- } \\
\text { 1.0CMP }\end{array}$ & 4.30 & 37.99 & $94 \%$ & 1.89 & 11.61 & 10.93 & 10.42 & 9.47 \\
\hline $\begin{array}{l}\text { 10. VS-0.82R-1.0HX- } \\
\text { 1.0CMP }\end{array}$ & 4.14 & 48.37 & $74 \%$ & 1.89 & 11.71 & 10.06 & 10.34 & 8.43 \\
\hline $\begin{array}{l}\text { 11. VS-1.00R-1.0HX- } \\
\text { 1.0CMP }\end{array}$ & 3.80 & 59.16 & $61 \%$ & 1.89 & 11.59 & 9.61 & 10.11 & 7.82 \\
\hline $\begin{array}{l}\text { 12. 2S-0.80R-1.0HX- } \\
\text { 1.0CMP }\end{array}$ & 3.79 & 46.45 & $52 \%$ & 2.09 & 10.05 & 8.97 & 8.88 & 7.54 \\
\hline
\end{tabular}




\begin{tabular}{|l|c|c|c|c|c|c|c|c|}
\hline $\begin{array}{l}\text { 13. 2T-0.57R-1.0HX- } \\
\text { 1.0CMP }\end{array}$ & 4.38 & 36.53 & $75 \%$ & 1.98 & 11.31 & 10.71 & 10.01 & 8.84 \\
\hline $\begin{array}{l}\text { 14. 2S-0.59R-1.0HX- } \\
\text { 1.0CMP }\end{array}$ & 3.78 & 34.04 & $71 \%$ & 2.09 & 9.92 & 9.73 & 8.87 & 8.41 \\
\hline $\begin{array}{l}\text { 15. VI-1.00R-1.0HX- } \\
1.0 \mathrm{CMP}\end{array}$ & 3.75 & 61.64 & $43 \%$ & 2.12 & 10.09 & 7.59 & 9.00 & 6.95 \\
\hline $\begin{array}{l}\text { 16. } 1 \mathrm{~S}-0.50 \mathrm{R}-2.0 \mathrm{HX}- \\
2.0 \mathrm{CMP}\end{array}$ & 3.58 & 62.72 & $80 \%$ & 1.92 & N/A & N/A & N/A & N/A \\
\hline
\end{tabular}

To facilitate building energy simulation of a variable speed heat pump system, the performance maps predicted by HPDM were reduced at individual compressor speeds, for the variable-speed systems, the speeds are selected at five levels of 1800 RPM (minimum), 2700 RPM, 3600 RPM, 4500 RPM (100\%) and 7200 (maximum). The curves cover $-25^{\circ} \mathrm{F}\left(-32^{\circ} \mathrm{C}\right)$ to $63^{\circ} \mathrm{F}\left(17.2^{\circ} \mathrm{C}\right)$ for outdoor dry bulb temperatures with $70 \%$ relative humidity, and $60^{\circ} \mathrm{F}\left(15.6^{\circ} \mathrm{C}\right)$ to $74^{\circ} \mathrm{F}\left(23.3^{\circ} \mathrm{C}\right)$ for indoor dry bulb temperatures.

We selected one small commercial lodging building, and one residential single-family detached house with heated basement for the building simulations. The input files of the small commercial lodging building were produced using the EnergyPlus Example File Generator (developed by NREL), for seven cities, i.e. Chicago, IL; Boulder, CO; Helena, MT; Minneapolis, MN; Duluth, MN; Fairbanks, AK, and Indianapolis, IN. The building is in a rectangular shape, with length of 131 feet $(40 \mathrm{~m})$ and width of 66 feet $(20 \mathrm{~m})$, and it has one floor and five zones, and each individual zone is conditioned by one heat pump unit. The building envelope characteristics, wall thickness, window sizing, etc., were chosen for each climate zone, according to ASHRAE 90.1-2007 (ASHRAE 2007). The input files of the residential, single-family house were converted from Residential Prototype Building Models (developed by PNNL), for seven cities: Minneapolis, MN; Duluth, MN; Fairbanks, AK; Helena, MT; Indianapolis, IN; Peoria, IL and Eagle County, $\mathrm{CO}$. The residential house used one heat pump unit for heating and cooling. We intended the residential building case to represent a retrofit application, and thus, the building envelope characteristics were chosen to match requirements in the 2006 International Energy Conservation Code (International Code Council 2006). For both buildings in heating season, the zone temperatures are uniformly controlled at $70^{\circ} \mathrm{F}$. We evaluated the 16 design and sizing options, as listed in Table 5, using the two buildings and allowing EnergyPlus to auto-size the equipment at a selected modulation level to match the building design cooling load, as described in Equation 3.

The small commercial lodging building and the residential single-family house not only differ in energy codes, but also, in relative ratios between the design cooling and heating loads. The commercial building has a larger percentage of interior lighting energy and more human occupants per unit indoor area, than the residential building. Consequently, the ratio of the design cooling load to the design heating load in the commercial building is larger than the residential building. In other words, a heat pump unit, sized in cooling mode, is more capable of meeting the heating demand in the commercial building, and uses less electric resistance heat. As illustrated in Figure 24, in the commercial building CCHPs can reduce resistance heat use below 10\% for Fairbanks, and below 3\% for Minneapolis, in comparison to the total annual heating energy consumption (heat pump energy consumption + supplemental heating). However for the residential building, as 
shown in Figure 25, using the same options, resistance heat use can only be reduced to $30 \%$ for Fairbanks, and to 10\% for Minneapolis. In Figure 26, we compared the average HSPFs of Minneapolis, simulated by EnergyPlus, to the calculated HSPFs, following AHRI 210/240 standard, for Region V. One can see that HSPFs calculated with EnergyPlus for the commercial building in Minneapolis lie approximately midway between those for the AHRI 210/240 DHRmin and DHRmax lines. On the other hand, annual HSPFs of the residential building in Minneapolis almost coincide with the DHRmax curve.

Note: DHR is a terminology defined in AHRI 210/240, which means Design Heating Requirement, representing the heating load at a design ambient condition specific to individual climate zones. $\mathrm{DHR}_{\min }$ means minimum design heating load in a building with high thermal insulation and low infiltration; $\mathrm{DHR}_{\max }$ means maximum design heating load in a building with lower thermal insulation and higher infiltration.

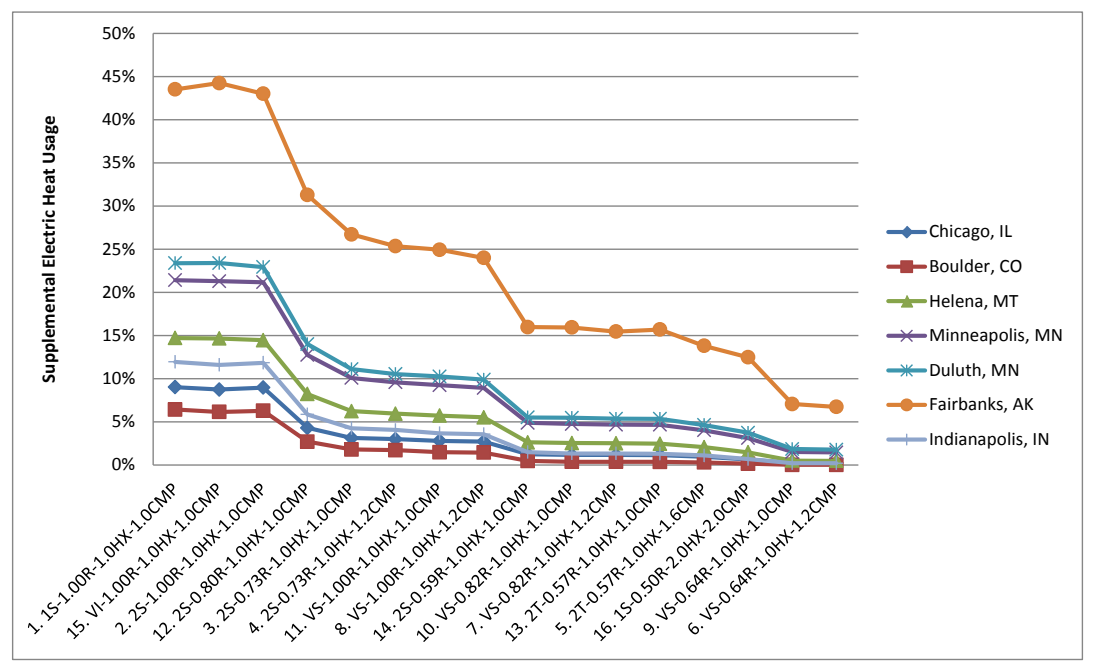

Figure 24: Supplemental Electric Resistance Heat Uses, Relative to Annual Heating Energy Consumption, in Commercial, Small Lodging Building

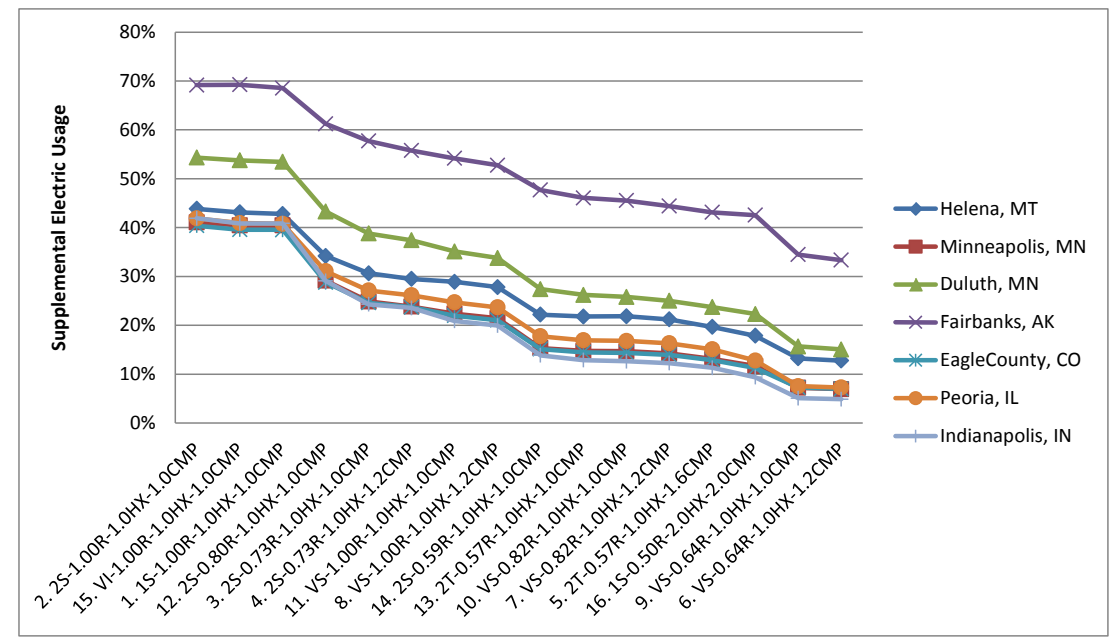

Figure 25: Supplemental Electric Resistance Heat Uses, Relative to Annual Heating Energy Consumption, in Residential, Single-Family Detached House with Heated Basement 


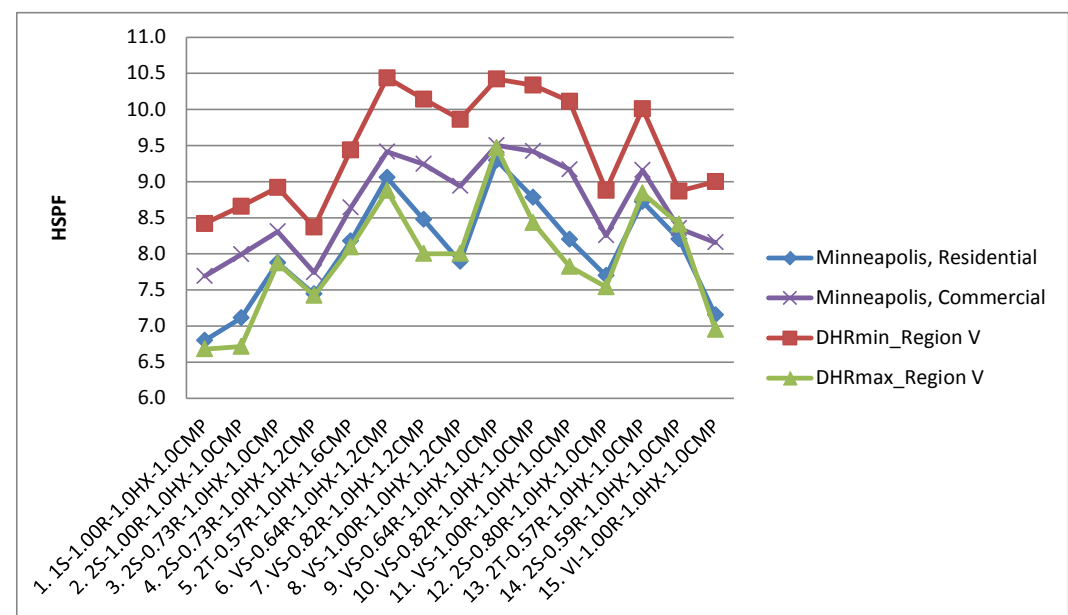

Figure 26: Comparisons of Annual, Average HSPFs (EnergyPlus Simulations) to Calculated HSPFs (AHRI 210/240) in Region V

Figures 27 and 28 illustrate ratios of annual heating energy usage compared to $100 \%$ electric resistance heating in the two buildings. Extremely cold regions like Fairbanks and Duluth have smaller percentages of annual heating energy reduction because in these locations the heat pump options require more backup heating. Figures 29 and 30 illustrate ratios of heating energy usage compared to the baseline heat pump. Using one of the CCHP design options to replace the single-speed heat pump appears more beneficial in the residential building than in the commercial building. For the commercial building, the percentages of backup heat uses are smaller, and thus, it has larger percentage of energy savings, compared to $100 \%$ electric resistance heat use, than the residential building for all the heat pumps; however, the benefit of over-speeding is less. Consequently, the relative advantage of a multiple-speed system over a single-speed system is smaller for the commercial building than the residential building.

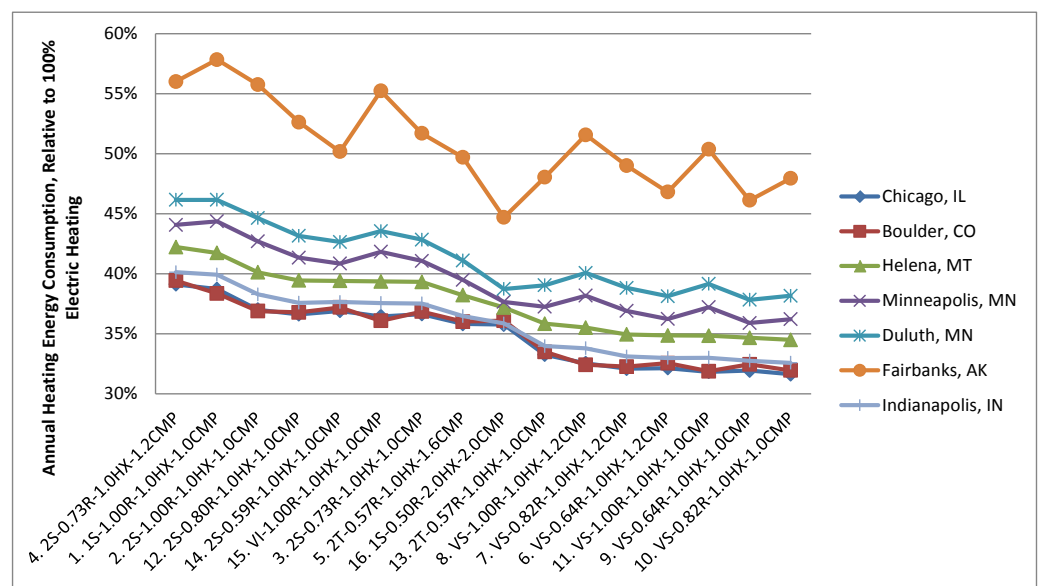

Figure 27: Ratios of Heating Energy Consumption, Compared to $100 \%$ Electric Resistance Heating in Commercial, Small Lodging Building 
Emerson CRADA final report, December 30, 2015

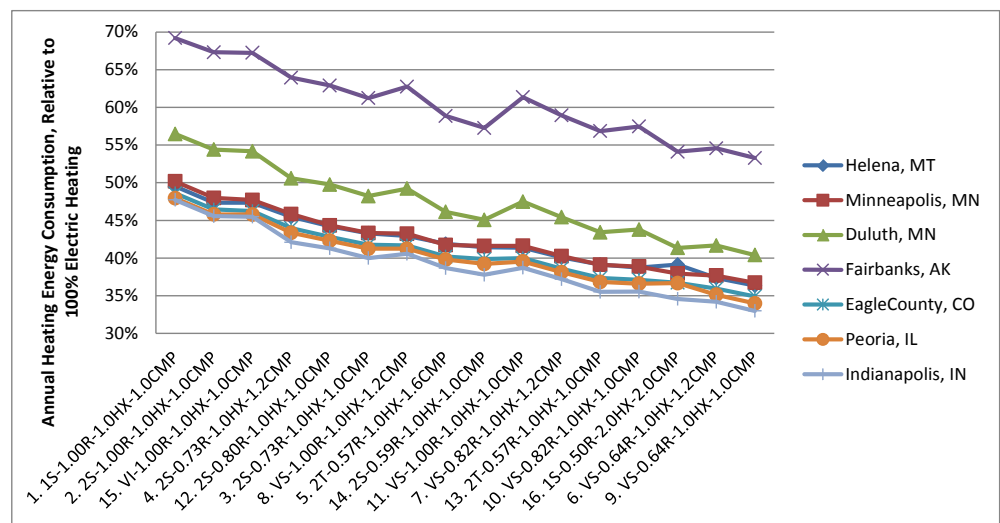

Figure 28: Ratios of Heating Energy Consumption, Compared to $100 \%$ Electric Resistance Heating in Residential, Single-Family Detached House

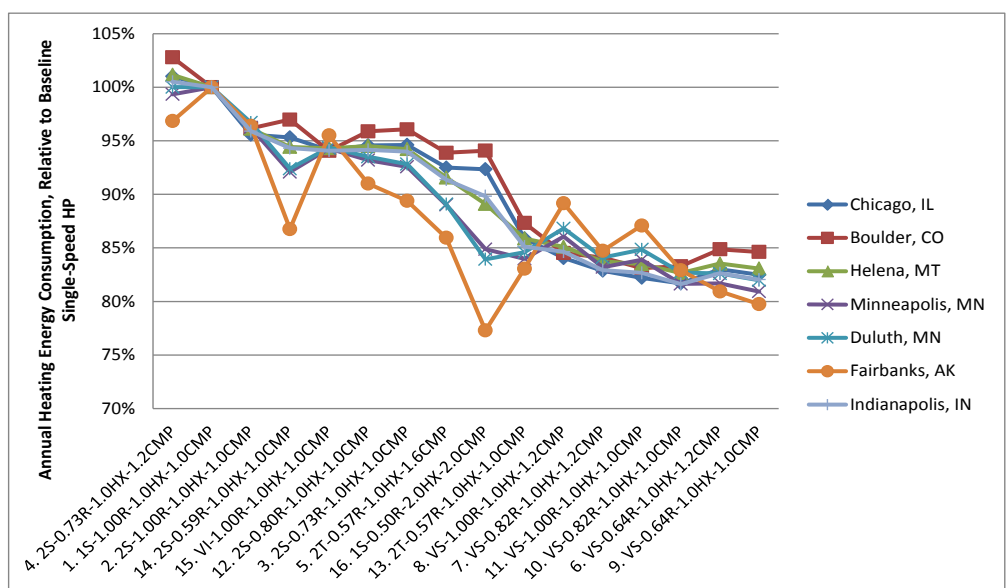

Figure 29: Ratios of Heating Energy Consumption, Compared to Baseline 9.6 HSPF, Single-Speed Heat Pump, in Commercial, Small Lodging Building

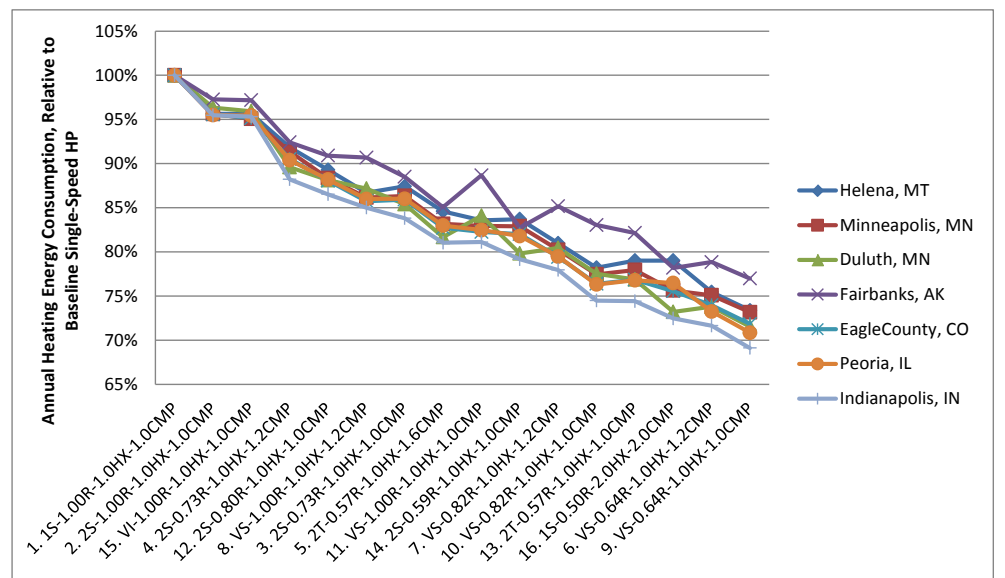

Figure 30: Ratios of Heating Energy Consumption, Compared to Baseline 9.6 HSPF, Single-Speed Heat Pump, in Residential, Single-Family Detached House

Heating energy reductions per ton of building design cooling capacity, in the commercial building, are shown in Figure 31 vs. 100\% electric resistance heating. These normalized values can be used to estimate payback periods for each design and sizing option. 
Assuming electricity cost of $\$ 0.10 / \mathrm{kWh}$, CCHPs can lead to annual savings ranging from up to $\$ 500$ per ton $(\$ 142 / \mathrm{kW})$ in Fairbanks to around $\$ 200$ per ton $(\$ 52 / \mathrm{kW})$ for Indianapolis. Figure 32 compares heating energy use reductions between the commercial building and residential building. The residential building modeled is less energyefficient (based on older codes) than the commercial building. In addition, its design cooling capacity is smaller relative to its design heating demand in each city. Hence, heating energy saving potential for the residential building can be almost double that for the commercial building depending upon location and heat pump sizing option.

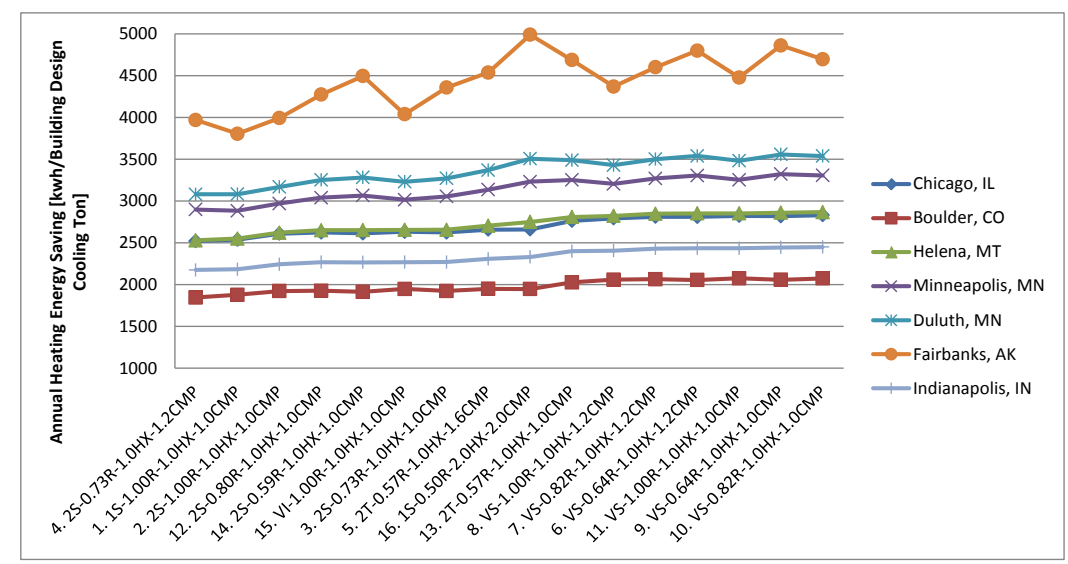

Figure 31: Heating Energy Reductions per Ton of Building Design Cooling Capacity, in Commercial, Small Lodging Building, Compared to $100 \%$ Electric Resistance Heating

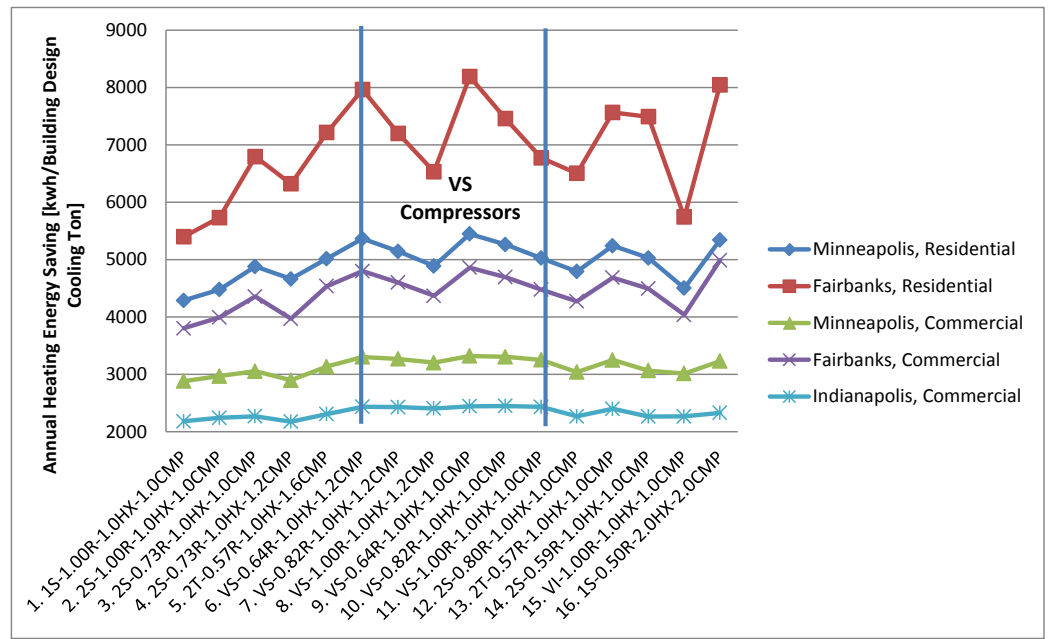

Figure 32: Comparing Heating Energy Reductions per Ton of Building Design Cooling Capacity, between Commercial, Small Lodging Building and Residential, Single-Family Detached House, Compared to $100 \%$ Electric Resistance Heating

To meet the goal (Capacity Ratio @- $13^{\circ} \mathrm{F}>75 \%$ ) with conventional heat pump systems, one would need to oversize the heat pump, either the equipment or the compressor. This will result in less electric resistance heat use at low ambient temperatures but at the expense of reducing operating efficiency at moderate ambient temperatures due to oversizing (cyclic loss, reduced relative heat transfer area, etc.). The system options using VS compressors provide the greatest efficiency since they have a good balance between 
the oversizing loss and the reduction in the resistance heat usage. The qualified options can maximize heating energy savings in northern cities, for both building types considered. However in warmer locations or with a more energy-efficient building, the benefit of oversizing would be offset by the cyclic loss. For example, for the commercial building in Indianapolis, the trend is flat when selecting the variable-speed systems at different speed levels. Design \# 4 (2S-0.73R-1.0HX-1.2CMP) and Design \# 12 (2S0.80R-1.0HX-1.0CMP) even hurt the energy performance, as compared to Design \# 2 (2S-1.00R-1.0HX-1.0CMP). That means that the reduction in electric resistance heat use can't make up for the increased cycling losses and lower operation efficiency at high ambient temperature. We can also see for Design \# 16 (1S-0.50R-2.0HX-2.0CMP, using two identical single-speed units), it is not a preferred choice for the commercial building in Indianapolis, IN due to increased cyclic losses; however, it stands out for Minneapolis, and Fairbanks, where reducing resistance heat becomes more important.

Figures 33 shows comparison to a baseline 90\% AFUE gas heating system in terms of source energy (assuming electricity source energy efficiency of 32\%). We can see that the only heat pump cases with lower primary energy consumption are the variable-speed heat pumps in warmer climates, e.g. Indianapolis, Peoria, and the other heat pump cases consume more primary energy in the residential building.

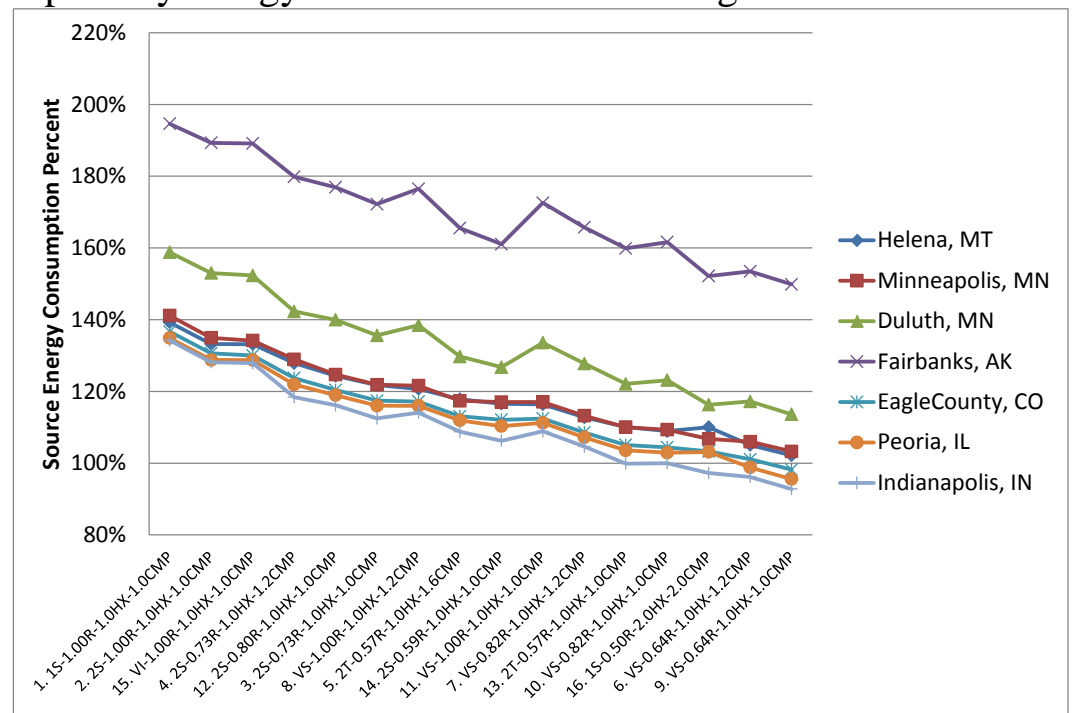

Figure 33: Total Source Energy Consumption Percentages Relative to Baseline 90\% AFUE Gas Heating in Residential, Single-Family Detached House

\section{Conclusion:}

In the sixteen design configurations listed in Table 5, eight can approximately meet the project heating capacity degradation target and can thus be labelled "CCHP designs". They are more advantageous in colder regions and in less energy-efficient buildings. However, in warmer regions and more energy-efficient buildings, the qualified options might not result in significant savings, since the reduction in electric resistance use is offset by the operation efficiency degradation at high ambient temperatures due to oversizing. If a cold climate heat pump is sized according to the building design cooling load, the payback period would be shorter for a residential building than a commercial 
building, since it has more heating energy reduction per ton of building design cooling capacity. The qualified options can't totally eliminate resistance heat usage in colder regions, e.g. Minneapolis, Duluth and Fairbanks, because various building types i.e. retrofit or new, result in different percentages of supplemental heating, even in the same climate zone.

The "best" concept selection varies with location. For warmer climates like Indianapolis, Boulder, and Chicago, where energy reductions are not sensitive to the equipment sizing ratio, we want to moderately oversize a heat pump unit in the less cold regions (e.g. rating a VS heat pump at 4500 RPM in Indianapolis) and gradually increasing the degree of oversizing in colder climates (e.g. rating the nominal heating capacity for a VS heat pump at 3600 RPM in Minneapolis, and 2700 RPM in Fairbanks).

To seek further energy savings, one may try improving system operation efficiencies at low ambient temperatures. Recommended design configurations include coupling an ejector cycle with a variable-speed compressor, using a variable-speed vapor injection compressor, or using two compressors in series rather than in parallel to reduce pressure ratio of each compressor and provide intermediate cooling for better compression efficiency. Better insulation on the compressor shell and discharge line should be considered to reduce the heat loss so as to boost the delivered heating capacity of a CCHP design.

\section{Laboratory Investigations}

From the analyses above, the HPs using tandem compressors with the rated capacity obtained with a single compressor, and a variable-speed compressor with the rated capacity obtained at a low speed level are able to meet the $75 \%$ capacity goal. We decided to focus our laboratory investigations on using tandem compressors than a variable-speed compressor, for four reasons.

1. Equal tandem, single-speed compressors generally have larger operation envelope than a variable-speed compressor of the same maximum capacity, in terms of pressure ratio and discharge temperature.

2. A variable-speed compressor is usually optimized at one speed level. When moving away from the optimum speed level, especially at maximum and minimum speeds, the VS compressor tends to have some level efficiency degradation.

3. A two-capacity heat pump using tandem compressors can easily accommodate with the widely available 2-stage thermostats on the market.

4. It is easier to develop a control system for the two-capacity HP within ORNL, without needing the significant support from an OEM.

The laboratory prototype was built by modifying a 5-ton, single-speed, York HP, made by Johnson Controls, having a factory rated HSPF of 8.5. We basically reused its heat exchangers, indoor blower and outdoor fan. The indoor blower has two speed levels and the outdoor fan is single-speed. Figure 34 illustrates the experimental set up of the outdoor unit, and Figure 35 shows the indoor air handler. We used an air flow monitor (a 
pitot tube array) to measure the indoor air flow rate at the exit of the indoor air handler, used $3 \times 3$ thermo-couple grids to measure the return and supply air temperatures, as well as the outdoor air temperature entering the coil. We used Ohio Semitronics Watt transducers to measure the electric power of the compressors, blower and fan individually. We also installed pressure transducers and inserted probe thermo-couples to monitor the refrigerant system.

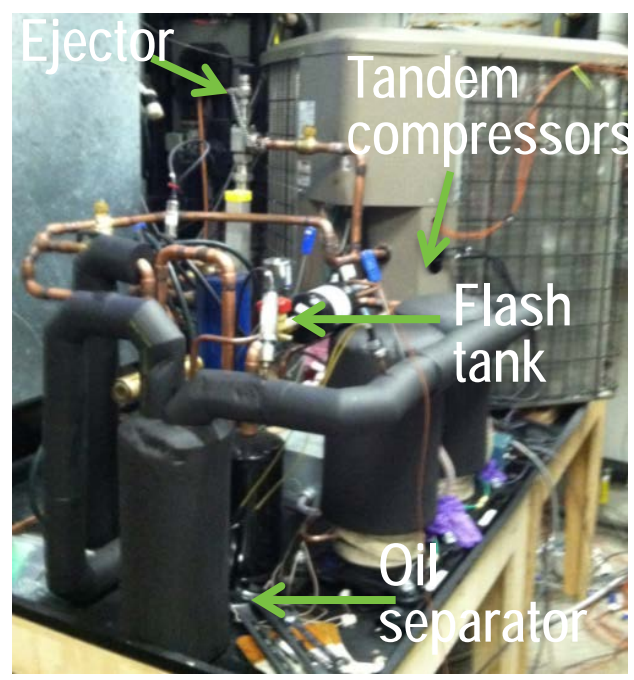

Figure 34: Lab Prototype - Outdoor Unit (setup for investigating an ejector)

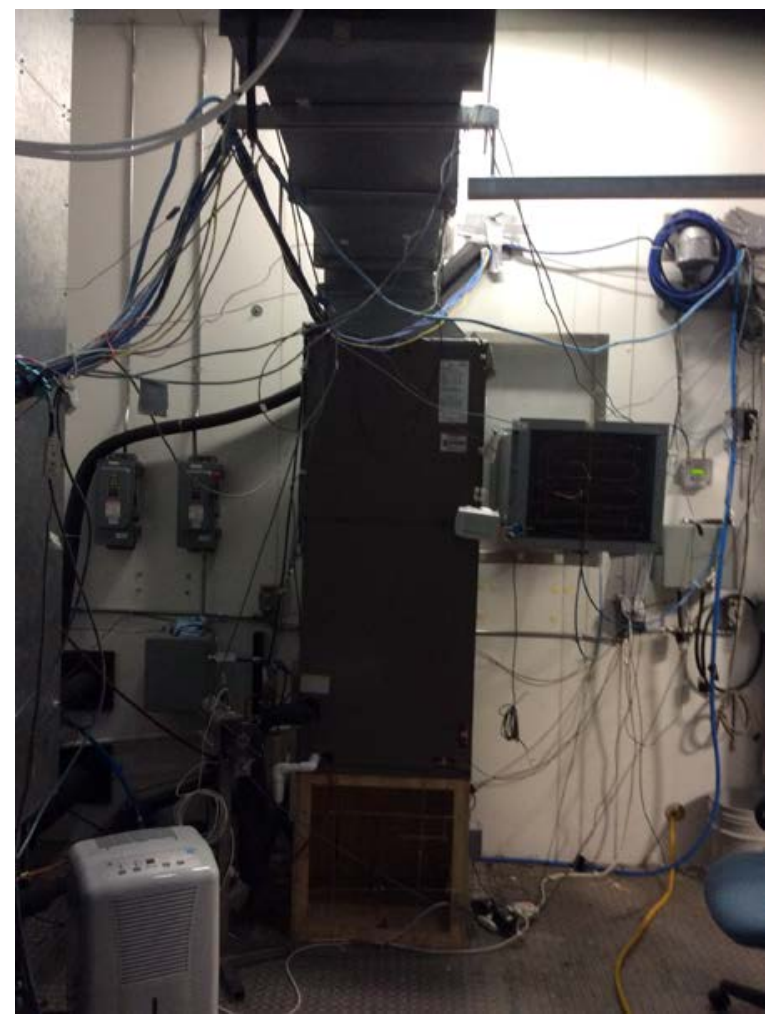

Figure 35: Lab Prototype - Indoor Air Handler

Page 47 of 86 
Emerson CRADA final report, December 30, 2015

The sections which follow introduce the three CCHP lab prototypes investigated using tandem single-speed or VI compressors. All the prototypes used R410A refrigerant.

\section{1 'Most Cost-Effective' Option - Equal Tandem, Single-Speed Compressors}

The 'Most cost-effective' option using two equal, single-speed compressors is shown in Figure 36. The design considerations are summarized as below:

1. The two equal, single-speed compressors were obtained from Emerson Climate Technologies. These featured special "heating application" design features, which allow the compressor to operate at higher discharge temperatures than most typical compressors (up to $280^{\circ} \mathrm{F}\left[137.8^{\circ} \mathrm{C}\right]$ ). This enables the heat pump to work at extremely low ambient temperatures.

2. Current two-capacity heat pumps on the market use a single, two-stage compressor having a displacement volume split ratio of $100 \%$ to $67 \%$. In comparison, the tandem compressors have a volume split ratio of $100 \%$ to $50 \%$, which provides a larger overcapacity potential, when the heat pump nominal COP and capacity ratings are established for the low capacity (e.g. one compressor) level. That is the reason that the heat pump using the tandem compressors reached $>75 \%$ capacity at $-13^{\circ} \mathrm{F}(-$ $\left.25^{\circ} \mathrm{C}\right)$.

3. The CCHP is sized to match a 3-ton building cooling load using a single compressor. The system uses heat exchangers of a typical 5-ton heat pump. When running a single compressor in cooling mode and at moderate temperatures in heating mode, the heat exchangers are unloaded, and this provides higher efficiency. That is the key that enabled the CCHP lab prototypes to reach a COP $>4.0$ at $47^{\circ} \mathrm{F}\left(8.3^{\circ} \mathrm{C}\right)$.

4. For CCHPs, the compressor(s) shall be well insulated and placed outside the outdoor air flow stream (shown in Figure 37), as to minimize the shell heat loss. Insulating the compressors impairs the cooling performance; however, this effect is negligible, since the condenser (outdoor heat exchanger) is now oversized for cooling mode operation with only one compressor.

5. Heating mode discharge temperature control, which uses an EXV, coupled with a suction line accumulator, is intended to optimize the active charge in the system over an extensive operation range. This mitigates the typical charge imbalance problem between cooling and heating modes. A standard thermostatic expansion valve (TXV) is used for cooling mode. 


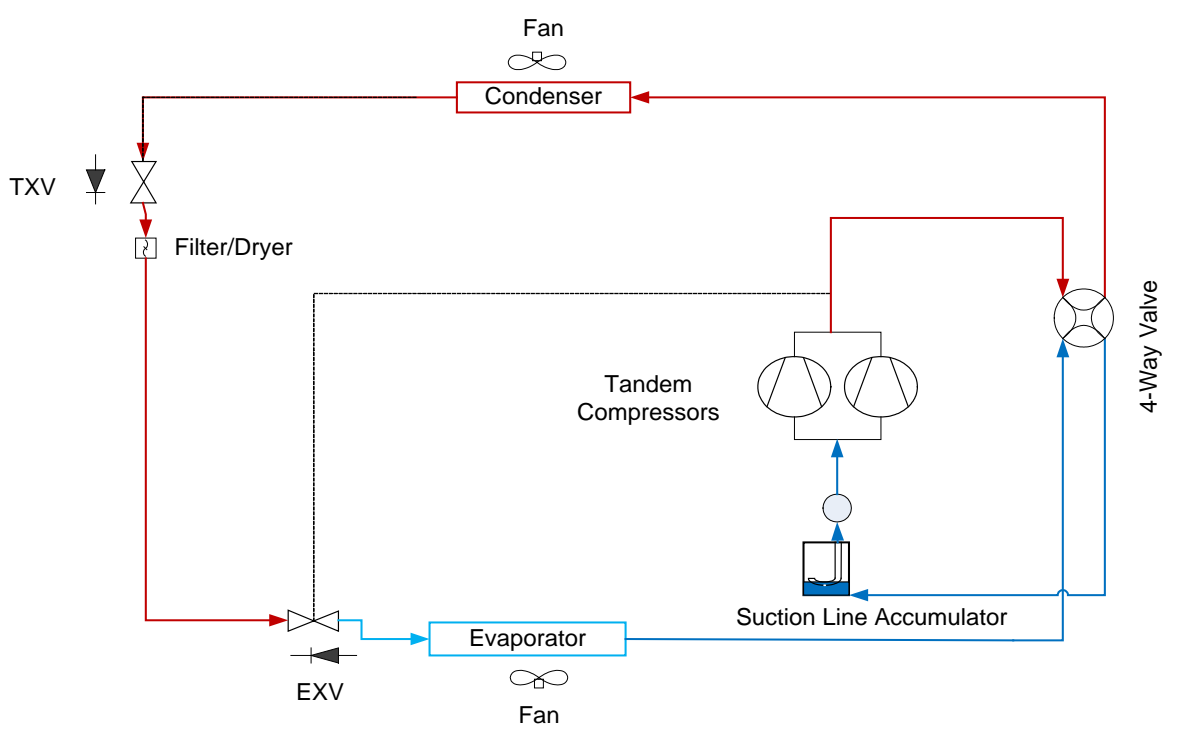

Figure 36: CCHP using tandem, single-speed compressors and an EXV for discharge temperature control in heating mode

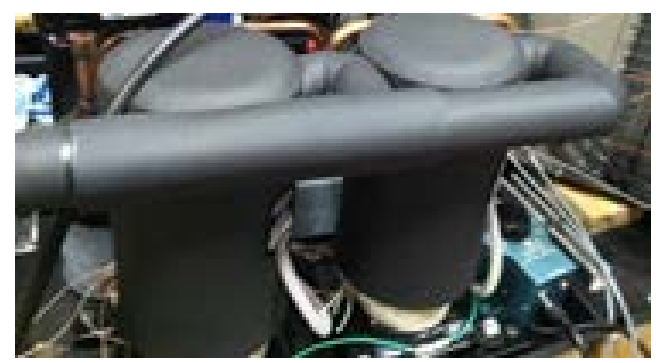

Figure 37: Insulated Copeland Tandem Compressors.

The lab prototype HP used a two-speed indoor blower, having a high air flow rate of $1750 \mathrm{CFM}\left(0.83 \mathrm{~m}^{3} / \mathrm{s}\right)$ and a power consumption of $460 \mathrm{~W}$, and a low air flow rate of $1420 \mathrm{CFM}\left(0.67 \mathrm{~m}^{3} / \mathrm{s}\right)$ consuming $270 \mathrm{~W}$. The outdoor fan was fixed-speed, consuming 300 Watts. We evaluated two samples of tandem compressors from Emerson, i.e. a pair of regular ZP31K optimized for cooling mode, and a specially-made pair of ZP31K optimized for heating mode. The tandem compressors, specially optimized for heating mode, provided better heating performance under all the operating conditions. The comparisons are given in Table 7 and 8 below. Table 7 shows the lab-measured performance indices at key ambient temperatures, i.e. $47^{\circ} \mathrm{F}, 17^{\circ} \mathrm{F}$ and $-13^{\circ} \mathrm{F},\left(8.3^{\circ} \mathrm{C}\right.$, $8.3^{\circ} \mathrm{C}$, and $-25^{\circ} \mathrm{C}$ ) with one or two compressors. Table 8 shows HSPFs (as calculated per AHRI Standard 210/240) in Region IV and V, with $\mathrm{DHR}_{\min }$ and $\mathrm{DHR}_{\max }$ building loads, respectively. The dropoff in rated $\mathrm{HSPF}$ (at $\mathrm{DHR}_{\min }$ loads) for the heating optimized design from Region IV to V is only $10.5 \%$. This compares with a drop of $\sim 16 \%$ for ducted variable-speed CCHPs. 
Emerson CRADA final report, December 30, 2015

Table 7: Performance indices of CCHPs using tandem single-speed compressors.

\begin{tabular}{|c|c|c|c|c|c|}
\hline & Ambient/Comp(s) & $\begin{array}{l}47^{\circ} \mathrm{F}, \\
1 \text { Comp }\end{array}$ & $\begin{array}{l}17^{\circ} \mathrm{F}, \\
2 \text { Comp }\end{array}$ & $\begin{array}{l}17^{\circ} \mathrm{F}, \\
1 \text { Comp }\end{array}$ & $\begin{array}{l}-13^{\circ} \mathrm{F}, \\
2 \text { Comp }\end{array}$ \\
\hline \multirow{4}{*}{$\begin{array}{l}\text { Optimized } \\
\text { for } \\
\text { cooling } \\
\text { mode }\end{array}$} & COP [-] & 4.09 & 2.76 & 2.89 & 1.85 \\
\hline & Capacity [Btu/h] & 37,960 & 50,455 & 25,860 & 30,040 \\
\hline & $\begin{array}{l}\text { Capacity Ratio to } \\
47^{\circ} \mathrm{F}\end{array}$ & $100 \%$ & $133 \%$ & $68 \%$ & $79 \%$ \\
\hline & $\begin{array}{l}\text { Discharge } \\
\text { Temperature }\left[{ }^{\circ} \mathrm{F}\right]\end{array}$ & 122 & 183 & 131 & 257 \\
\hline \multirow{4}{*}{$\begin{array}{l}\text { Optimized } \\
\text { for } \\
\text { heating } \\
\text { mode }\end{array}$} & COP [-] & 4.24 & 2.80 & 2.97 & 1.94 \\
\hline & Capacity [Btu/h] & 39,717 & 50,921 & 25,917 & 30,245 \\
\hline & $\begin{array}{l}\text { Capacity Ratio to } \\
47^{\circ} \mathrm{F}\end{array}$ & $100 \%$ & $128 \%$ & $65 \%$ & $76 \%$ \\
\hline & $\begin{array}{l}\text { Discharge } \\
\text { Temperature [F] }\end{array}$ & 124 & 181 & 124 & 213 \\
\hline \multicolumn{2}{|c|}{ \%COP Increment } & $3.7 \%$ & $1.4 \%$ & $2.8 \%$ & $4.9 \%$ \\
\hline
\end{tabular}

Table 8: Heating Seasonal Performance Factors of CCHPs using tandem single-speed compressors.

\begin{tabular}{|l|c|c|}
\hline Load & HSPF/cooling optimized & HSPF/heating optimized \\
\hline & \multicolumn{2}{|c|}{ Heating Season Ratings, Region: IV } \\
\hline DHRmin & 11.04 & 11.21 \\
\hline DHRmax & 10.90 & 10.95 \\
\hline & \multicolumn{2}{|c|}{ Heating Season Ratings, Region: V } \\
\hline DHRmin & 9.90 & 10.03 \\
\hline DHRmax & 9.18 & 9.26 \\
\hline
\end{tabular}

One noticeable advantage of the new tandem (optimized for heating mode) is that they achieved similar heating capacity ratio at $-13^{\circ} \mathrm{F}\left(-25^{\circ} \mathrm{C}\right),>75 \%$ of the rated capacity at $47^{\circ} \mathrm{F}\left(8.3^{\circ} \mathrm{C}\right)$, with a much lower discharge temperature than the previous pair (optimized for cooling mode). This indicates that the new tandem compressors are able to work at lower ambient temperature without approaching the discharge temperature limit of $280^{\circ} \mathrm{F}$ $\left(137.8^{\circ} \mathrm{C}\right)$, and have potential to provide larger heating capacities at extremely low ambient temperatures.

We conducted a series of refrigerant flow control tests at $-13^{\circ} \mathrm{F}\left(-25^{\circ} \mathrm{C}\right)$ to demonstrate the trend of air-side COP and heating capacity as a function of the discharge temperature, and compared the performance between the new (heating optimized) and previous tandems (cooling optimized). Figure 38 compares the air side COPs. One can see that the new tandem achieves the maximum COP at $213^{\circ} \mathrm{F}\left(100.6^{\circ} \mathrm{C}\right)$, in comparison to $257^{\circ} \mathrm{F}$ $\left(125^{\circ} \mathrm{C}\right)$ for the previous tandem. Figure 39 compares the air-side capacities. The discharge temperature variation has less impact on heating capacity in the new tandem than the previous tandem. When changing the discharge temperature from $200^{\circ} \mathrm{F}$ to $260^{\circ} \mathrm{F}\left(93.3^{\circ} \mathrm{C}\right.$ to $\left.126.7^{\circ} \mathrm{C}\right)$, the heating capacity of the new tandem increases by $3 \%$. 
However, the heating capacity of the previous tandem increases up to 9\%. Therefore, the benefit of discharge temperature control on the new tandem is less.

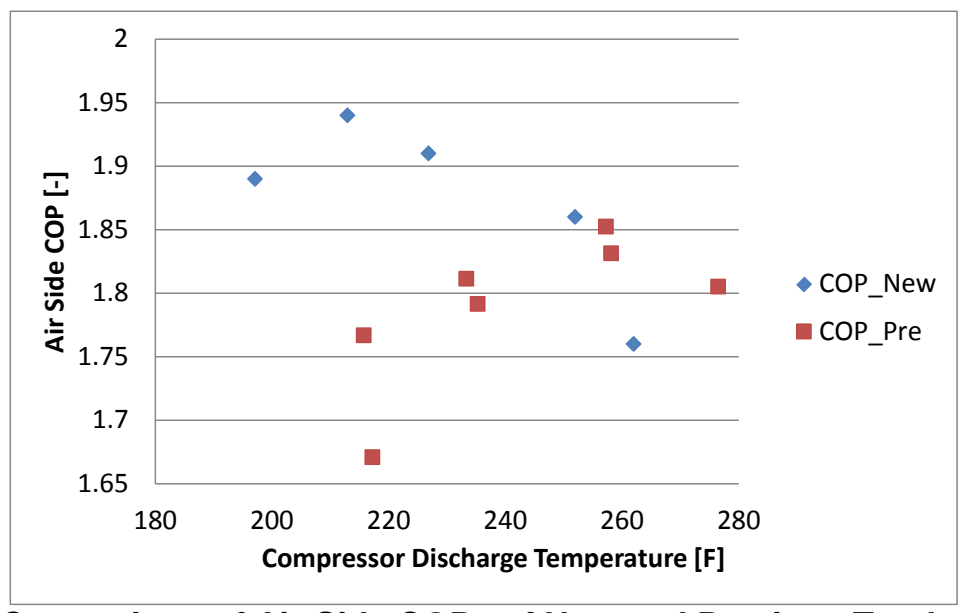

Figure 38: Comparison of Air-Side COPs of New and Previous Tandems at $-13^{\circ} \mathrm{F}$

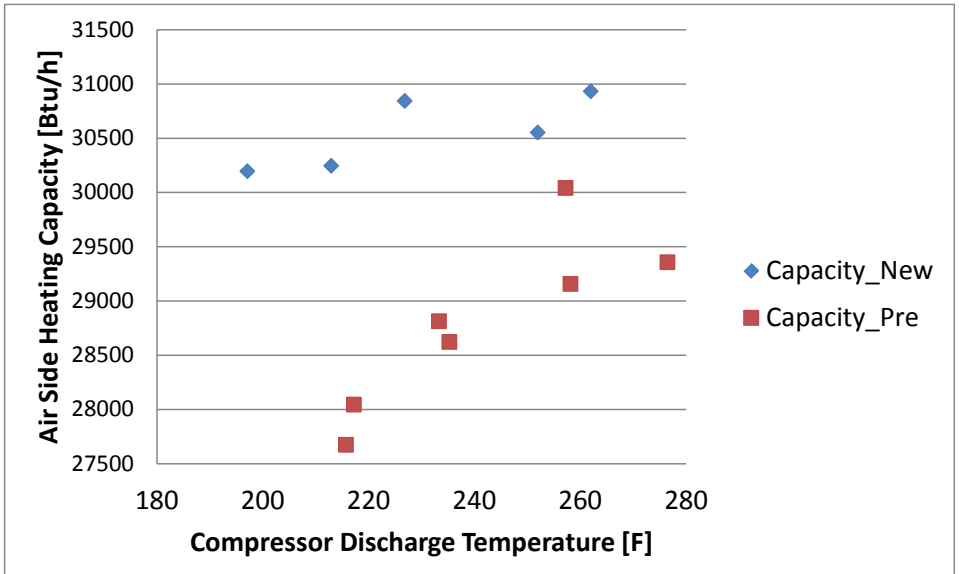

Figure 39: Comparison of Air-Side Heating Capacities of New and Previous Tandems at $13^{\circ} \mathrm{F}$

\section{2 'Premium' Option - Equal Tandem, Vapor Injection Compressors}

Use of tandem VI compressors resulted in increases in both the heating capacity and efficiency. We obtained a sample of tandem VI compressors from Emerson Climate Technologies and evaluated the performance in the same breadboard unit as the 'most cost-effective' configuration. The tandem VI compressors were investigated in three scenarios. The first used a TXV to control the evaporator exit superheat; the second (Figure 40) used an EXV to control the compressor discharge temperature; the third (Figure 41) coupled the discharge temperature control with a suction line heat exchanger (SLHX). 
Emerson CRADA final report, December 30, 2015

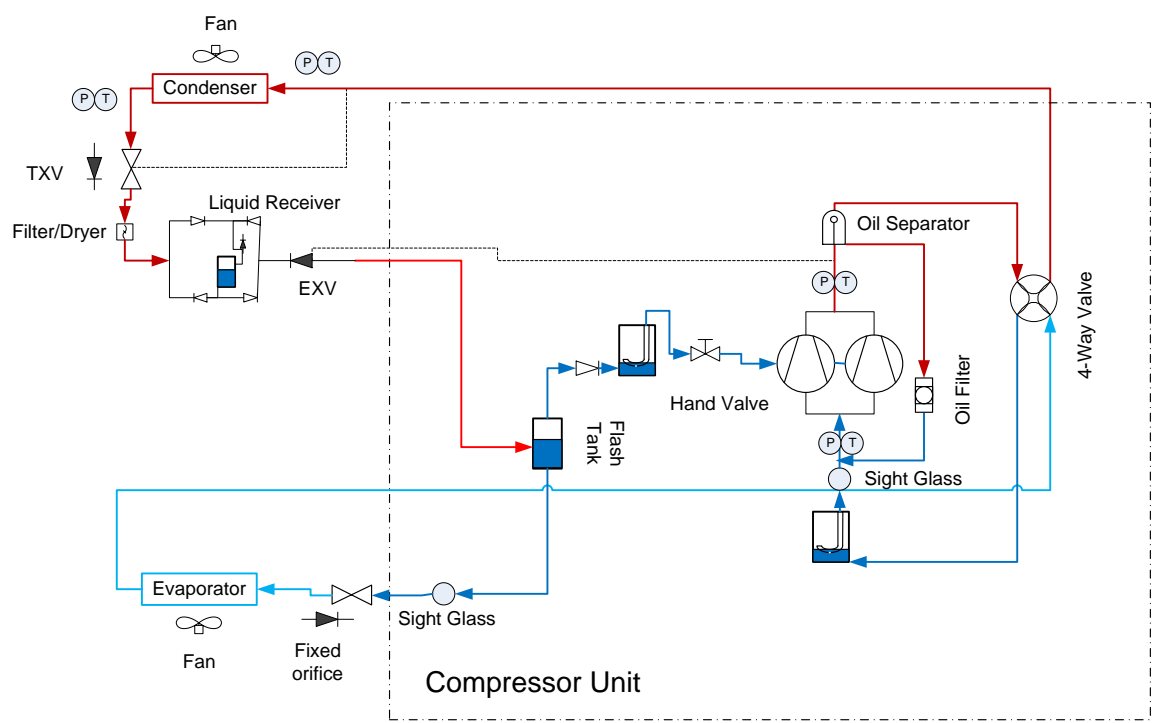

Figure 40: CCHP using tandem VI compressors and an EXV for discharge temperature control in heating mode

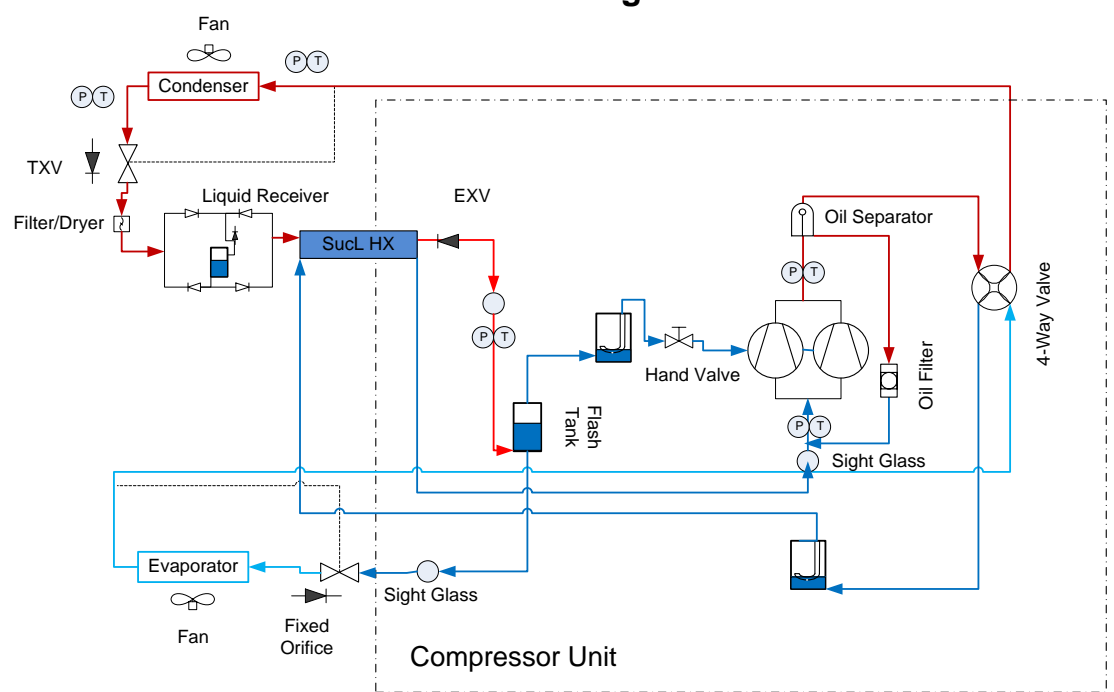

Figure 41: CCHP using tandem VI compressors and suction line heat exchanger

It was observed that using an EXV for discharge temperature control led to better performance than using a TXV for compressor suction superheat control. We tested the CCHP using the tandem VI compressors, with and without the SLHX, over extensive ambient temperatures. The SLHX addition didn't show any positive effects on the heat pump COPs and heating capacities. It was observed to increase the compressor suction superheat degree and discharge temperature, which increased the heating capacity per unit refrigerant mass flow rate. However, the increased suction superheat also decreased the suction density, and reduced the compressor mass flow rate. In addition, the compressor efficiency appeared to decrease due to elevated suction and discharge temperatures. Consequently, neither capacity nor efficiency gain was observed with the SLHX. Therefore, this option is not selected in the final design. 
The final system configuration, having the tandem VI compressors and discharge temperature control, achieved 5\% better COPs than the tandem, single-speed compressors at various ambient conditions. It achieved $88 \%$ capacity and $2.0 \mathrm{COP}$ at $-13^{\circ} \mathrm{F}\left(-25^{\circ} \mathrm{C}\right)$, $4.4 \mathrm{COP}$ and $40 \mathrm{kBtu} / \mathrm{h}$ rated capacity at $47^{\circ} \mathrm{F}\left(8.3^{\circ} \mathrm{C}\right)$. When delivering $90 \%$ capacity at $17^{\circ} \mathrm{F}\left(-8.3^{\circ} \mathrm{C}\right)$ (interpolated between a single compressor and two-compressor operations), it achieved 3.1 COP. Figure 42 compares the heating capacities of the tandem single-speed compressors (heating optimized) and the tandem VI compressors, at two speed levels, as a function of the ambient temperature. Figure 43 compares the heating COPs.

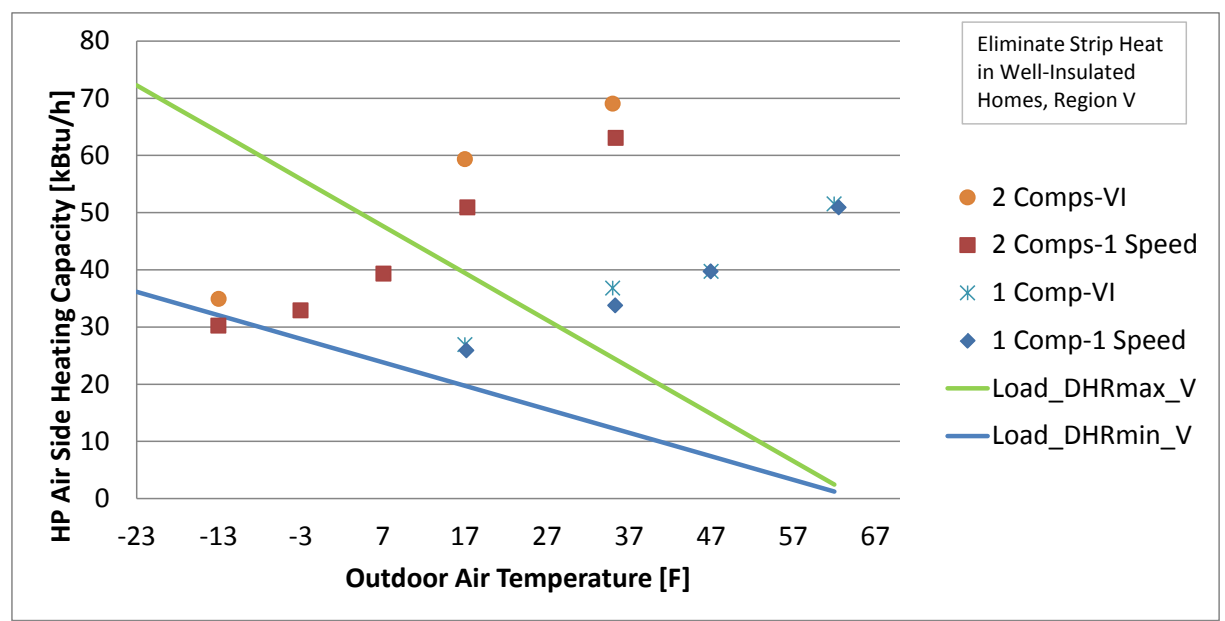

Figure 42: Heating capacity vs. ambient temperature, for tandem single-speed compressors and tandem VI compressors

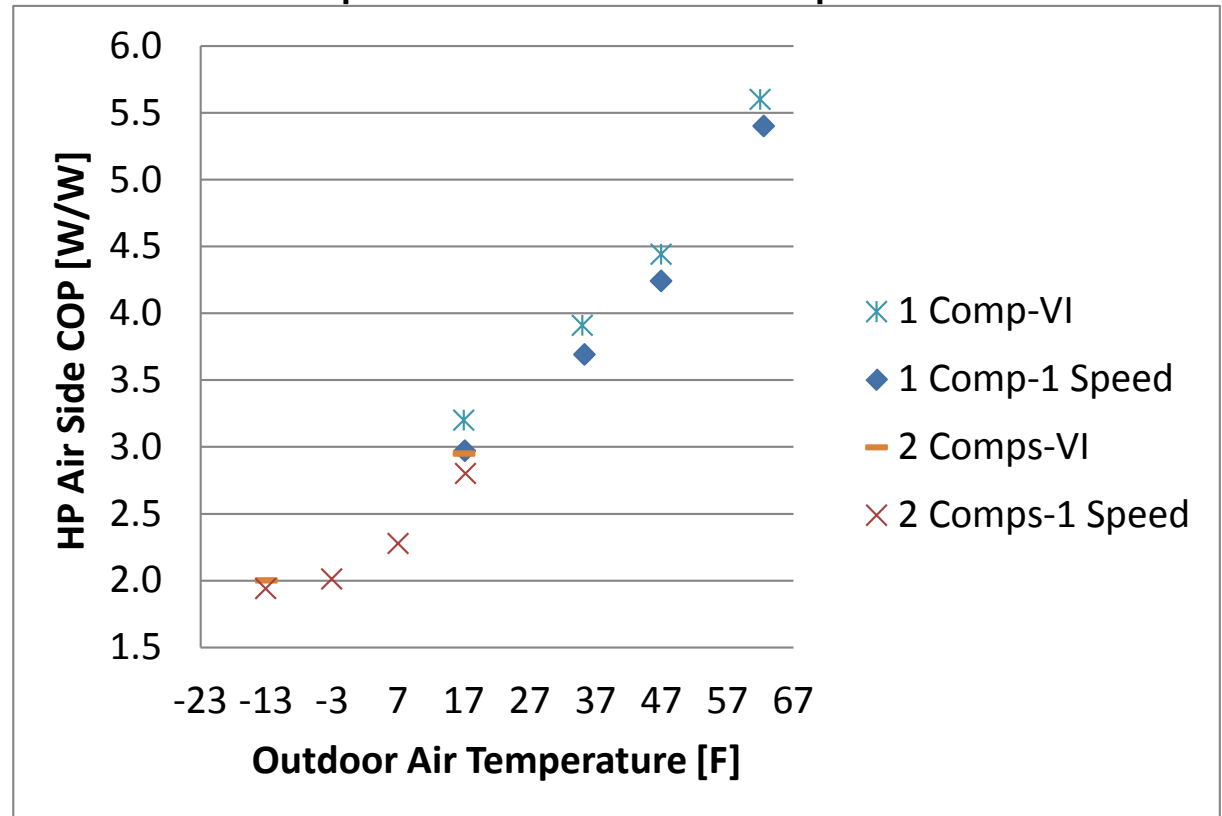

Figure 43: Heating COP vs. ambient temperature, for tandem single-speed compressors and tandem VI compressors

Table 9 reports the calculated HSPFs from lab-measured data of the system using the tandem VI compressors and discharge temperature control in DOE climate regions IV 
and V. Figure 44 shows supply air temperature as a function of the ambient temperature. It should be mentioned, for the tandem single-speed compressors, when running a singlecompressor, the indoor air flow rate was set to Low; when running two compressors, the indoor air flow rate was set to High, with the ambient temperature $>=17^{\circ} \mathrm{F}\left(-8.3^{\circ} \mathrm{C}\right)$, and it was set to low, with the ambient temperature $<17^{\circ} \mathrm{F}\left(-8.3^{\circ} \mathrm{C}\right)$, as to maintain a comfortable supply air temperature. However, for the tandem VI compressors, since there were sufficient heating capacities, the indoor air flow was always set at High when running two compressors. It can be seen that down to $-13^{\circ} \mathrm{F}\left(-25^{\circ} \mathrm{C}\right)$, both the tandem single-speed compressors and VI compressors were able to maintain a comfortable supply air temperature higher than $89^{\circ} \mathrm{F}\left(31.7^{\circ} \mathrm{C}\right)$.

Table 9: Heating Seasonal Performance Factors of CCHPs using tandem VI compressors and discharge temperature control.

\begin{tabular}{|l|l|}
\hline Load & HSPF/tandem VI compressors \\
\hline & Heating Season Ratings, Region: IV \\
\hline DHRmin & 11.84 \\
\hline DHRmax & 11.80 \\
\hline & Heating Season Ratings, Region: $V$ \\
\hline DHRmin & 10.68 \\
\hline DHRmax & 10.10 \\
\hline
\end{tabular}

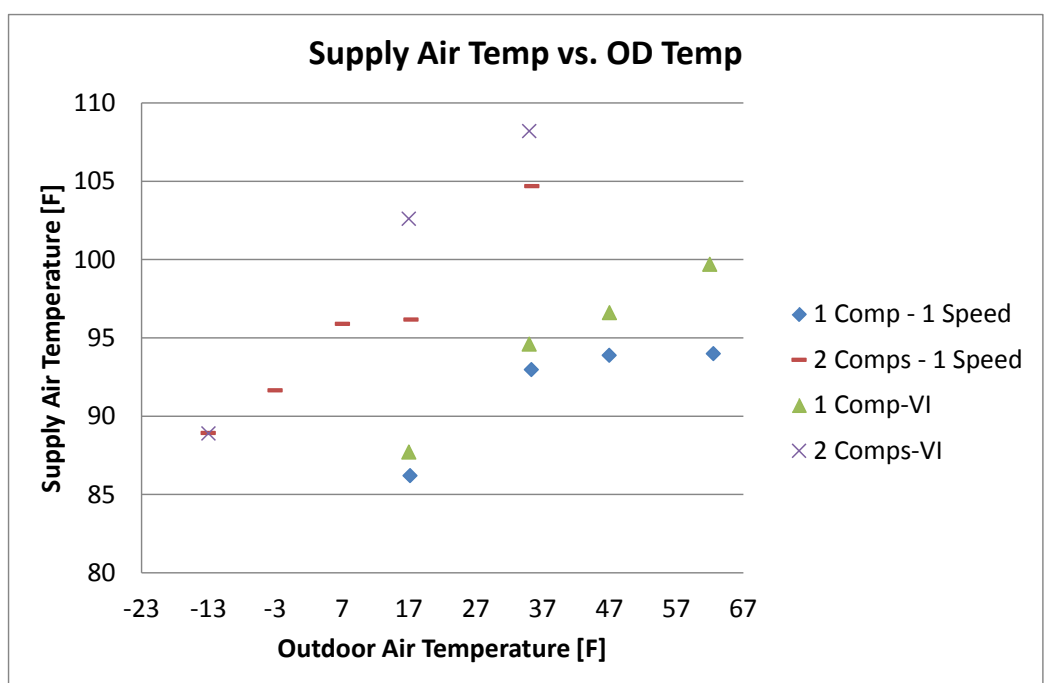

Figure 44: Supply Air Temperature vs. ambient temperature, for tandem single-speed compressors and tandem VI compressors

Figure 45 shows an interesting comparison between tandem single-speed compressors and a Max Tech on the market, i.e. Mitsubishi Hyper Heat (H2i) Series P. The H2i product is promoted for cold climates and has a similar configuration as shown in Figure 2. H2i uses a variable-speed compressor, and thus, the curve, from its product literature, in Figure 45 is for its rated capacity. One can see that the H2i product reaches a similar rated heating capacity to that of the tandem's 1 -compressor operation at $47^{\circ} \mathrm{F}\left(8.3^{\circ} \mathrm{C}\right)$, and it keeps a constant rated capacity down to $7^{\circ} \mathrm{F}\left(-13.9^{\circ} \mathrm{C}\right)$, and then follow the trend of 
our 2-compressor operation from $7^{\circ} \mathrm{F}$ to $-13^{\circ} \mathrm{F}\left(-13.9^{\circ} \mathrm{C}\right.$ to $\left.-25^{\circ} \mathrm{C}\right)$. This indicates that $\mathrm{H} 2 \mathrm{i}$ has a very similar capacity rating and relative low ambient capacity as our design. The $\mathrm{H} 2 \mathrm{i}$ unit has a lower COP rating at max capacity operation at $17^{\circ} \mathrm{F}$ and $5^{\circ} \mathrm{F}$ using a variable-speed compressor design.

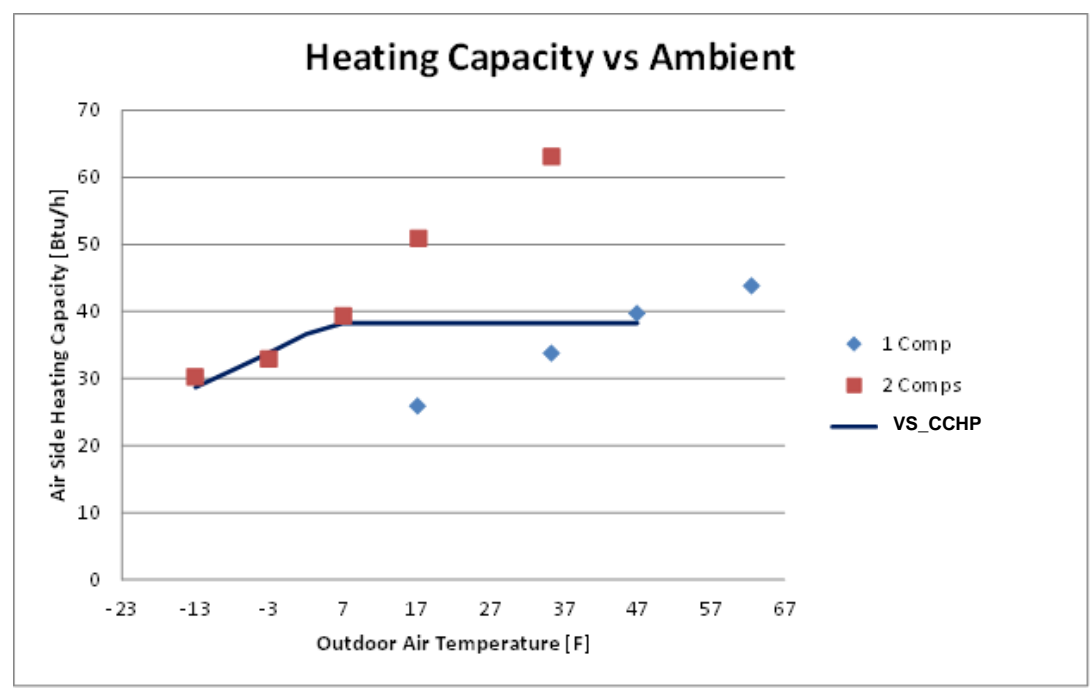

Figure 45: Heating capacity vs. ambient temperature, for tandem single-speed compressors and Mitsubishi Hyper Heat (H2i) Series $P$

\subsection{Ejector Cycle Investigations}

Ejector technology as shown in Figure 46, is usually used to recover throttling loss from high side to low side in a vapor compression system. In a HP system, its throttling nozzle is connected to the condenser exit, suction nozzle is connected to the evaporator exit, and the mixing and expansion port is connected to the compressor suction. By recovering the work, the pressure is lifted from the evaporator exit to the compressor suction, which increases the compressor mass flow rate and reduces the compression pressure ratio. There are examples successfully applying ejectors in supercritical $\mathrm{CO}_{2}$ systems, which have most significant pressure difference between the high side and low side. In order to improve the efficiency of CCHP, we investigated coupling an ejector with the tandem single-speed compressors in Figure 47. In order to provide a fair, side-by-side comparison, bypass loops were installed with On/Off hand valves. By switching these valves, the system could be run with using an ejector or an EXV for discharge temperature control. 
Emerson CRADA final report, December 30, 2015

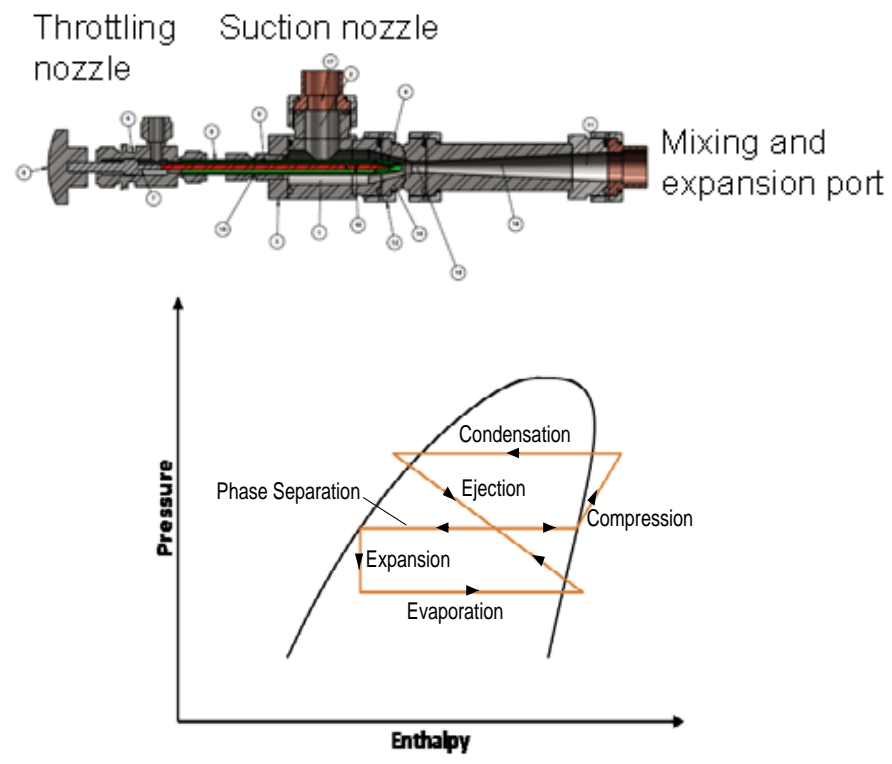

Figure 46: An Ejector and P-H diagram of the ejector cycle.

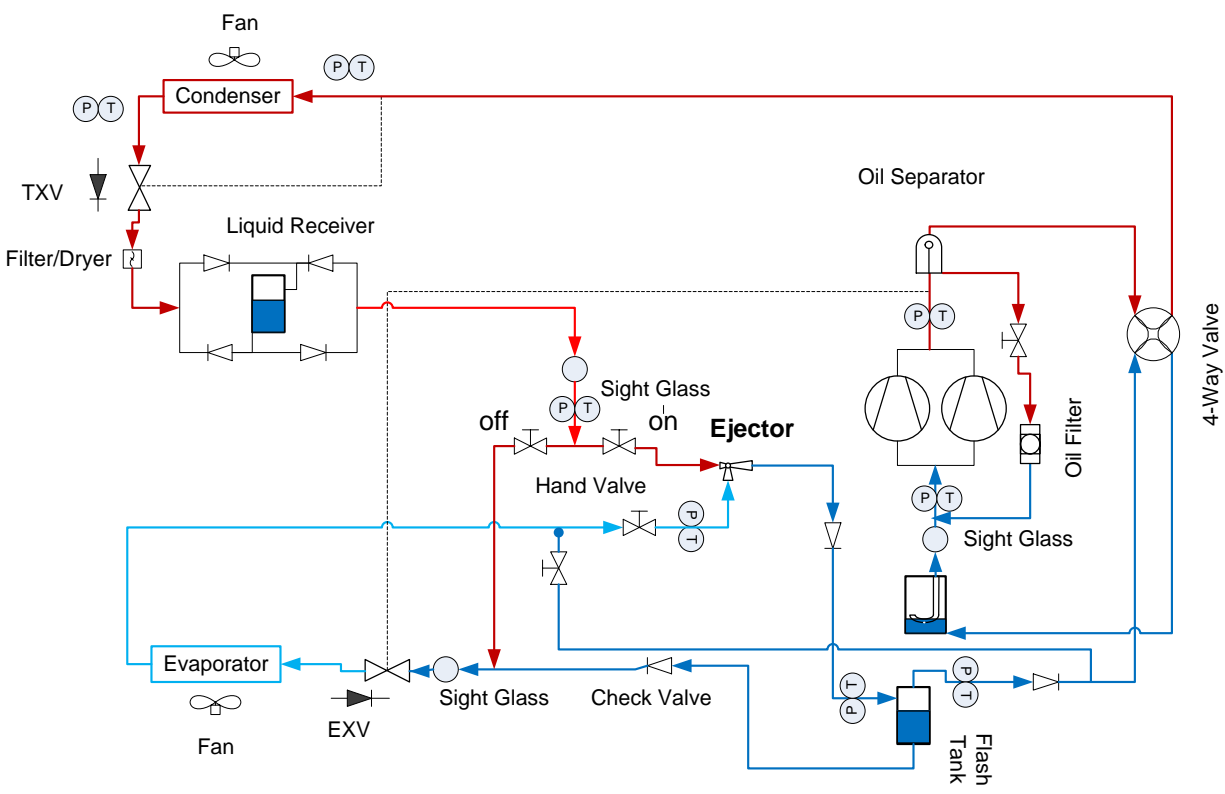

Figure 47: CCHP laboratory system, for comparing Ejector to EXV.

Figure 46 illustrated the ejector parts and assembly. The design incorporated a needle valve to control the nozzle opening. Consequently, optimum flow cross-sectional areas can be identified at different working conditions. 

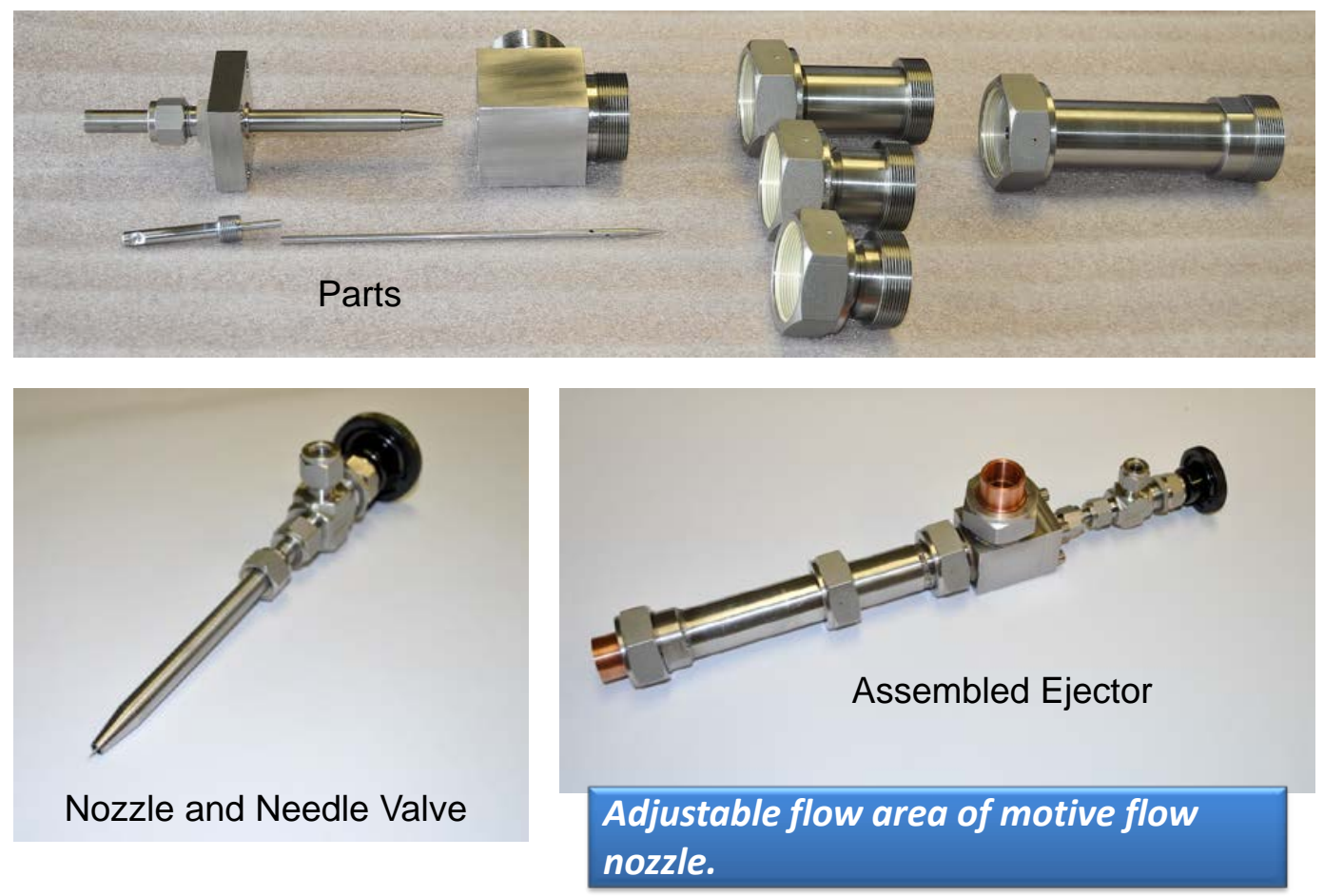

Figure 48: Ejector parts and assembly

We performed a comprehensive assessment on using various sizes of ejectors in the lab prototype CCHP. Added to the configuration in Figure 47, two liquid refrigerant circulation pumps were installed downstream of the ejector to boost the pressure lift by the ejector, when needed. We had extensive parametric studies, by varying the outdoor temperature from $47^{\circ} \mathrm{F}$ to $-13^{\circ} \mathrm{F}\left(8.3^{\circ} \mathrm{C}\right.$ to $\left.-25^{\circ} \mathrm{C}\right)$, running one or two compressors, and changing the indoor air flow rate at two levels, i.e. 1420 CFM and 1750 CFM (0.67 and $0.83 \mathrm{~m}^{3} / \mathrm{s}$ ). The intention for this study is to have a back-to-back comparison between the ejector cycle and using an EXV. As discussed before, using an EXV to control the compressor discharge temperature facilitates optimum heating COPs over a wide operation range, which has a much simpler system configuration than the ejector cycle. Therefore, if the ejector cycle can't lead to noticeably better performance than using the $\mathrm{EXV}$, this ejector design was not intended for use in the final product.

Based on the comprehensive evaluation, it was concluded that the ejector cycle is not a viable concept for CCHP over extensive working conditions. We have three observations given below:

- The working range of a fixed-size ejector is limited. Although we can alter the ejector size during laboratory testing, the ejector's size needs to be fixed in the final product. The figure below shows the evaporator refrigerant temperature profile obtained with a properly sized ejector, in comparison to that obtained using an EXV to control optimum discharge temperature. For an ejector to yield better system performance than an EXV, it has to have lower evaporating temperature than the EXV system, so as to absorb more source energy from the outdoor air. In addition, its compressor 
suction pressure should be higher than the one resulted by using the EXV, as a result, the compressor is able to drive larger mass flow rate.

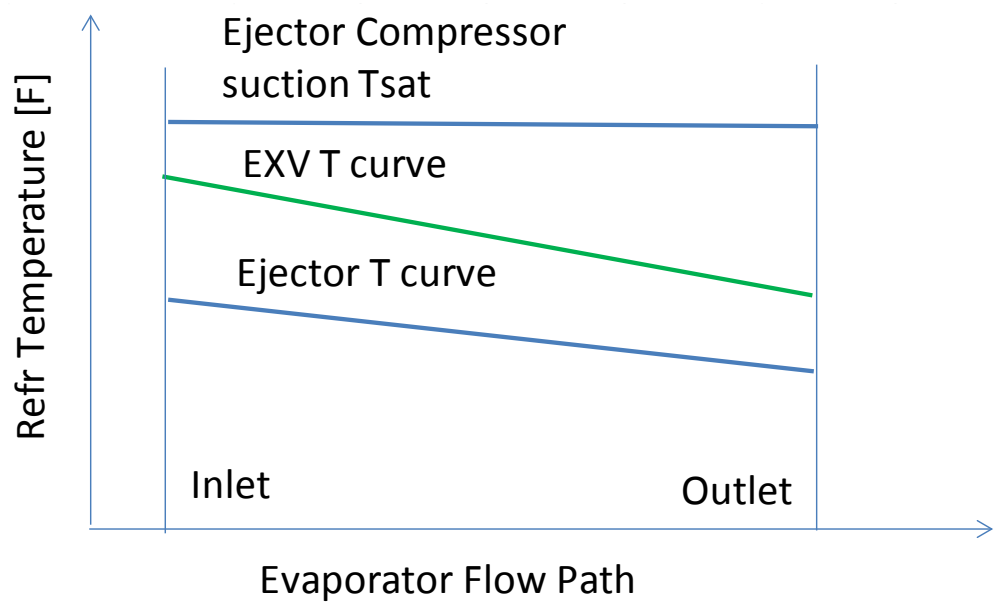

Figure 49: Scenario A: Temperature Profiles with a Properly Sized Ejector

The figure below shows a scenario having an oversized ejector. An oversized ejector elevates the evaporating temperature higher than the one led by the EXV. This means that less heat will be absorbed from the environment and the ejector cycle is less efficient than using the EXV.

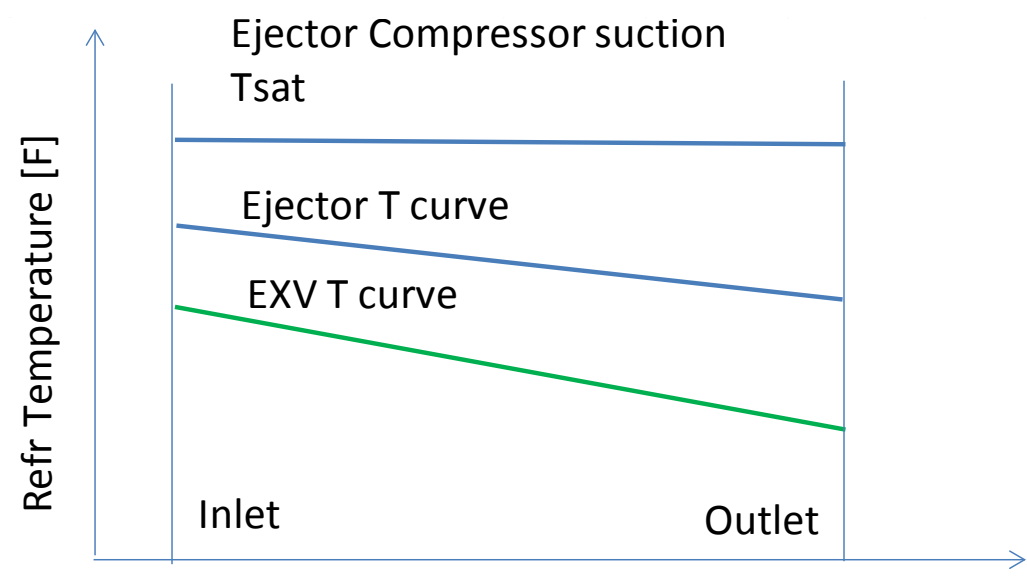

Evaporator Flow Path

Figure 50: Scenario B: Temperature Profiles with an Over-Sized Ejector

The figures below show two scenarios having an under-sized ejector. The left figure illustrates, that the ejector results in a lower evaporating pressure, and higher compressor suction pressure than the EXV. However, the ejector is not able to drive sufficient refrigerant mass flow rate through the evaporator leaving a significant portion with superheated vapor. Therefore, the evaporator surface area is not fully utilized, and it absorbs less heat than the EXV system. The right figure shows a further undersized ejector, which has compressor suction pressure lower than the evaporating pressure in the EXV system, as a result, the compressor(s) drive less 
refrigerant mass flow rate. For both the scenarios, the ejector cycle is less efficient than the EXV system.
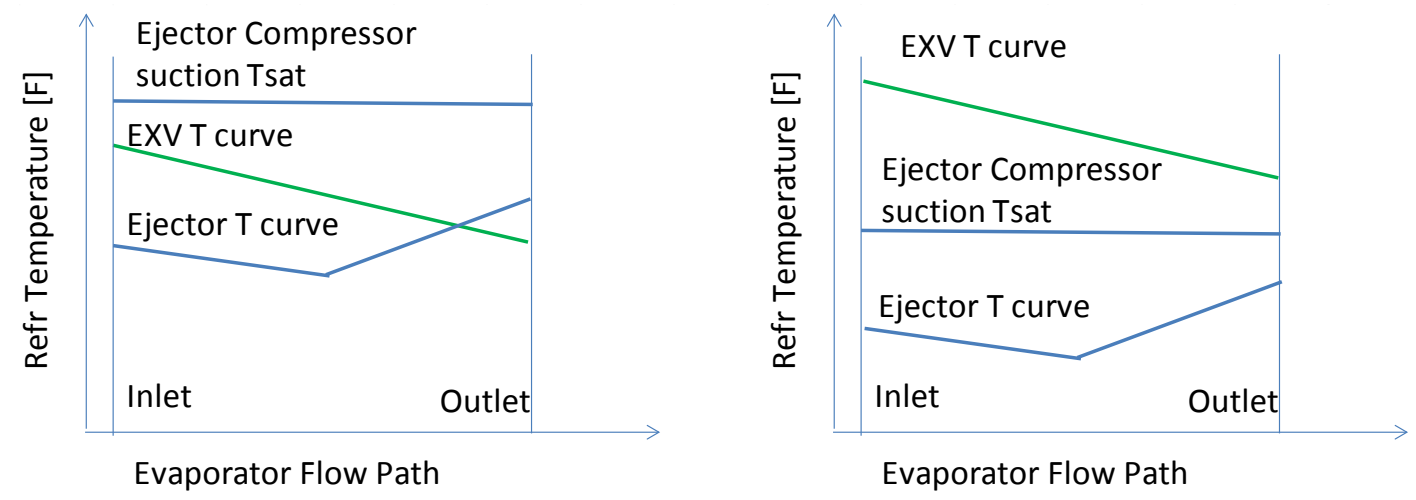

Figure 51: Scenarios C and D: Evaporator Temperature Profiles with an Undersized Ejector

The ejector sizing logic above implies that a fixed-size ejector has a limited working range with respect to being advantageous over an EXV. The figure below shows ratios of measured heating COP using an ejector versus using an EXV, at different ambient temperatures and numbers of running compressors. For one series (Size A), an ejector was sized properly at $17^{\circ} \mathrm{F}\left(-8.3^{\circ} \mathrm{C}\right)$ with running one compressor, which actually resulted in $3 \%$ better COP than the EXV. However, at $47^{\circ} \mathrm{F}\left(8.3^{\circ} \mathrm{C}\right)$ with running one compressor and $17^{\circ} \mathrm{F}\left(-8.3^{\circ} \mathrm{C}\right)$ with running two compressors, the ejector led to much worse performance, because the ejector was undersized for the conditions. The other series (Size B) illustrates an ejector sized properly at $17^{\circ} \mathrm{F}(-$ $8.3^{\circ} \mathrm{C}$ ) with running two compressors, which resulted in a comparable COP as the $\mathrm{EXV}$. However, the ejector is oversized at $-13^{\circ} \mathrm{F}\left(-25^{\circ} \mathrm{C}\right)$ when running two compressors, and resulted in noticeably worse performance than the EXV.

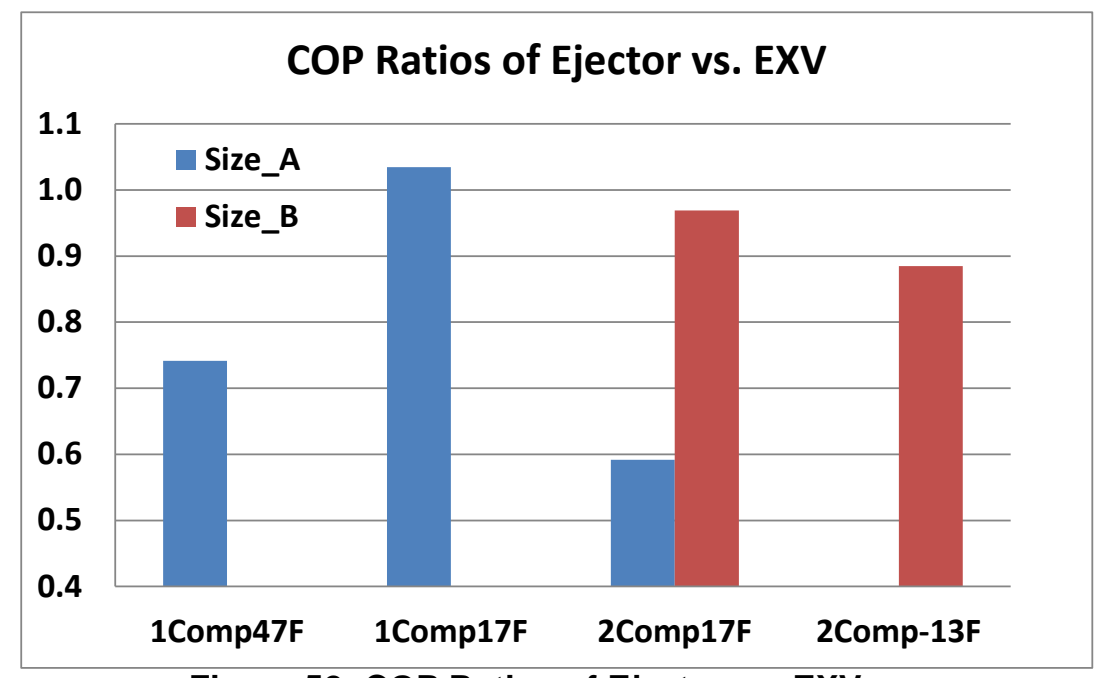

Figure 52: COP Ratios of Ejector vs. EXV

- Liquid refrigerant circulation pump(s) downstream of the ejector enhanced the performance of an undersized ejector, but couldn't extend the working range to cover 
all the operation conditions. The liquid refrigerant circulation pump(s) downstream of the ejector boosted the pressure lift given by the ejector and drove larger refrigerant mass flow rate through the evaporator. Using the pump(s) enhanced the performance of an undersized ejector, when the evaporator exit superheat degree was large. The figure below presents COP enhancements by using one or two pumps to boost the pressure head by an undersized ejector, with running one or two compressors at $17^{\circ} \mathrm{F}$ $\left(-8.3^{\circ} \mathrm{C}\right)$. As compared to the ejector cycle without using a pump, the COP enhancement can be up to $7 \%$.

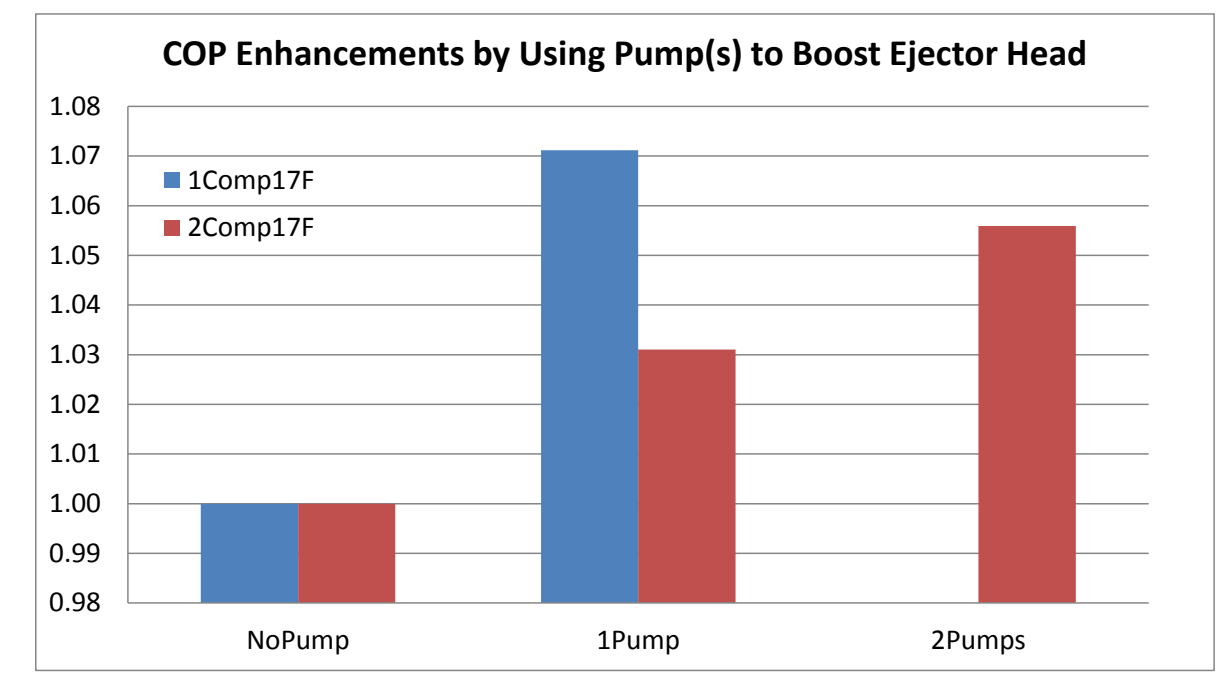

Figure 53: COP Enhancements by Using Pump(s) to Boost Ejector Flow

However, using pump(s) to boost the ejector head also has a limited working range. It makes the situation worse when the ejector is oversized. The pump(s) decreased the superheat degree at the expense of raising the evaporating temperature at the evaporator inlet. When the ejector is undersized at a minor degree and the evaporator exit superheat degree is small, e.g. below $5 \mathrm{R}(2.8 \mathrm{~K})$, using the pump(s) is able to decrease the superheat degree; however, the gain can't cover the heat transfer degradation at the evaporator entrance. When the ejector is severely undersized, the resultant compressor suction pressure is lower and the compressor(s) drive smaller refrigerant flow rate than the EXV system. In the case, the pump(s) are able to enhance the performance of the ejector cycle, but it is still not as efficient as the EXV system. In addition, if the pump(s) are oversized, i.e. provide pressure head more than needed, it causes unstable system operations, when the pump(s) withdraw liquid and vapor from the flash tank periodically. We observed big fluctuations in the system pressures and discharge temperature when using an oversized pump.

- The ejector cycle can't provide benefit at moderately low temperature, e.g. $17^{\circ} \mathrm{F}$ ($8.3^{\circ} \mathrm{C}$ ), when running two compressors. For the cold climate heat pump, the majority of working hours are around $17^{\circ} \mathrm{F}\left(-8.3^{\circ} \mathrm{C}\right)$ ambient by running two compressors to match the heating capacity larger than $90 \%$ relative to the rated capacity. So, that is the working operation we want to optimize the heat pump performance as possible. Unfortunately, around $17^{\circ} \mathrm{F}\left(-8.3^{\circ} \mathrm{C}\right)$, when large refrigerant mass flow rate is needed, an ejector in a R410A system can't provide sufficient pressure head to overcome the 
pressure resistance in a conventional outdoor heat exchanger. During the laboratory testing, we identified several cases that an ejector led to better COPs than the EXV, when running one compressor. However, we never identified any beneficial cases when running two compressors, regardless of how the ejector is sized. The outdoor coil we are using is a conventional heat exchanger, which has six parallel circuits and a distributor. When running two compressors at $17^{\circ} \mathrm{F}\left(-8.3^{\circ} \mathrm{C}\right)$ using the EXV system, the measured pressure resistance in the evaporator, including the distributor, is around $40 \mathrm{psiD}$, and the estimated coil resistance is around 6 psiD with the inlet two-phase quality around $30 \%$ and saturated evaporator exit. The largest measured pressure lift by the ejector at $17^{\circ} \mathrm{F}\left(-8.3^{\circ} \mathrm{C}\right)$ was $7 \mathrm{psiD}$, corresponding to $4^{\circ} \mathrm{F}\left(2.2^{\circ} \mathrm{C}\right)$ difference in saturation temperature. The pressure lift is barely enough to drive the same amount of refrigerant mass flow as in the EXV system. Therefore, it is hard to get superior performance by coupling an ejector with a conventional outdoor heat exchanger at this condition. We also tried boosting the mass flow rate by running the pump(s); however, the benefit was negligible, since the pump(s) raised the evaporating temperature at the evaporator inlet as a penalty. To make the ejector work at $17^{\circ} \mathrm{F}(-$ $8.3^{\circ} \mathrm{C}$ ) with 2 compressors running, we may have to redesign the outdoor heat exchanger to reduce the coil flow resistance, e.g. having more circuits.

On the other hand, at $-13^{\circ} \mathrm{F}\left(-25^{\circ} \mathrm{C}\right)$, the measured pressure lift by the ejector is around $10 \mathrm{psiD}$ and the estimated coil flow resistance is around 3 psiD. Therefore, a properly sized ejector should be able to overcome the flow resistance and drive sufficient mass flow rate through the evaporator. From this perspective, the ejector cycle has a better chance to work at extremely low ambient temperatures.

In summary, the system configuration for use of an ejector cycle is complicated, hard to control and expensive, since it requires a separate bypass loop for defrosting and cooling modes, and an additional oil separator and loop. If we add pump(s) to boost the ejector pressure lift and extend its working range, it will add more cost and cause operation instabilities. Even with all the measures taken, the ejector cycle still can't cover all the working conditions as needed by CCHP, i.e. ambient temperatures from $60^{\circ} \mathrm{F}$ to $-13^{\circ} \mathrm{F}$ $\left(15.6^{\circ} \mathrm{C}\right.$ to $\left.-25^{\circ} \mathrm{C}\right)$, large variation of mass flow rate from using one to two compressors, etc. Comparing the cost, performance, reliability, the ejector cycle was not selected as viable technology for CCHP using R410A.

\section{Field Study}

\subsection{Field Installation}

An occupied, single-story ranch home in Ohio (Shown in Figure 54), was selected to host the field testing, which is owned by an engineer from Emerson Climate Technologies. One breadboard unit was used to replace a Goodman HP, having a 3.0 to 3.5-ton design cooling load. The Goodman outdoor unit was a 3-ton model of CPLJ36-1B. It was rated at $34000 \mathrm{Btu} / \mathrm{h}$ at $95^{\circ} \mathrm{F}\left(35^{\circ} \mathrm{C}\right)$ ambient for cooling, and $35000 \mathrm{Btu} / \mathrm{h}$ at $47^{\circ} \mathrm{F}\left(8.3^{\circ} \mathrm{C}\right)$ ambient for heating. The Goodman indoor air handler was a 3.5-ton model of ARUF042- 
00A-1/-1A, having a 42,000 Nominal Cooling Capacity Btu/h. the supplemental resistance heater is $19.5 \mathrm{~kW}$.

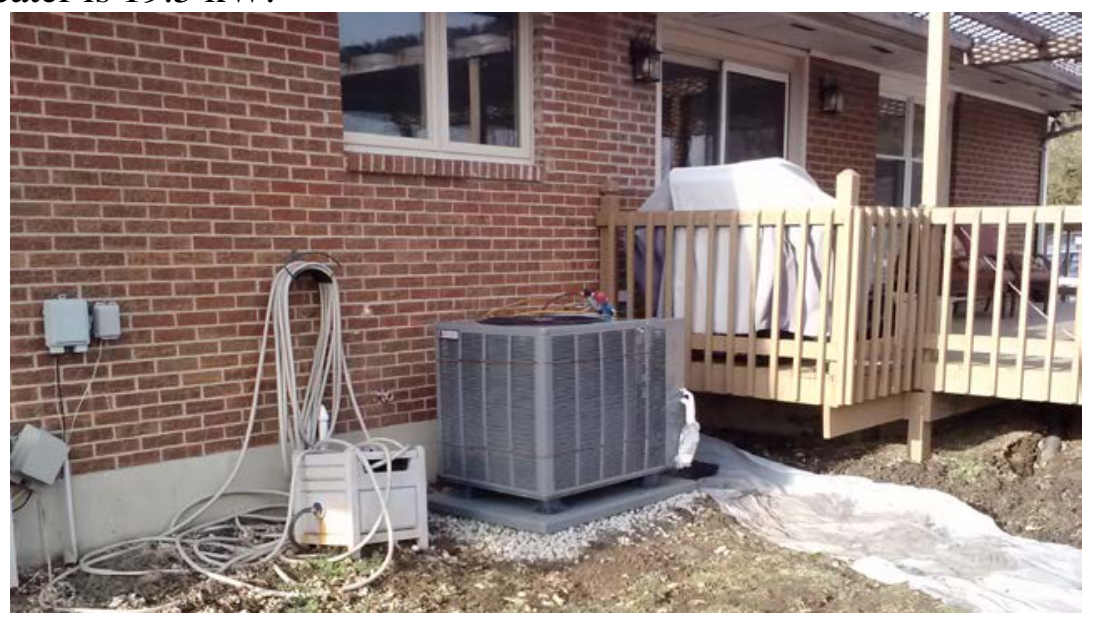

Figure 54: Field Testing Home.

To fabricate the field testing breadboard unit, we modified a Rheem 5-ton heat pump unit (15.5 SEER, 9.15 HSPF, outdoor unit Model No: RPRL061JEC, indoor unit Model No: RHPLHM6024JC.) by replacing an UltraTech, 2-speed compressor with the Emerson tandem compressors optimized for heating mode, and by adding control and data acquisition (DAQ) devices from National Instruments Inc.

As discussed in Section 5, it's easier to configure the system control for tandem compressors than variable-speed compressors since we can leverage existing 2-stage thermostat and controller already in existing systems. For the field testing unit, the control is the original Rheem 2-speed HP control. We re-wired the 24 VAC signal (to call the UltraTech, 2-speed compressor) with a relay to call the second compressor. We used a standard, 24 VDC, 2-stage thermostat (made by Honeywell and wifi enabled). Its Y1signal calls the first stage and Y2 signal calls the second stage. Each stage corresponds to an individual indoor air flow rate, i.e. low or high air flow rate, but having the same outdoor air flow rate. The thermostat can be programmed manually to prevent running the second stage, which we did for the cooling operation. The defrost control is an ondemand control, with the logic embedded in the original Rheem control board. It measures the coil surface temperature and senses the temperature difference between the ambient air and the coil surface to start the defrosting cycle. During the defrosting cycle, it always runs two compressors, i.e. the high stage to accelerate the defrosting with the indoor air flow on.

As illustrated in Figure 39, the heating-optimized tandem's performance is much less sensitive to the discharge temperature, than the cooling-optimized tandem. In addition, after placing the tandem compressors in the Rheem outdoor unit, there were hardly any room left to install any other components, as indicated in Figure 55. Based on these observations, and discussion with Emerson engineers, for the field testing investigation, we decided to simplify the control and reduce the cost by changing the discharge temperature control to the conventional suction superheat control using a TXV with 
optimized system charge for heating mode. The TXV was able to control the evaporator superheat degree around $10 \mathrm{R}(5.6 \mathrm{~K})$. The Rheem recommended charge, optimized for cooling mode, is $17 \mathrm{lbs}(7.6 \mathrm{~kg})$. The new charge, optimized for heating mode, is $15.5 \mathrm{lbs}$ (6.9 kg), i.e. 9\% lower than the manufacturer suggested charge. The optimized charge led to $3 \mathrm{R}(1.7 \mathrm{~K})$ condenser subcooling degree at $82^{\circ} \mathrm{F}\left(27.8^{\circ} \mathrm{C}\right)$ in cooling mode when running one compressor and around $20 \mathrm{R}(11.1 \mathrm{~K})$ subcooling degree at $17^{\circ} \mathrm{F}\left(-8.3^{\circ} \mathrm{C}\right)$ in heating mode when running two compressors. Figure 55 shows the installed outdoor unit for field testing, and one can see the compressors were wrapped by a thermal insulation layer. Figure 56 illustrates the indoor air handler and data acquisition system, which were located in the basement.

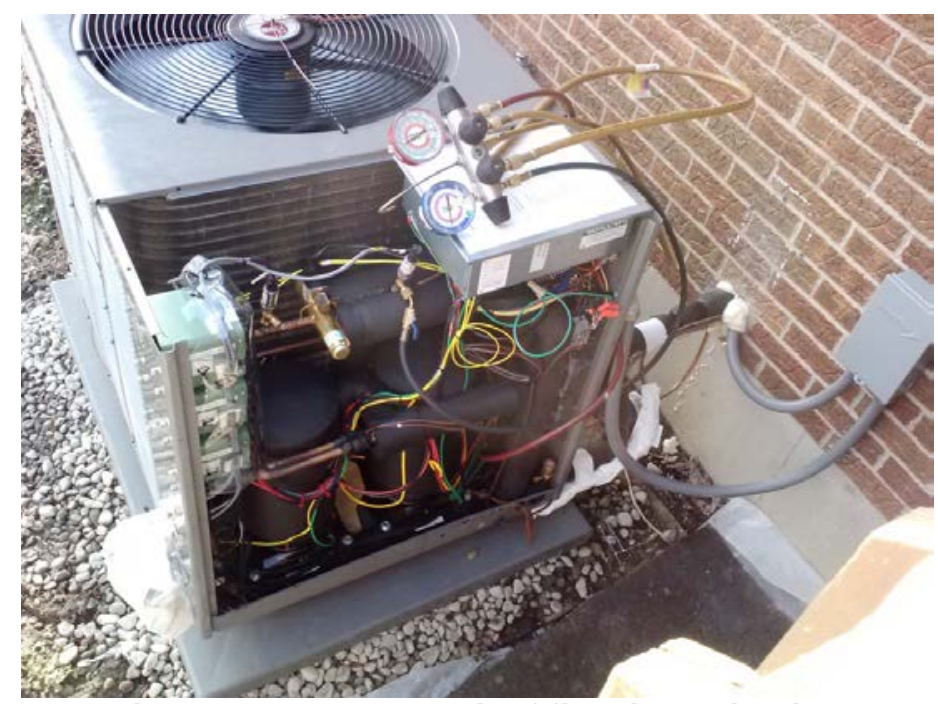

Figure 55: Outdoor unit of field investigation

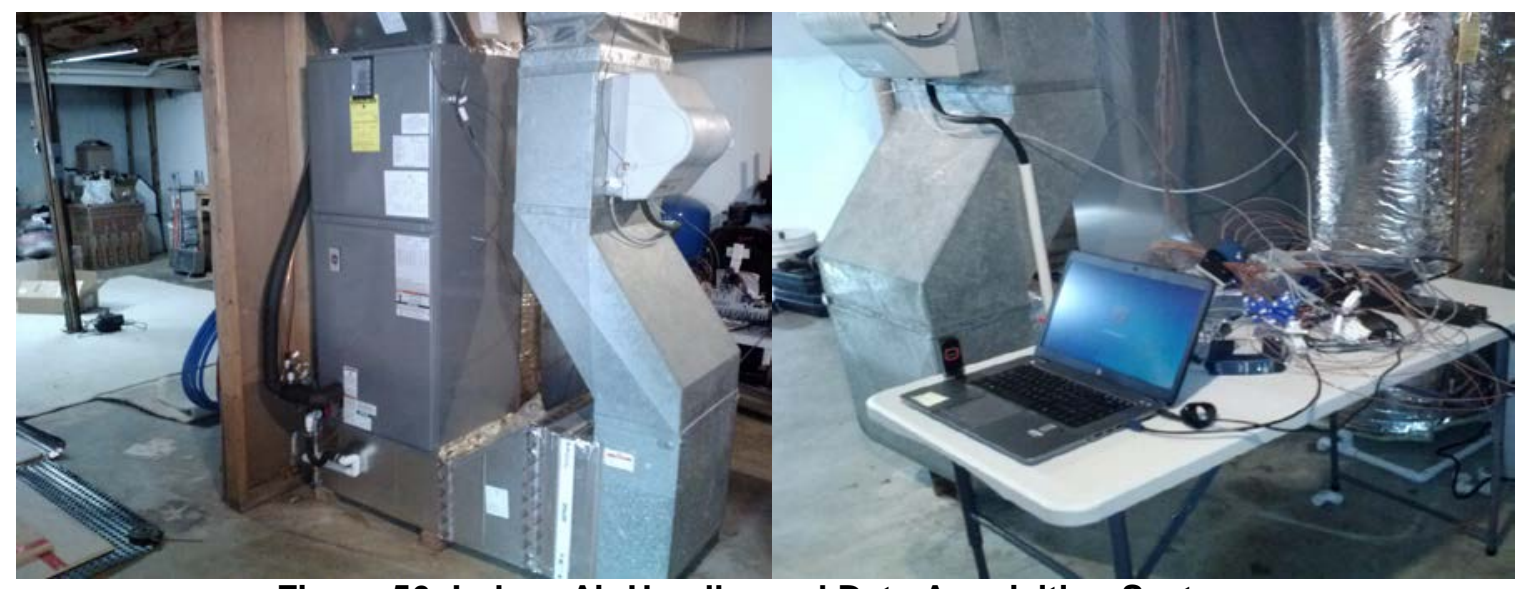

Figure 56: Indoor Air Handler and Data Acquisition System.

The thermostat was a conventional two-stage thermostat (made by Honeywell), located in the hallway. If the Delta-T between the temperature setting and the zone temperature is below $1^{\circ} \mathrm{F}\left(0.6^{\circ} \mathrm{C}\right)$, the thermostat calls a single-compressor running (Y1); if it is above $1^{\circ} \mathrm{F}\left(0.6^{\circ} \mathrm{C}\right)$, it calls the second stage. When the Delta-T goes beyond $2^{\circ} \mathrm{F}\left(1.1^{\circ} \mathrm{C}\right)$, the supplemental resistance heat will be activated. 
Emerson CRADA final report, December 30, 2015

\subsection{Data Acquisition and Measurement System}

We developed and debugged a data acquisition (DAQ) system for the field data monitoring. Since the field test was in an occupied home, a wireless DAQ system was designed to eliminate wire connections between the indoor and outdoor, and minimize interruptions on the home owner. As illustrated in the figure below, a DAQ controller and measurement devices (from National Instruments Inc.) were used to monitor the outdoor unit, which were connected to an indoor host computer through wireless communication. The host computer and other measurement devices were used to monitor the indoor unit. The field testing data are sent back to ORNL through Dropbox via internet connectivity.

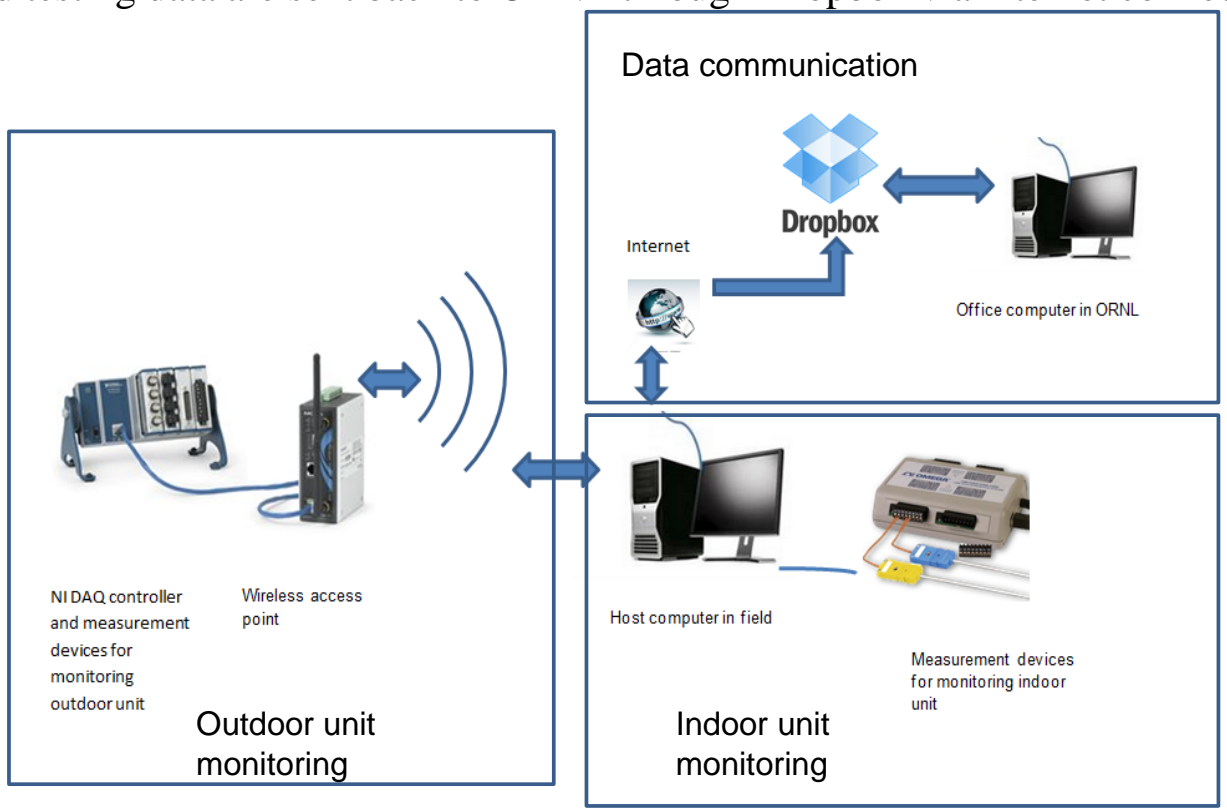

Figure 57: Data acquisition system schematic for CCHP field test.

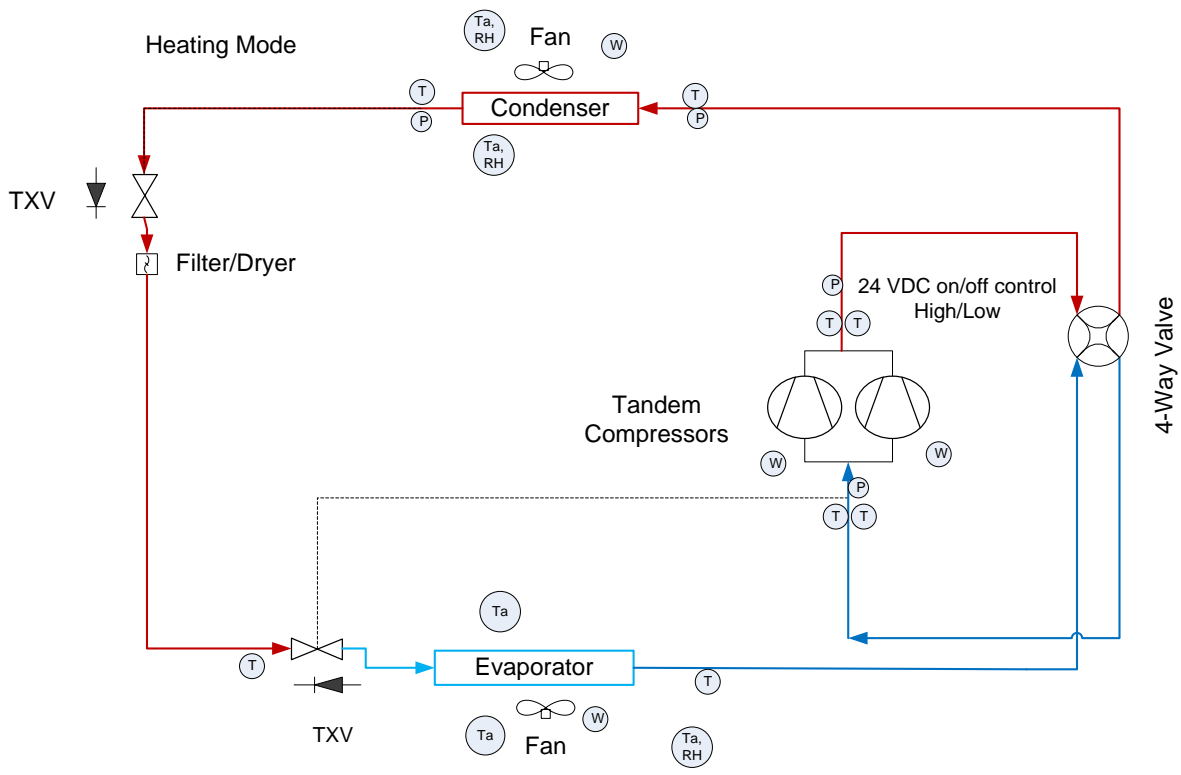

Page 64 of 86

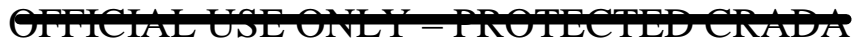


Figure 58: System Diagram of Field Testing HP and Instrumentations

Figure 58 describes the system diagram and instrumentations. The air temperatures flowing in and out of the outdoor coil were measured using T-type thermo-couples. The outdoor humidity was monitored using a Relative Humidity sensor. Three thermocouples were evenly placed at the entrance of the indoor unit to measure the average return air temperature, and a RH sensor was used to measure the return RH. At the exit of the indoor coil, and upstream of the blower, three thermo-couples and a $\mathrm{RH}$ sensor were used to monitor the supply air state. Wire thermo-couples were soldered on tube wall to measure the refrigerant temperatures entering and leaving the indoor coil, and also, the suction and discharge temperatures of each compressor. Four pressure transducers were used to measure the refrigerant pressures entering and leaving the indoor coil, as well as entering and leaving the compressors. Four Ohio Semitronics Watt transducers were used to measure the powers of the outdoor fan, indoor blower and two compressors, individually. Another Ohio Semitronics Watt transducer was used to measure the total power consumption of the outdoor unit. The total outdoor power consumption was determined using the larger value between the total power measurement and sum of the individual power measurements. In particular, we put a thermo-couple in the duct downstream of the indoor unit to indicate the electric supplemental heater on/off. The DAQ system scanned all the sensors and recorded the data every half minute.

The field testing was conducted in an occupied home with an old ductwork. To minimize the interruption on the home owner, we didn't install an air flow monitor in the duct. Instead, we used "true flow grid" to measure the air flow rates for once during the heating season and another time during the cooling season. As shown in Figure 59, "true flow grid" composes a grid of pitot tubes. It is usually used in the slot of an air filter, to provide one time measurement during field installation and diagnosis.

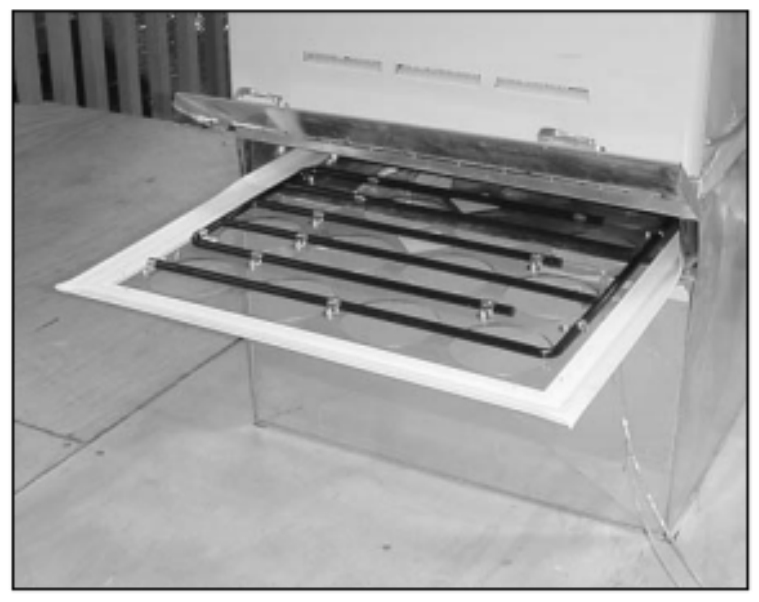

Figure 59: True flow grid air flow monitor

For heating mode, the measured air flow rates are given below:

1.) Single-compressor operation in heating mode measured reading 1120 CFM $(0.53$

$\mathrm{m}^{3} / \mathrm{s}$ ) with True Flow meter. (The product literature indicates 1200 CFM (0.57 
$\mathrm{m}^{3} / \mathrm{s}$ )for cooling operation with the same blower setting), at a blower power of 230 W.

2.) Two-compressor operation in heating mode measured reading $1350 \mathrm{CFM}\left(0.64 \mathrm{~m}^{3} / \mathrm{s}\right)$ with True Flow meter. (The product literature indicates 1500 CFM $\left(0.71 \mathrm{~m}^{3} / \mathrm{s}\right)$ for cooling operation with the same setting), at a blower power of $430 \mathrm{~W}$.

We also measured the duct external static pressure, from entering the filter to downstream of the indoor blower, which was 0.775 Inch WC $(1.97 \mathrm{~cm} \mathrm{WC})$, when both compressors ran, i.e. high air flow rate. The duct was relatively restrictive when running the high air flow rate, and caused larger blower power consumption than the manufacturer's data. The indoor blower used an ECM motor and was able to maintain a constant volumetric flow rate at the blower exit, regardless of the external static pressure. One reason for the lower measured value of the air flow compared to the product literature is that the product air flow rates correspond to cooling operation. If converted to heating operation and assume the blower driving the same CFM at its exit, the return air flow rates in heating mode shall be scaled by a ratio of supply air density in heating mode at $95^{\circ} \mathrm{F}\left(35^{\circ} \mathrm{C}\right) \mathrm{DB}$ and $20 \% \mathrm{RH}$ and in cooling mode at $50^{\circ} \mathrm{F}\left(10^{\circ} \mathrm{C}\right) \mathrm{DB}$ and $90 \% \mathrm{RH}$. The scaling factor is 0.92, which leads to 1104 CFM and 1380 CFM in heating mode. Therefore, the "True flow grid” measured indoor air flow rates are credible.

The air flow rates above were used for the entire heating season. The measured blower powers were used to indicate the air flow rates, i.e. if the blower power was less than 350 $\mathrm{W}$, the return air flow rate was assumed as $1120 \mathrm{CFM}\left(0.53 \mathrm{~m}^{3} / \mathrm{s}\right)$; if the blower power was bigger than $350 \mathrm{~W}$, the return air flow rate was $1350 \mathrm{CFM}\left(0.64 \mathrm{~m}^{3} / \mathrm{s}\right)$.

\subsection{Field Heating Performance}

The field testing in the past heating season was monitored from the beginning of February to the end of April/2015 for three full months. We were able to capture the coldest condition in Ohio when the field temperature went down to $-13^{\circ} \mathrm{F}\left(-25^{\circ} \mathrm{C}\right)$.

Figure 60 illustrates fractions when running two compressors, and total compressor run time (running one and two compressors), relative to the time when the ambient temperature in each bin. It can be seen that the second compressor was turned on more frequently towards lower ambient temperature. At $-13^{\circ} \mathrm{F}\left(-25^{\circ} \mathrm{C}\right)$, the total compressor run time was $100 \%$, but the second compressor still cycled with $80 \%$ running time. It indicates the HP still having room to provide more capacity at $-13^{\circ} \mathrm{F}$. 


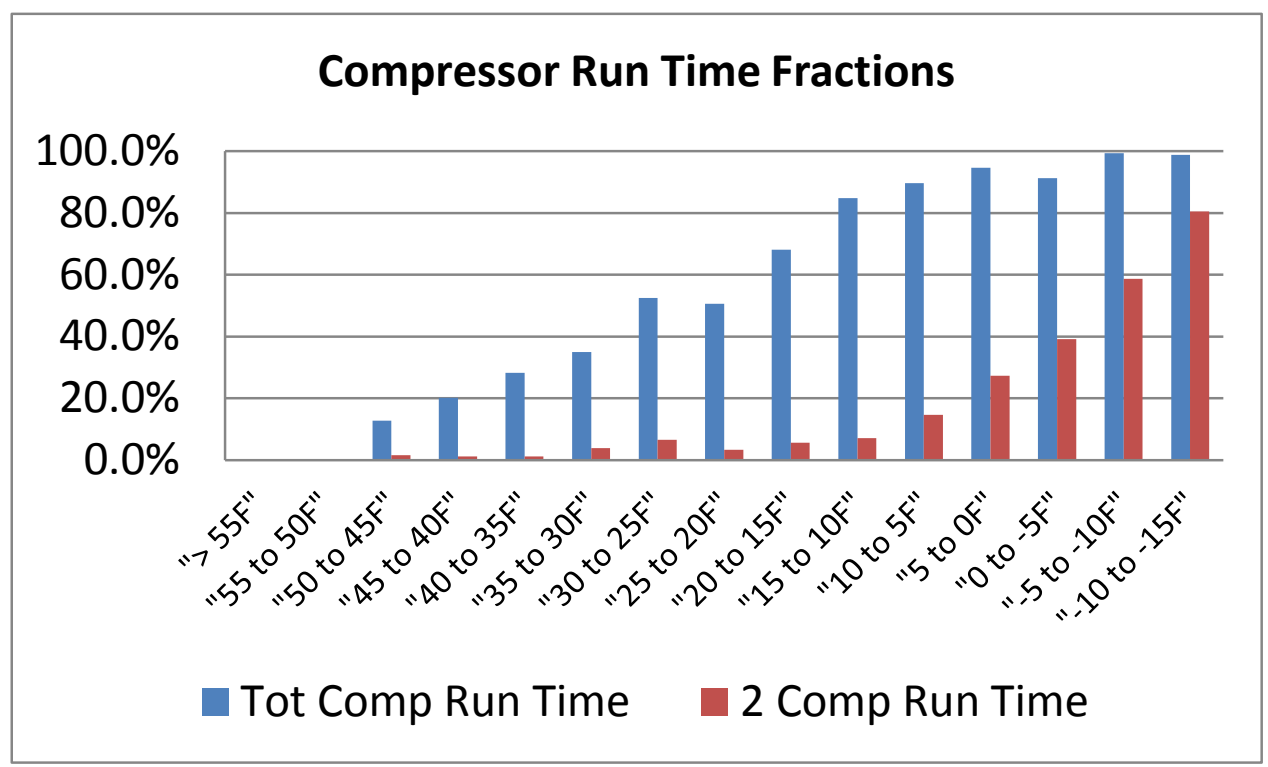

Figure 60: Compressor Run Time Fractions

Figure 61 shows delivered capacities with running a single-compressor and both, in comparison to the total delivered heating load line. It can be seen that the second compressor was needed when the ambient temperature went below $10^{\circ} \mathrm{F}\left(-12.2^{\circ} \mathrm{C}\right)$. At $13^{\circ} \mathrm{F}\left(-25^{\circ} \mathrm{C}\right)$, running two compressors delivered $30,416 \mathrm{Btu} / \mathrm{h}(8.9 \mathrm{~kW})$, which is $75 \%$ of the rated capacity of 39,717 Btu/h $(11.6 \mathrm{~kW})$, as given in Table 7.

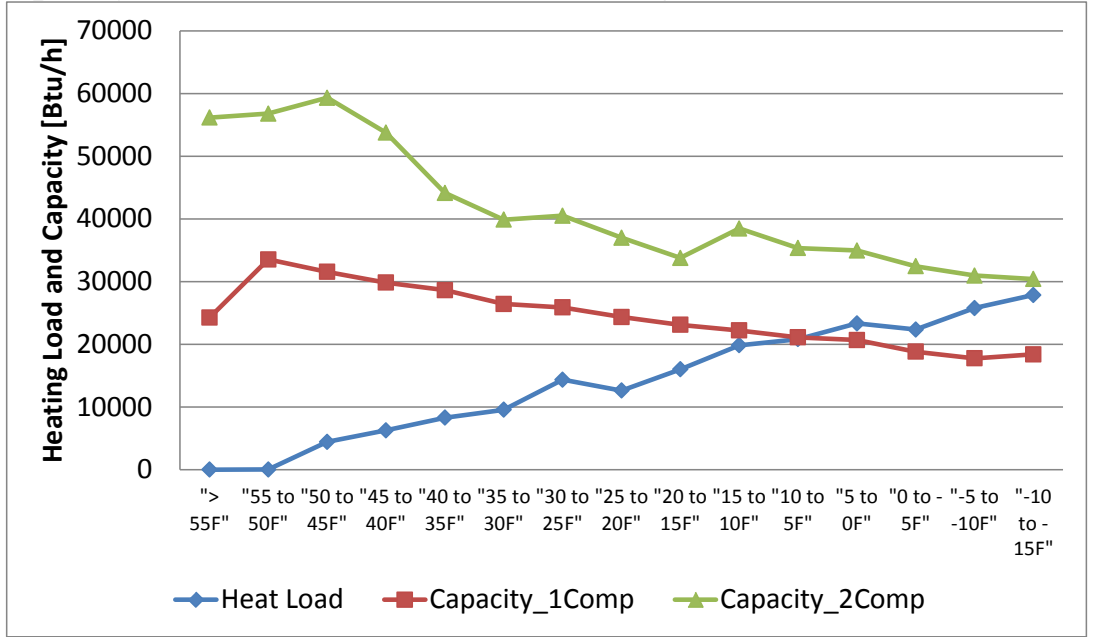

Figure 61: Delivered Heat Capacities and Measured Building Heating Load Line

Figure 62 illustrates percentage of supplemental resistance heat use to the total energy use in each temperature bin. The resistance heat uses were negligible, which were mainly caused by control issues. At $-13^{\circ} \mathrm{F}\left(-25^{\circ} \mathrm{C}\right)$, the resistance energy use was $3.2 \%$, when the second compressor still cycled by $80 \%$. This means that the heat pump responded slower than needed, that the thermostat hit the $-2 \mathrm{R}(1.1 \mathrm{~K})$ dead band first. The resistance heat use can be eliminated by changing the control to prevent running a single compressor below a certain ambient temperature. It is interesting to see that the resistance heat was also turned on at moderate ambient temperatures between $45^{\circ} \mathrm{F}$ and $20^{\circ} \mathrm{F}\left(7.2^{\circ} \mathrm{C}\right.$ to - 
$6.7^{\circ} \mathrm{C}$ ). This is mainly due to temperature set-back behavior when the home owner came back home and increased the temperature setting somewhat over $2^{\circ} \mathrm{F}$.

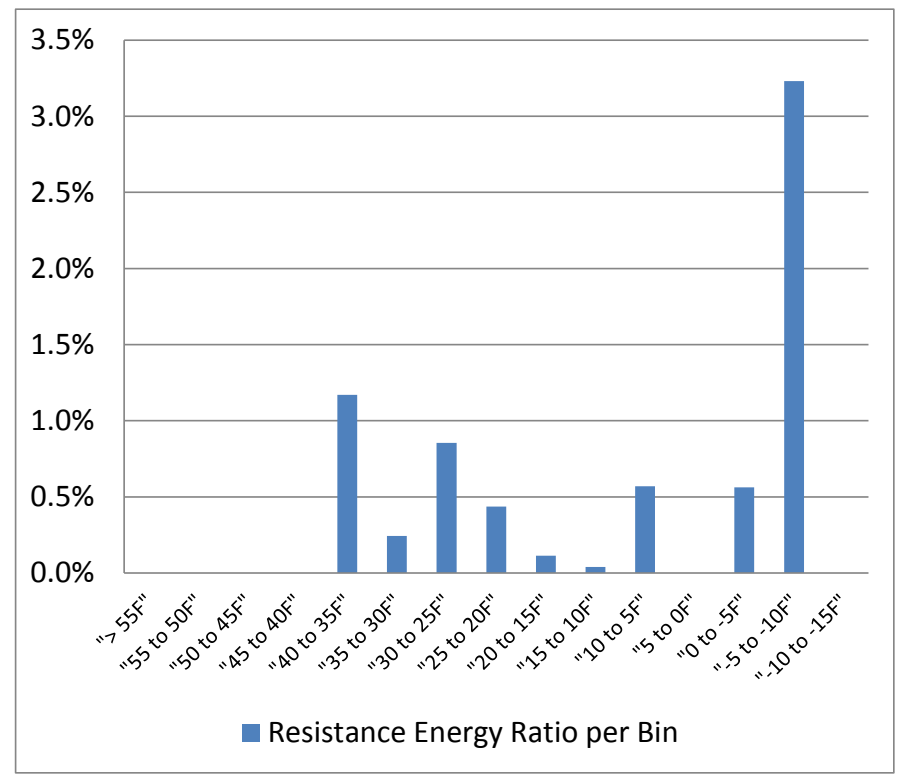

Figure 62: Supplemental Resistance Heat Uses

Figure 63 shows the return and supply air temperatures. The return temperature profile indicates that the home owner set the thermostat at $68^{\circ} \mathrm{F}$ during the majority of time when the heat pump was operating. This caused the zone temperature to change from $66^{\circ} \mathrm{F}$ to $70^{\circ} \mathrm{F}\left(18.9^{\circ} \mathrm{C}\right.$ to $\left.21.1^{\circ} \mathrm{C}\right)$. At $-13^{\circ} \mathrm{F}\left(-25^{\circ} \mathrm{C}\right)$, the heat pump was able to deliver the supply air at $86^{\circ} \mathrm{F}\left(30^{\circ} \mathrm{C}\right)$ out of the indoor blower and before the resistance heater, with the high air flow rate of 1350 CFM $\left(0.64 \mathrm{~m}^{3} / \mathrm{s}\right)$. It should be mentioned that, we allowed the indoor air flow rate to change with the compressor staging without subjecting to the ambient temperature, due to simplifying the control during the field testing.

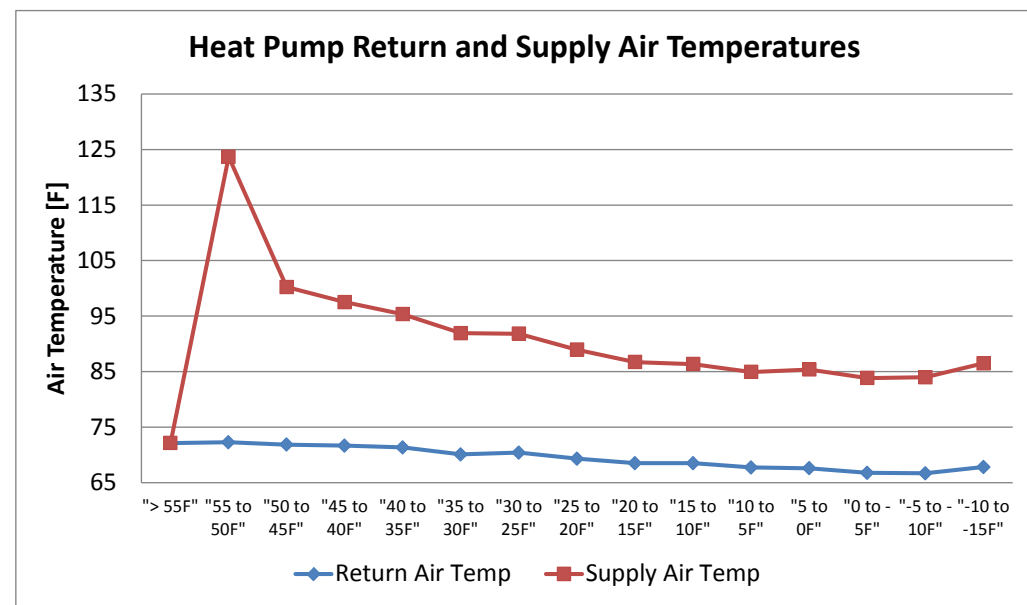

Figure 63: Return and Supply Air Temperatures

Figure 64 presents running time fraction of defrosting cycle, relative to the total HP operation time, as well as the added heating load due to defrosting, compared to the total Page 68 of 86

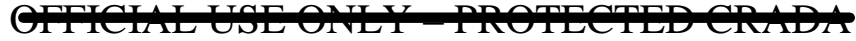


heating energy delivered in each temperature bin. It can be seen that defrost frequency and resultant energy losses were minimal for the CCHP, for two reasons: 1). with running one compressor at the temperature range prone to frost growth, frost formation was slow, due to the oversized outdoor HX and higher evaporating temperature than a typical HP; 2). when two compressors were needed at low ambient temperatures, the humidity level was very low and hardly any moisture condensed on the outdoor coil.

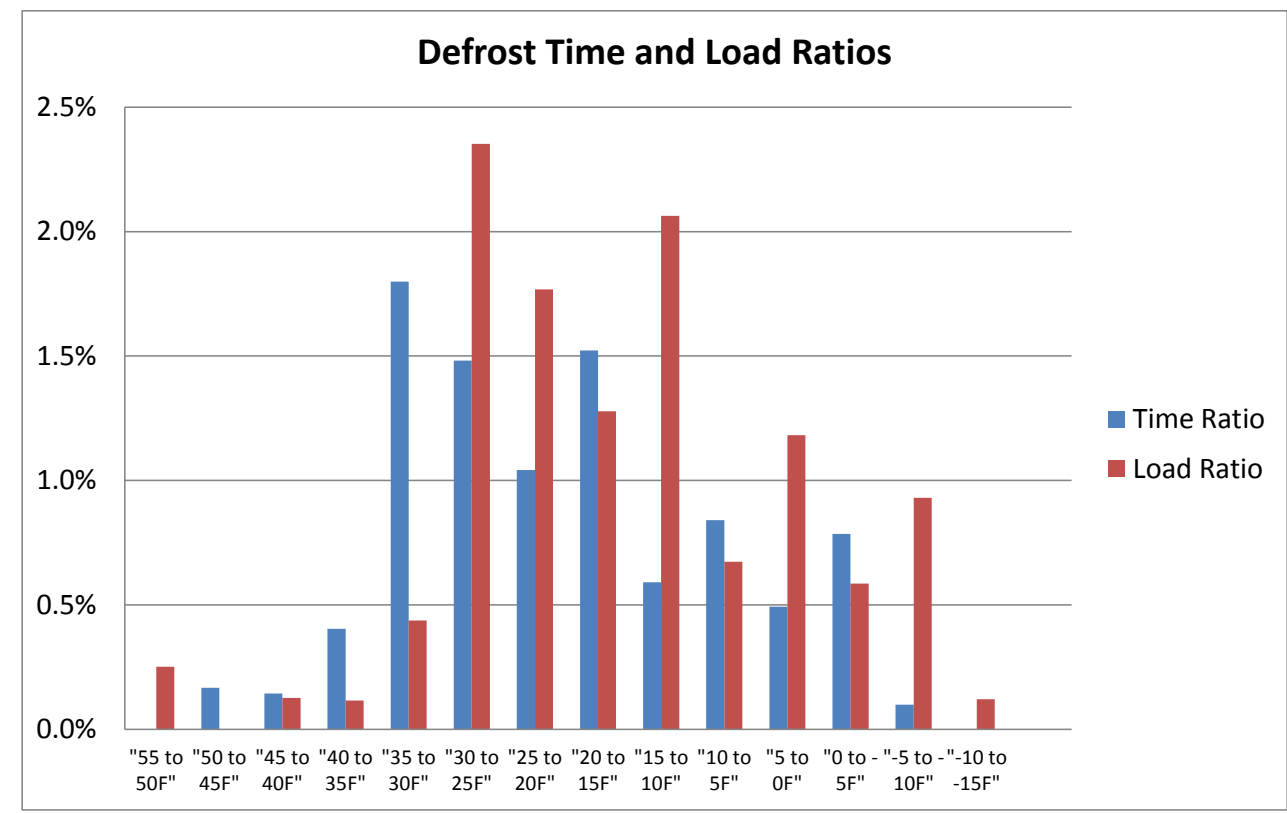

Figure 64: Defrost time ratio and load relative to capacity delivered in each bin

Figure 65 shows the COPs when running a single-compressor and two compressors, as a function of the bin temperature; the total COP was calculated by the total energy delivery divided by the total energy consumed, including cyclic loss, supplemental resistance heat use, frosting/defrosting, and switching between running one compressor and two compressors. It can be seen, from $45^{\circ} \mathrm{F}$ to $50^{\circ} \mathrm{F}\left(7.2^{\circ} \mathrm{C}\right.$ to $\left.10^{\circ} \mathrm{C}\right)$, the $\mathrm{COP}$ running a single compressor is 4.05 . The total COP is 3.83, which is lower because of the cyclic loss and occasionally running the second compressor. It should be mentioned, the second compressor operation at moderately low temperatures, can be prevented by adjusting the control, and then, the field COP would follow the COP curve running a single compressor.

It is encouraging to see that, at $-13^{\circ} \mathrm{F}\left(-25^{\circ} \mathrm{C}\right)$, the total COP was 2.2 i.e. $120 \%$ more efficient than resistance heating. The field COP at $-13^{\circ} \mathrm{F}\left(-25^{\circ} \mathrm{C}\right)$ is higher than the measured COP in the lab, i.e. 1.94 given in Table 7 , because the field return air temperature is 2 to $4^{\circ} \mathrm{F}\left(1.1\right.$ to $\left.2.2^{\circ} \mathrm{C}\right)$ lower than the controlled value in the lab. In addition, the second compressor still cycled by $80 \%$, and partially running a single compressor boosted the COP. 
Emerson CRADA final report, December 30, 2015

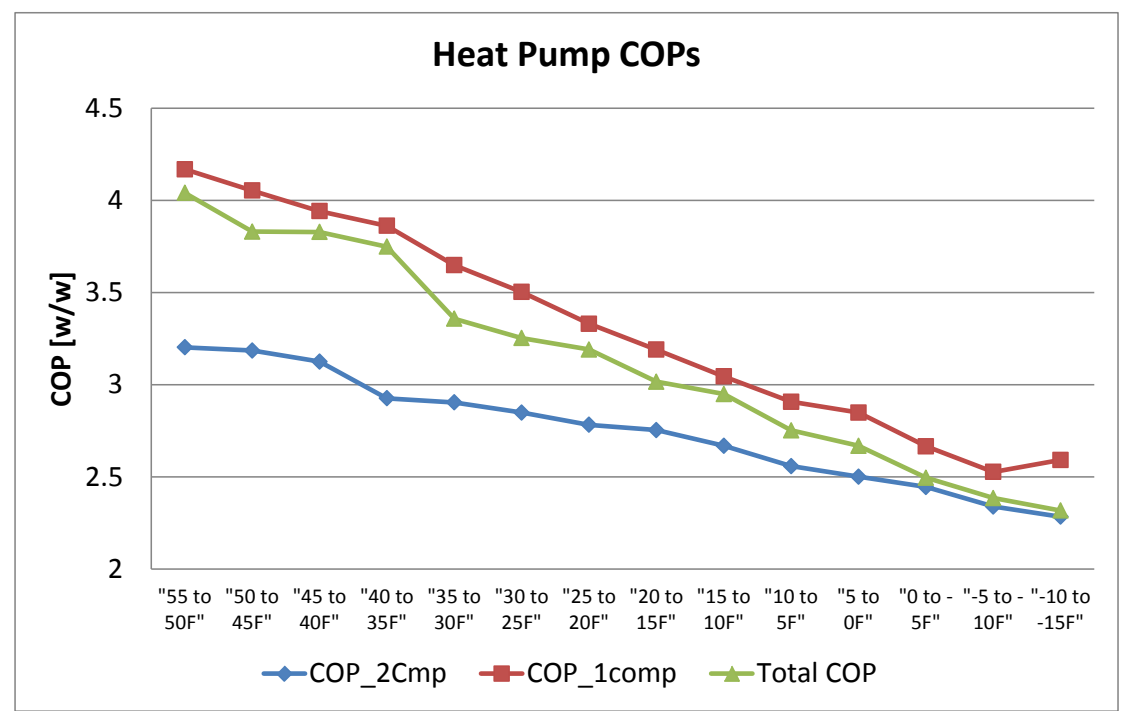

Figure 65: Field COPs in heating mode

In the three months of heating operation, the field-measured HSPF (heating seasonal performance factor) is 10.8, i.e. an average COP of 3.16. Figure 66 compares heat energy delivered as a function of the temperature bin, between the field data and the AHRI 210/240 DHRmin load in region IV. It can be seen that the test home had more percentages of heating energy delivered at lower ambient temperatures, because the past winter in Ohio was colder than usual.

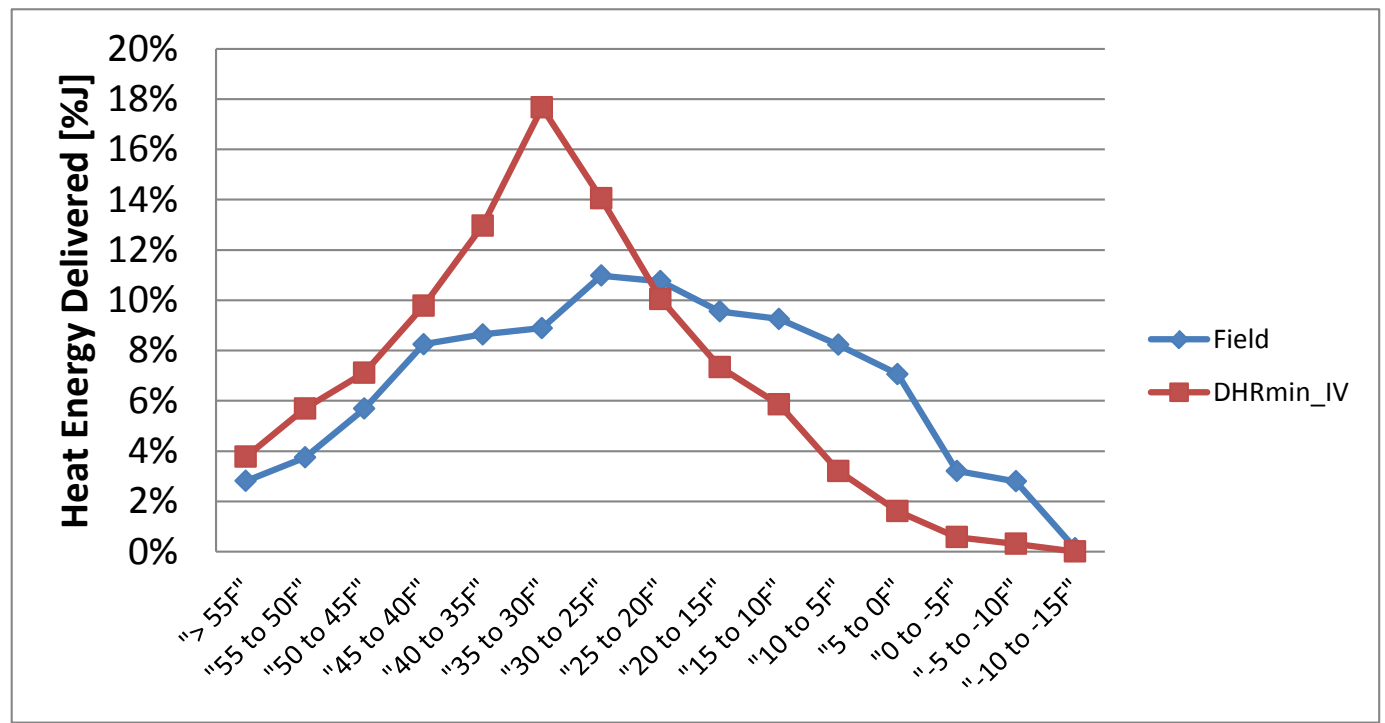

Figure 66: Percentages of Heat Energy Delivered by Bins in 2015

\subsection{Field Cooling Performance}

The cooling season data was recorded from the beginning of June to the end of August, for three months. In the cooling season, the control board was adjusted to prevent the second compressor running, i.e. only operating a single compressor and one air flow rate. We measured the indoor air flow rate using a "True Flow Grid", specifically for cooling 
operation. The measured air flow rate was 1380 CFM $\left(0.65 \mathrm{~m}^{3} / \mathrm{s}\right)$, which is in excellent agreement with the Rheem factory setting at 1375 CFM $\left(0.65 \mathrm{~m}^{3} / \mathrm{s}\right)$ rated.

Figure 67 shows averaged return and supply air temperatures as a function of the ambient temperature. It can be seen that the home owner had the home air temperature settings from 70 to $78^{\circ} \mathrm{F}\left(21.1\right.$ to $\left.25.6^{\circ} \mathrm{C}\right)$. The field unit was able to lower the air temperature consistently around $18 \mathrm{R}(10 \mathrm{~K})$. Figure 68 shows average, delivered cooling capacities at air side. From 60 to $75^{\circ} \mathrm{F}\left(15.6\right.$ to $\left.23.9^{\circ} \mathrm{C}\right)$ ambient, the cooling capacity increased due to the cyclic loss reduction. From 75 to $95^{\circ} \mathrm{F}\left(23.9\right.$ to $\left.35^{\circ} \mathrm{C}\right)$, the cooling capacity decreased due to the evaluated ambient temperature. At $95^{\circ} \mathrm{F}\left(35^{\circ} \mathrm{C}\right)$, the field average capacity was right at 36,000 Btu/h, i.e. 3-ton rated cooling capacity.

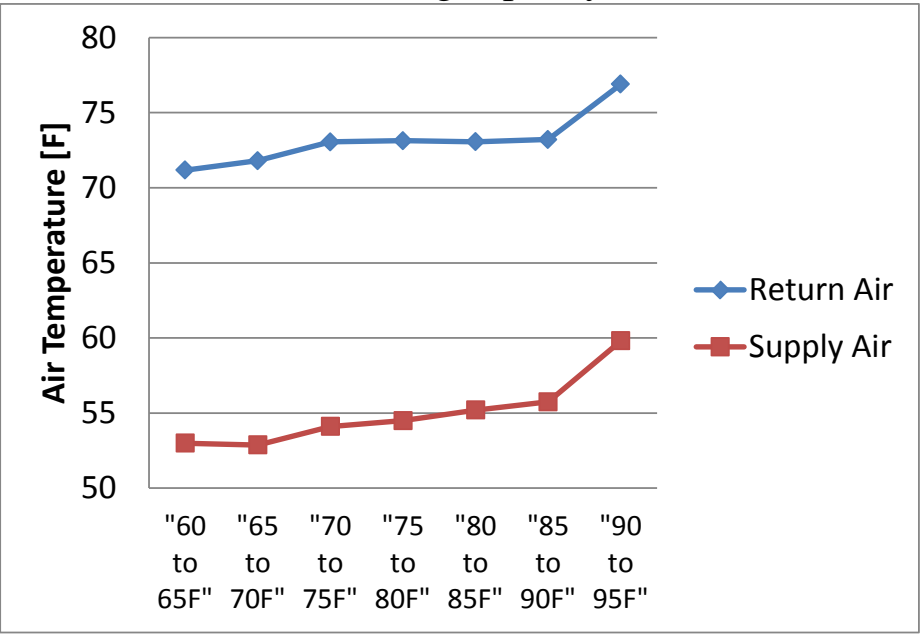

Figure 67: Return and supply air temperatures in cooling mode.

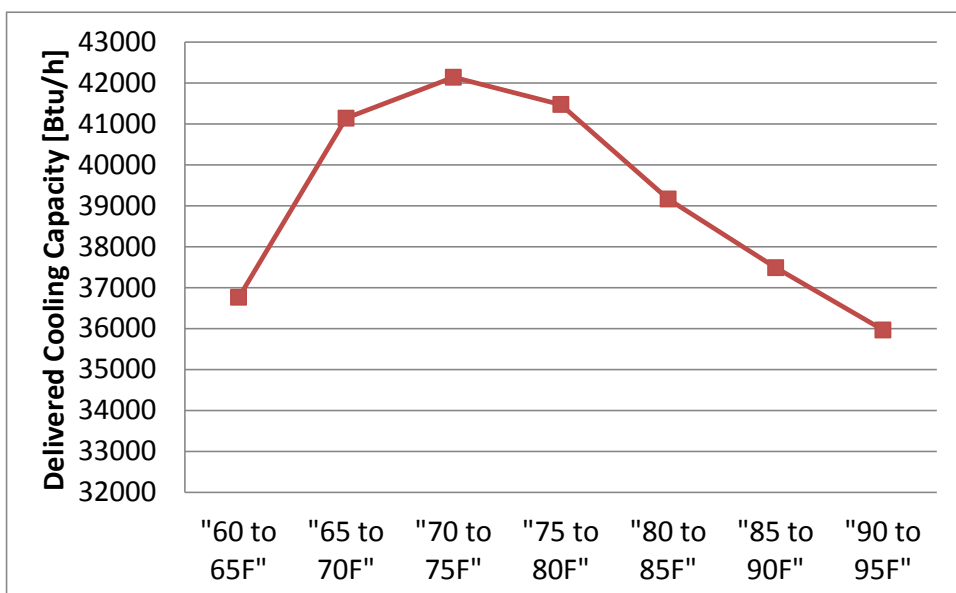

Figure 68: Delivered cooling capacities in cooling mode.

During the cooling season, only the low speed of the CCHP, i.e. a single compressor, was operated to meet the building cooling load. In this case, the indoor and outdoor heat exchangers, sized for two compressors, are oversized for a single compressor, and thus, led to superior cooling performance. The averaged field measured COP is 5.2, i.e. the average SEER is 17.8 , with the return air temperature varying from 70 to $78^{\circ} \mathrm{F}(21.1$ to $\left.25.6^{\circ} \mathrm{C}\right)$, and the average ambient temperature of $78^{\circ} \mathrm{F}\left(25.6^{\circ} \mathrm{C}\right)$. Figure 69 below shows 
the field measured COP as a function of the ambient temperature. It can be seen that, at $95^{\circ} \mathrm{F}\left(35^{\circ} \mathrm{C}\right)$, the field $\mathrm{COP}$ is 4.1 , with a return air temperature at $78^{\circ} \mathrm{F}\left(25.6^{\circ} \mathrm{C}\right)$.

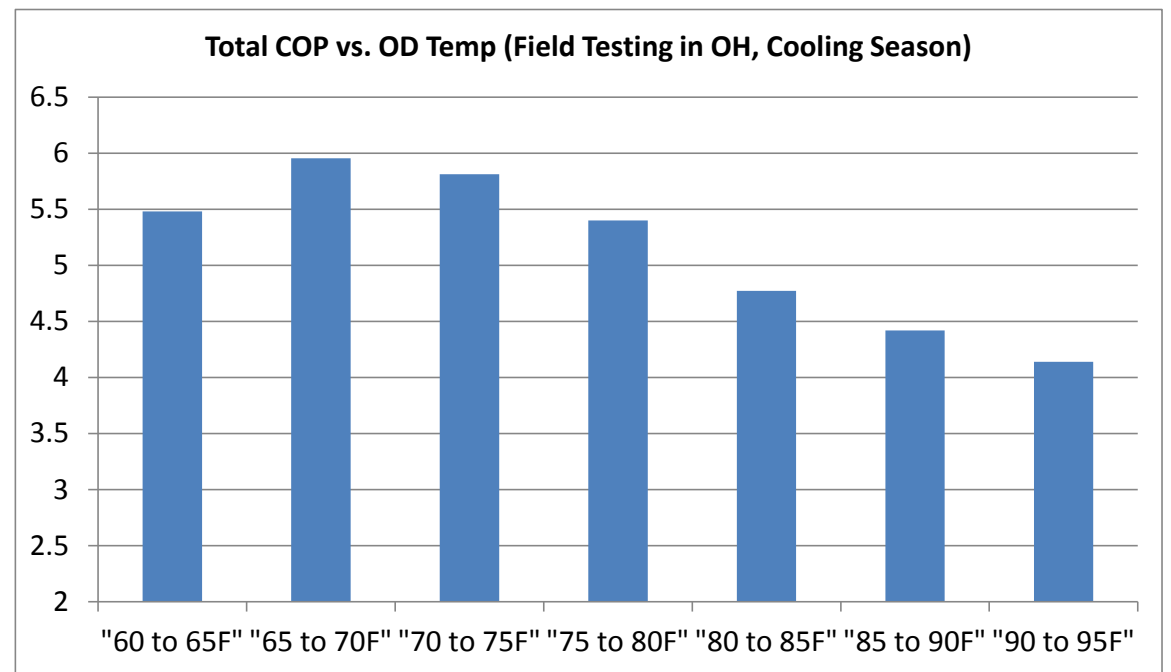

Figure 69: Field COPs in cooling mode

\subsection{Compare the Electricity Bills Before and After Installing the CCHP}

We collected the electric bills of the field testing home in the past three years. As shown in the figure below, in comparison to a previous single-speed HP (13.0 SEER/8.0 HSPF), described in Table 10. In the same house, $>40 \%$ energy reduction was achieved during the coldest months with similar average temperatures around $20^{\circ} \mathrm{F}$.

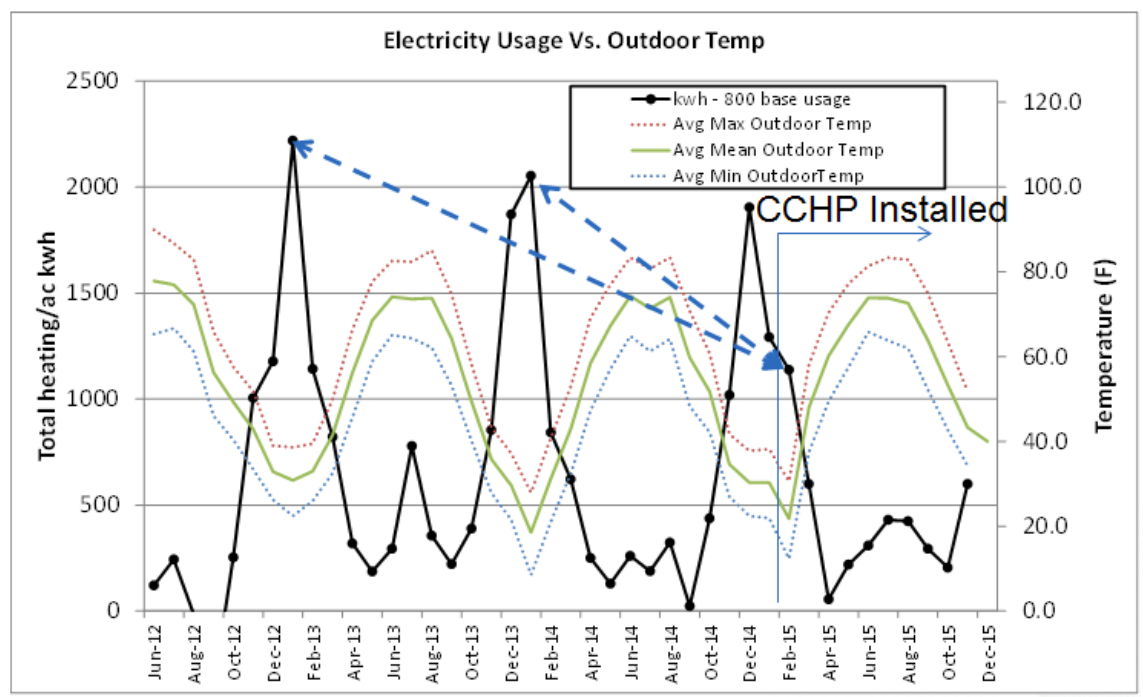

Figure 70: Comparing electric bills of the field testing home beforelafter installing the CCHP with tandem single-speed compressors.

The figure below overlays the field measured $\mathrm{kwh} /$ day, i.e. total measured $\mathrm{kWh}$ at a certain ambient temperature divided by the total time at the temperature, with the 
electricity bills, as a function of the average ambient temperature. It can be seen that the field data is very close to the CCHP electricity bills, which indicates good field measurement accuracy.

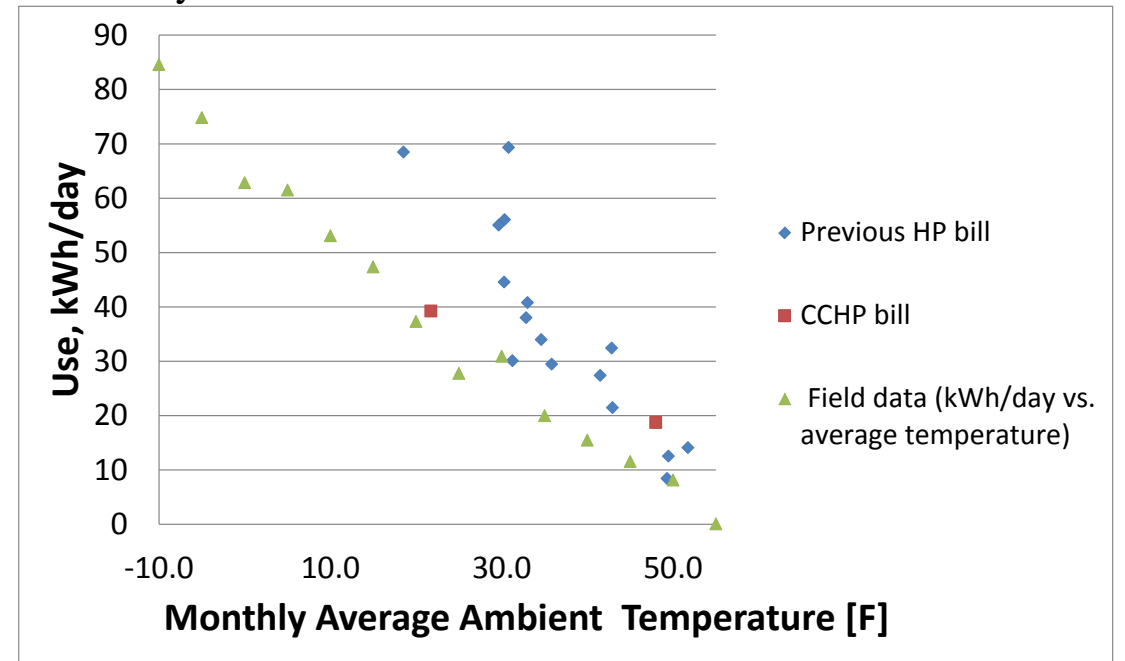

Figure 71: Overlay the field testing data with the electricity bills

Table 10: Previous Single-Speed Heat Pump in the Testing Home

\begin{tabular}{|l|l|l|}
\hline Parameters & Indoor Unit & Outdoor Unit \\
\hline Manufacturer & Goodman & Goodman \\
\hline Model No & ARUF042-00A-1A & CPLJ36-1B \\
\hline Rated Capacity & $42,000 \mathrm{Btu} / \mathrm{h}$ (3.5-ton) & 35,000 (3-ton) \\
\hline Air Flow Rate & $1470 \mathrm{cfm}$ & \\
\hline Electric Resistance Heater & $20 \mathrm{~kW}$ & \\
\hline SEER/HSPF & & 13.0 SEER/8.0 HSPF \\
\hline Refrigerant & & R22 \\
\hline
\end{tabular}

In Figure 70, it can be seen that there are no apparent energy savings in the cooling months. This is due to a family situation change that the home owner had a new baby in the 2015 summer and the heat pump ran more frequently and had a higher comfort level setting, as compared to the previous cooling seasons.

\subsection{Sensitivity Study using the Heating Seasonal Data in 2016}

Before the end of this CRADA project, we collected another set of heating data from 2015/12/11 to 2016/02/01, i.e. the period with peak heating demand in 2016. In the heating season, the home owner set the thermostat at $71^{\circ} \mathrm{F}\left(21.7^{\circ} \mathrm{C}\right)$, i.e. $3^{\circ} \mathrm{F}\left(1.7^{\circ} \mathrm{C}\right)$ higher than the previous heating season. And, we added a new temperature controller in the CCHP. The temperature controller prevents the second compressor from running when the ambient temperature is above $25^{\circ} \mathrm{F}\left(-12.2^{\circ} \mathrm{C}\right)$. As observed in the last winter, at moderately low ambient temperatures, the first stage, i.e. a single compressor is sufficient to meet the building load; however, the thermostat may still call the second stage due to the slow response of the original controller. Thus, using the extra temperature controller to prevent running the second compressor above a certain temperature will boost the 
operation COP, without decreasing the comfort level. Due to the increased comfort request, the return air temperatures to the CCHP in 2016 were consistently $4^{\circ} \mathrm{F}\left(2.2^{\circ} \mathrm{C}\right)$ higher than those in 2015, as shown in Figure 72. The higher temperature setting led to bigger heating load in 2016, as illustrated in Figure 74. Consequently, the second compressor ran more frequently at low ambient temperatures in 2016. For example, in the temperature bin from $-5^{\circ} \mathrm{F}$ to $0^{\circ} \mathrm{F}\left(-20^{\circ} \mathrm{C}\right.$ to $\left.-17.8^{\circ} \mathrm{C}\right)$, the second compressor running time fraction was $88 \%$ in 2016, in comparison to $40 \%$ in 2015, as shown in Figure 75 . On the other hand, the resistance heat was not turned on, and the CCHP provided supply air temperature at $91^{\circ} \mathrm{F}\left(32.8^{\circ} \mathrm{C}\right)$, at the lowest ambient temperature in 2016 , as shown in Figure 73. Thus, this CCHP is still fully capable to meet the building heating load, with the higher comfort level setting.

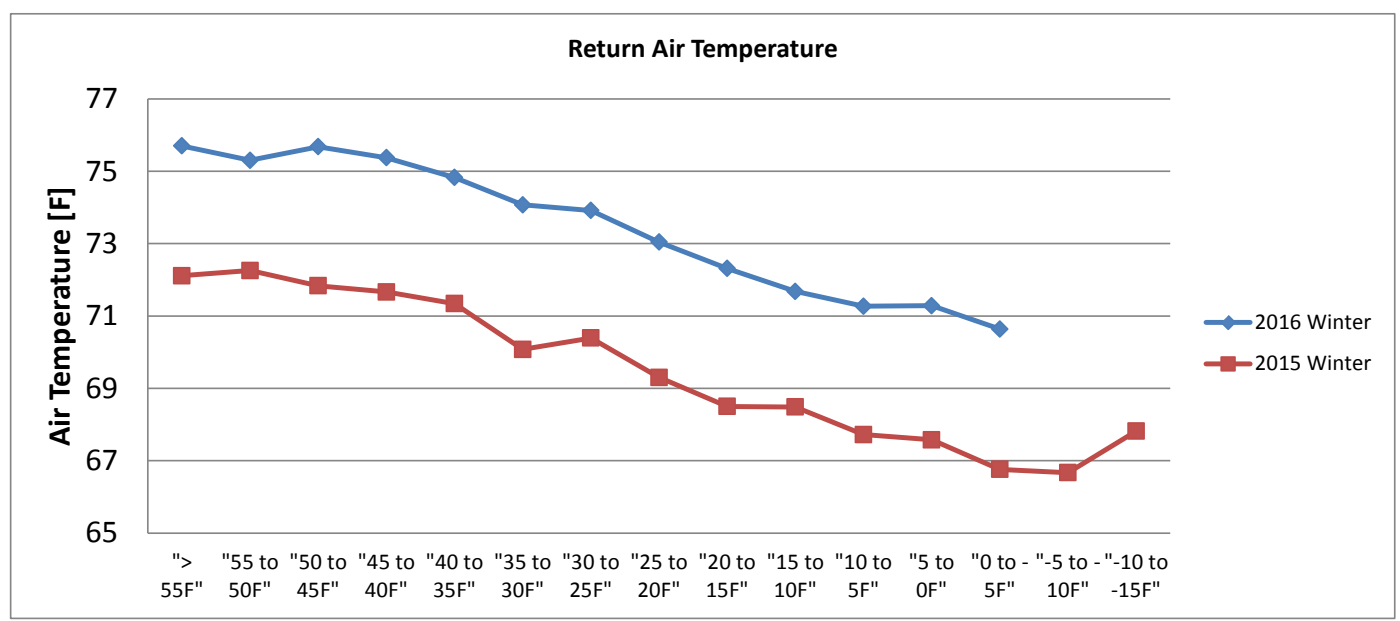

Figure 72: Return air temperatures in 2015 and 2016 heating seasons

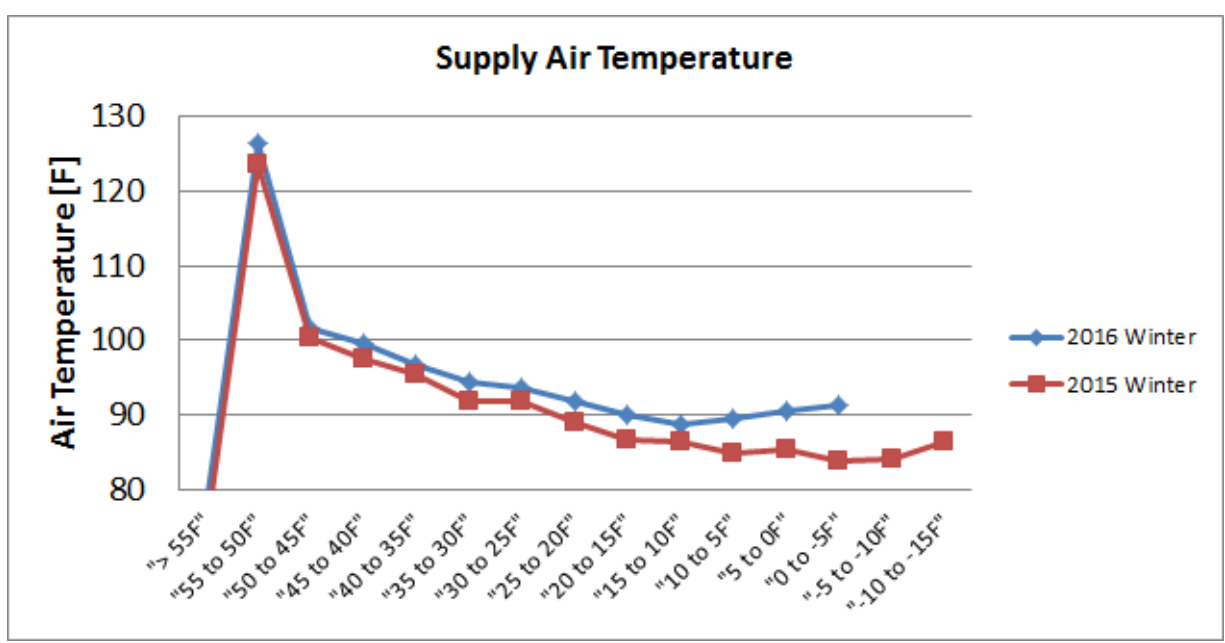

Figure 73: Supply air temperatures in 2015 and 2016 heating seasons 
Emerson CRADA final report, December 30, 2015

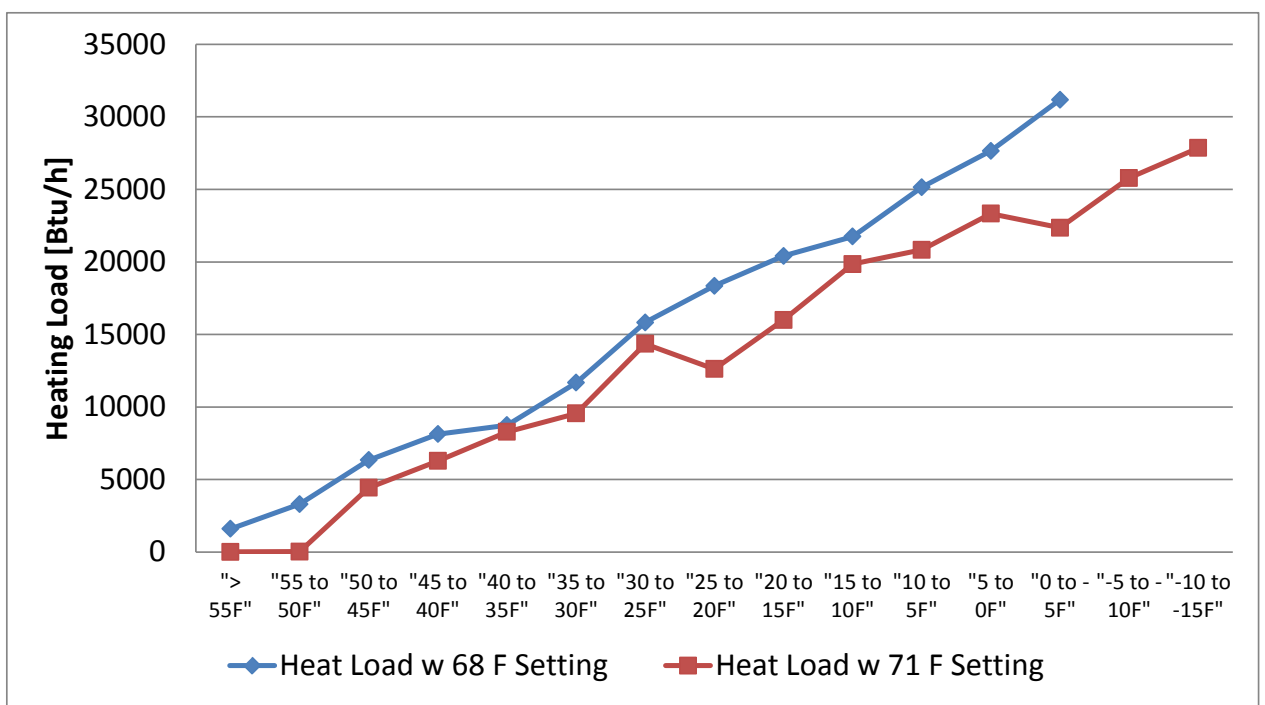

Figure 74: Comparing building heating loads in 2015 and 2016

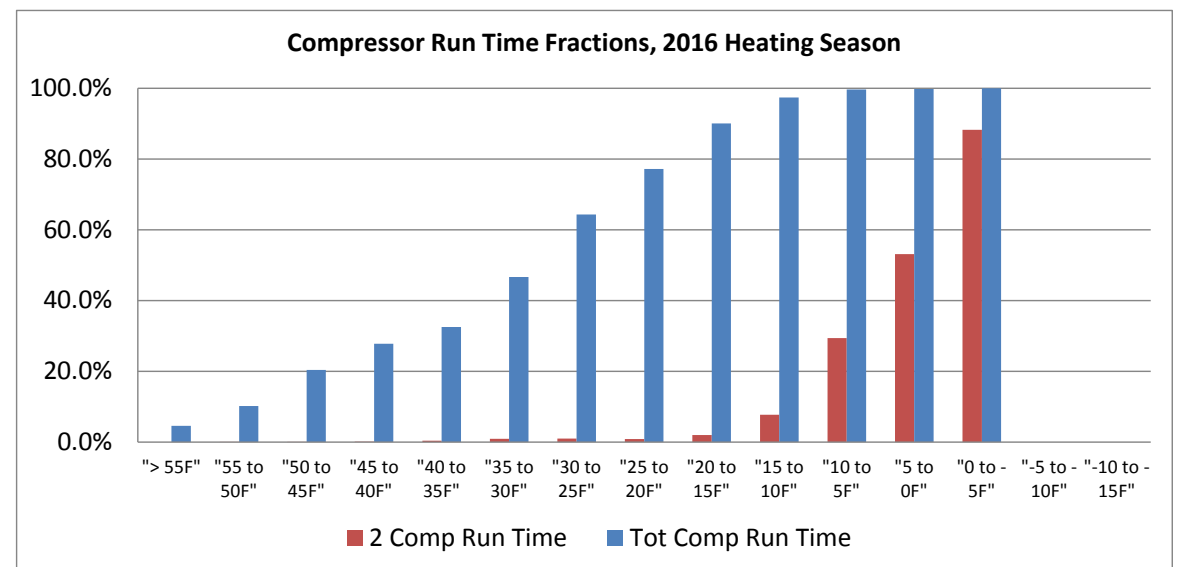

Figure 75: Compressor running time fractions in the 2016 heating season

Figure 76 compares the average heat pump COPs of 2015 and 2016 heating seasons, as a function of the ambient temperature. Because of the higher temperature setting and $4^{\circ} \mathrm{F}$ $\left(2.2^{\circ} \mathrm{C}\right)$ higher return air temperature to the CCHP, the heat pump heating COPs of 2016 are $10 \%$ to $15 \%$ lower than those of 2015 . 


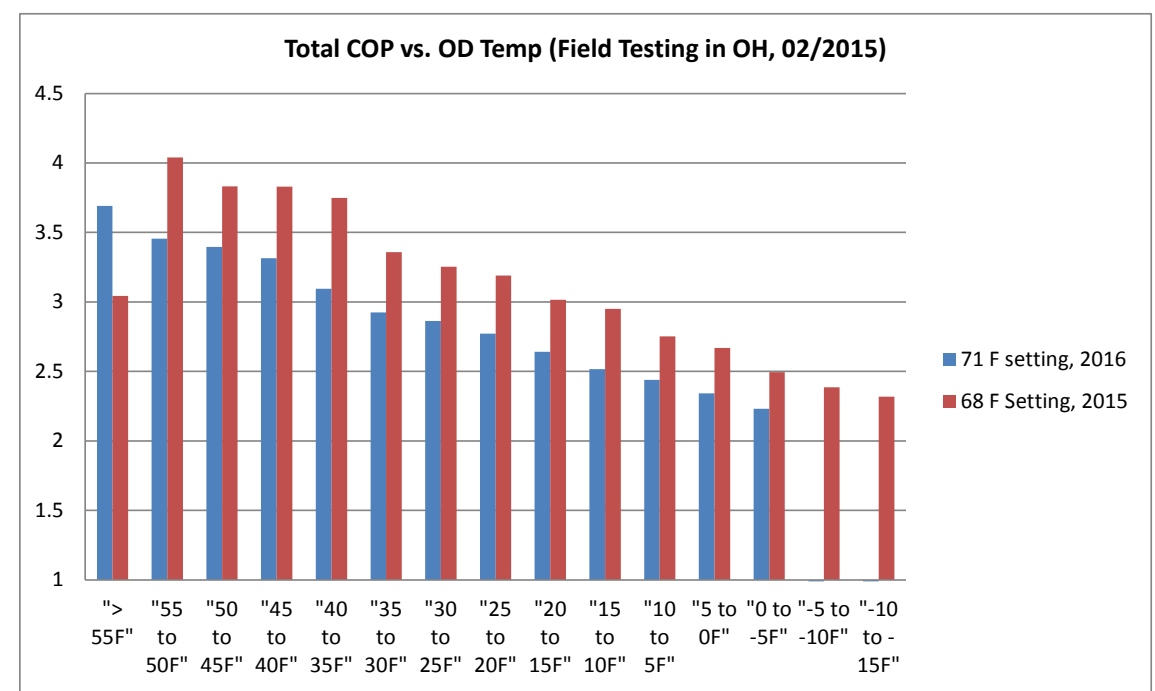

Figure 76: Average total COPs in 2015 and 2016

The field measured, averaged HSPF in 2016 is 9.7, and the energy distribution profile is shown in Figure 77. It can be seen that the CCHP delivered more energy at lower ambient temperatures than the standard DHRmin_IV load line.

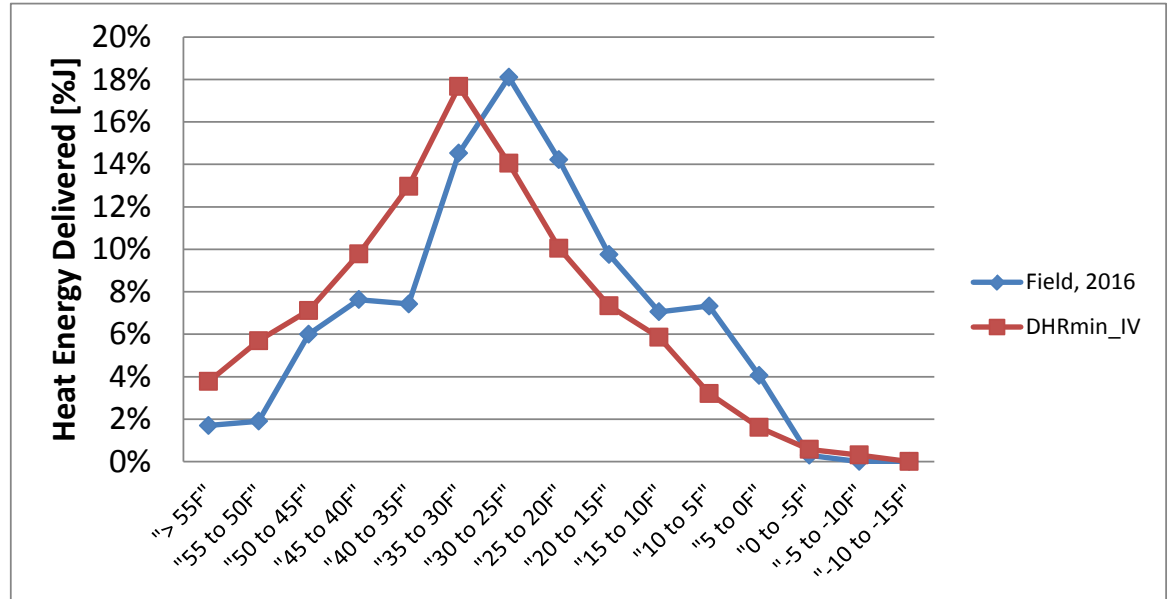

Figure 77: Percentages of Heat Energy Delivered by Bins in 2016

\section{Comparison to NEEP's Cold Climate Air-Source Heat Pump Listing}

NEEP (Northeast Energy Efficiency Partnerships) recently published a "Cold Climate Air Source Heat Pump Specification" and conducted an extensive survey on the available products suitable for cold climate applications. We cross-compared NEEP's cold climate air source heat pump survey to our tandem CCHPs.

Figure 78 illustrates the rated capacity ratios at $17^{\circ} \mathrm{F}\left(-8.3^{\circ} \mathrm{C}\right)$ relative to the rated heating capacity at $47^{\circ} \mathrm{F}\left(8.3^{\circ} \mathrm{C}\right)$. It can be seen that the tandem single-speed HP achieves almost 
130\% capacity ratio, and the tandem VI CCHP achieves $150 \%$ capacity ratio, which are much higher than NEEP CCHP ratios at the similar capacity level. It indicates that the tandem CCHPs have the maximum rated over-capacity potential at low ambients.

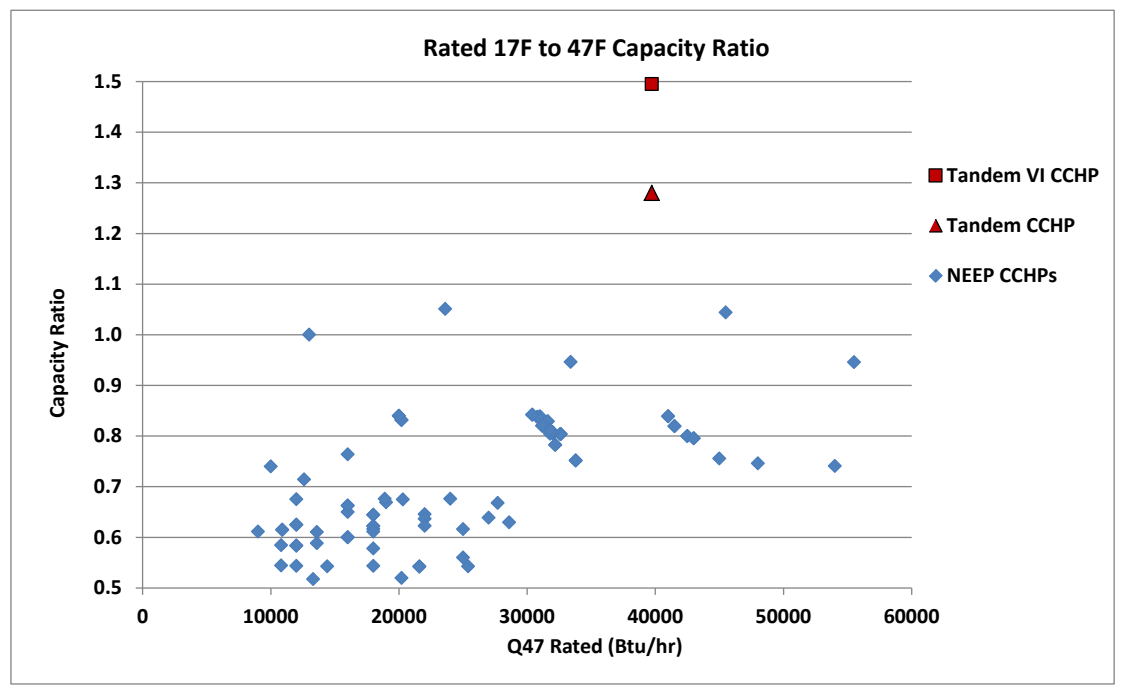

Figure 78: Rated Capacity Ratios at $17^{\circ} \mathrm{F}$ vs Rated Heating Capacity

Figures 79 and 80 show the heat pump COPs at $47^{\circ} \mathrm{F}\left(8.3^{\circ} \mathrm{C}\right)$ and $17^{\circ} \mathrm{F}\left(-8.3^{\circ} \mathrm{C}\right)$, vs. the rated heating capacity at $47^{\circ} \mathrm{F}$. It can be seen that the tandem CCHPs reach the top COP level at the rated capacity around 40,000 Btu/h $(11.72 \mathrm{~kW})$.

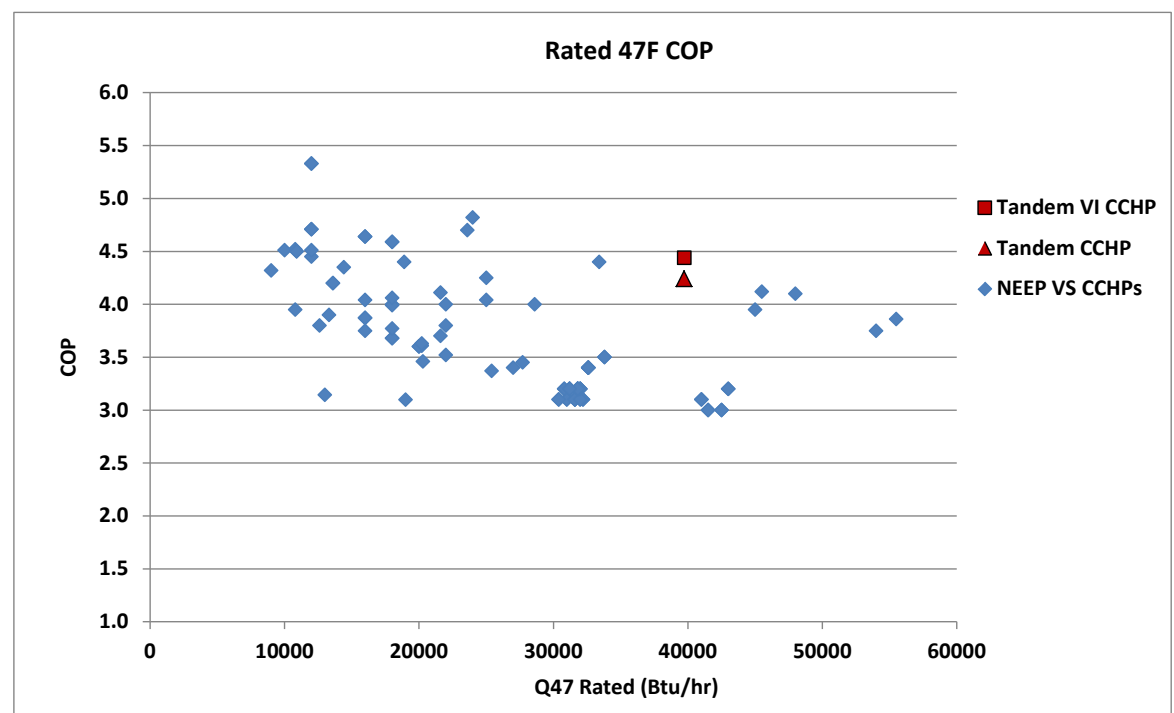

Figure 79: COPs at $47^{\circ} \mathrm{F}$ vs. Rated Heating Capacity 
Emerson CRADA final report, December 30, 2015

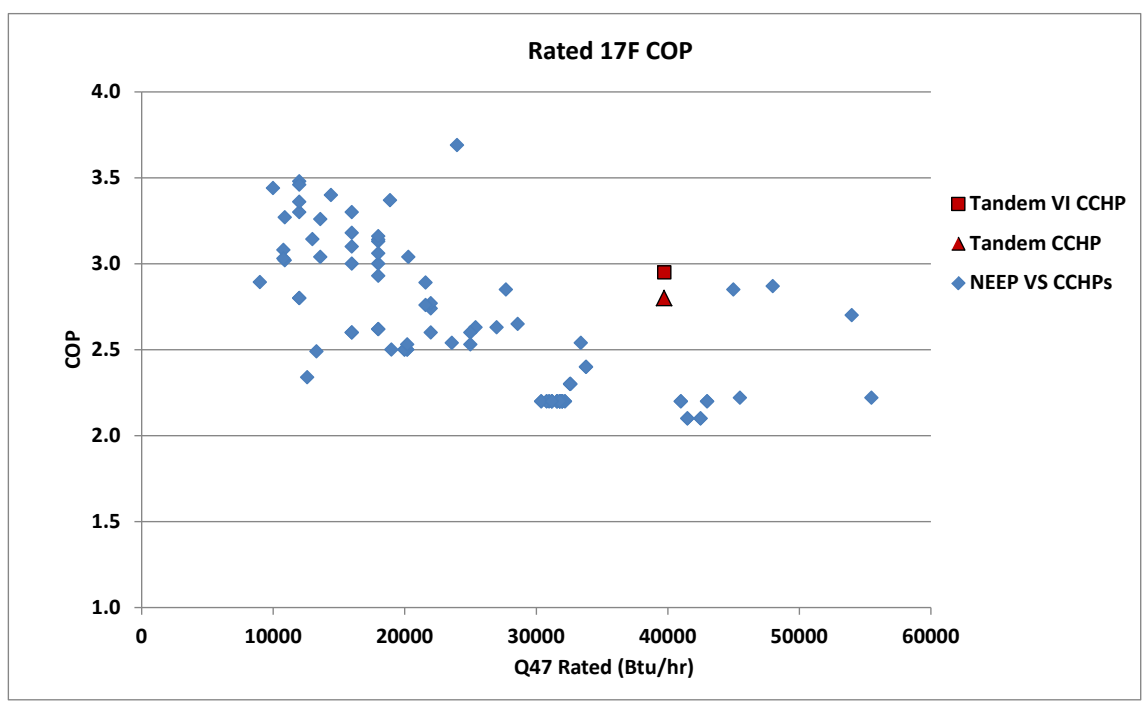

Figure 80: COPs at $17^{\circ} \mathrm{F}$ vs. Rated Heating Capacity

Figure 81 compares the tandem CCHPs to the NEEP listed VRF, mini-split and multisplit CCHPs, having published COPs at extremely low ambient temperatures around $13^{\circ} \mathrm{F}\left(-25^{\circ} \mathrm{C}\right)$. The tandem CCHPs approach the max levels of COP of just over 2.0in the same delivered capacity range. The three comparable multi-split VRF HPs have similar to higher COPs most likely because they are ductless units and the indoor blowers consume less power. They also have a similar rated HSPF of $\sim 11$.

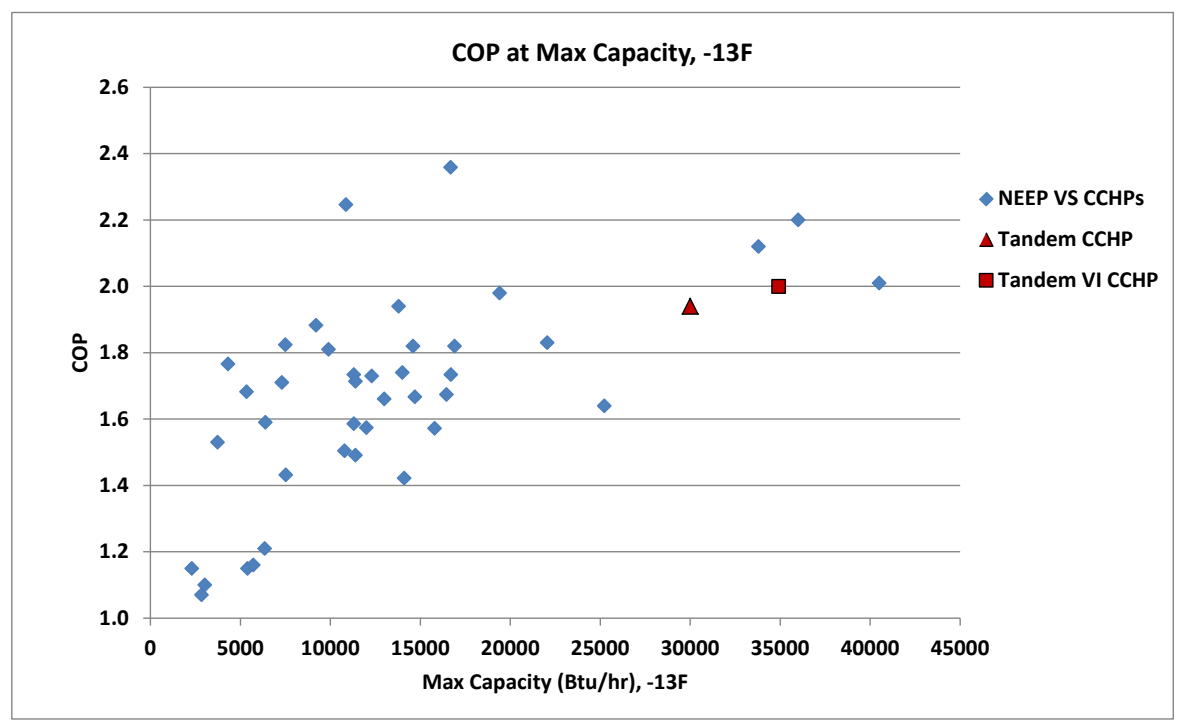

Figure 81: COPs at $-13^{\circ} \mathrm{F}$ vs. Max Capacity at $-13^{\circ} \mathrm{F}$ to $-15^{\circ} \mathrm{F}$

From the comparisons above, one can see that the tandem CCHPs have met or exceeded the Max Tech VRF CCHPs on the market today. 
In Table 8, one can see, at different load lines, i.e. DHRmin and DHRmax, the tandem design holds up very well with a higher load line, in contrast to a comparable ducted VS CCHP on the market, which has more than a 30\% dropoff in HSPF from DHRmin to DHRmax loads in both region IV and V. This design is very robust in maintaining high efficiency over a range of house heating loads. A reason for this stronger showing can be seen below. The plots show that for bins above $25^{\circ} \mathrm{F}\left(-3.9^{\circ} \mathrm{C}\right)$, the tandem unit has a higher net COP for the higher load line due to lower cycling losses in low capacity operation. As the peak of the delivered seasonal load is centered around $32^{\circ} \mathrm{F}\left(0^{\circ} \mathrm{C}\right)$ in Region IV, shown in Figure 82, the higher COP in low capacity operation at these ambients offsets to large degree the increased resistance heat use below $17^{\circ} \mathrm{F}\left(-8.3^{\circ} \mathrm{C}\right)$ ambient in Region IV, with the resultant HSPF dropping by only $2.3 \%$. In Region V, shown in Figure 83, a similar effect is seen but with the peak of the delivered seasonal load centered around $27^{\circ} \mathrm{F}\left(-2.8^{\circ} \mathrm{C}\right)$, the DHR_max integrated COP (including resistance heat needed to meet the building heating load) does not hold up quite as well, but still drops by only $7.7 \%$. In contrast, a comparable ducted VS CCHP on the market has more than a 30\% dropoff in HSPF from DHRmin to DHRmax loads in both regions IV and V.

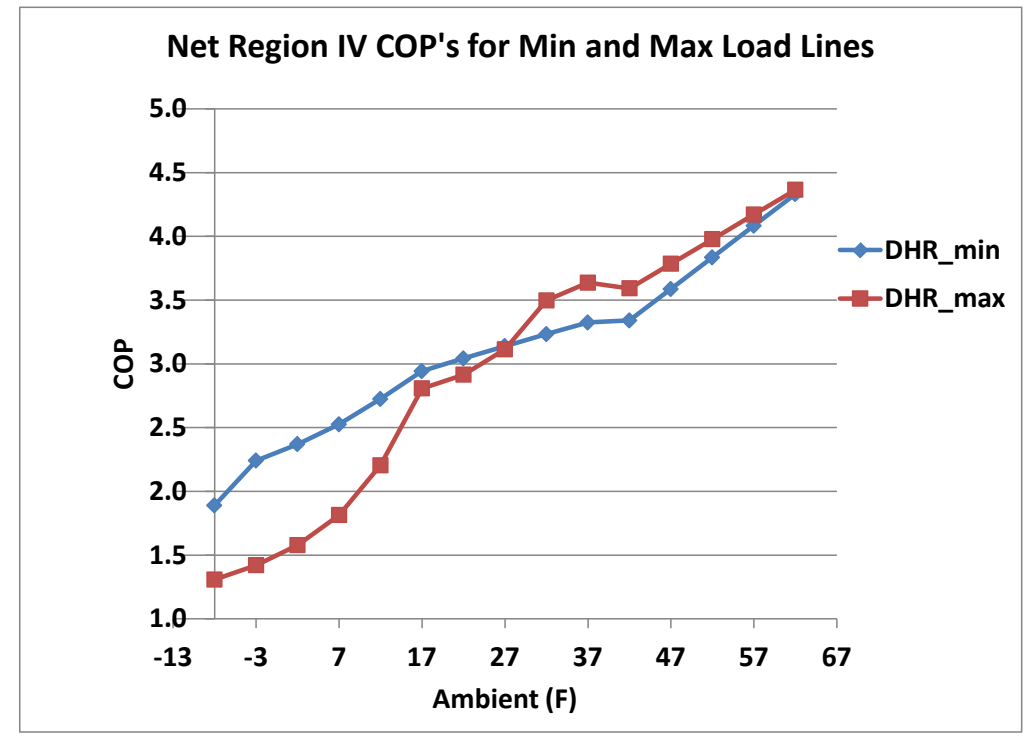

Figure 82: CCHP Net COPs Matching Min and Max Load Lines in Region IV 


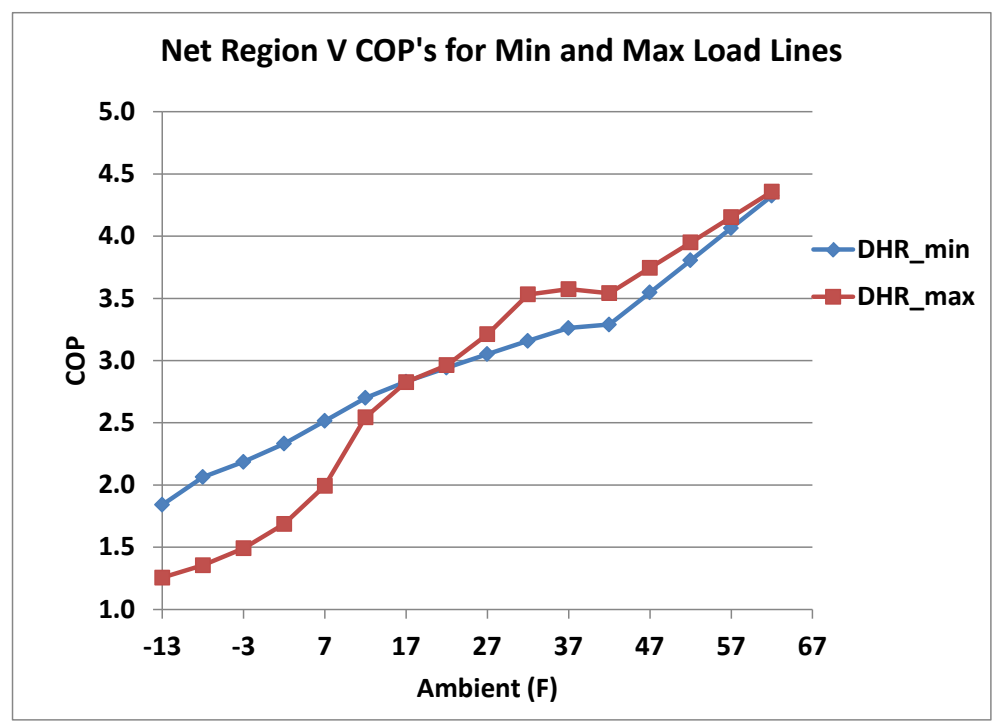

Figure 83: CCHP Net COPs Matching Min and Max Load Lines in Region V

\section{Summary}

CCHPs are targeted to the climate zones having significant portion of heating energy delivered below $17^{\circ} \mathrm{F}\left(-8.3^{\circ} \mathrm{C}\right)$, for the homes without connection to low cost gas supply. To develop a CCHP working under extremely low ambient temperatures, the first key is to make sure that the compressor(s) is able to operate without exceeding the compressor discharge temperature and pressure ratio limits. For this, optimizing the system charge for heating mode, properly sizing the HXs, and controlling discharge temperature are necessary. In addition, the compressor(s) should be able to tolerate high discharge temperature, for example, as high as 250 to $280^{\circ} \mathrm{F}\left(121.1\right.$ to $\left.137.8^{\circ} \mathrm{C}\right)$.

To maintain a good HP efficiency at low ambient temperatures, it is most important to provide sufficient heat pump capacity and eliminate most of the resistance backup heating. .At low ambient temperatures, heating load increases substantially, however, the heating capacity of a typical single-speed HP decreases steadily with reducing the ambient temperature, which degrades to $20 \%$ to $40 \%$ of the rated heating capacity. Thus, oversizing is mandatory for a CCHP, i.e. using only part of the compressor capacity to meet the rated heating capacity at $47^{\circ} \mathrm{F}\left(8.3^{\circ} \mathrm{C}\right)$ and the building design cooling load. On the other hand, the system should also provide good part-load efficiency in heating mode at moderate ambient temperature, as well as in cooling mode. These requirements point to using tandem compressors or variable-speed compressors with capacity modulation capability, among which the option of tandem compressors is more cost-effective.

We developed lab and field testing prototypes and successfully met DOE's performance targets for CCHPs 1) to maintain heating capacity at $-13^{\circ} \mathrm{F}\left(-25^{\circ} \mathrm{C}\right)$ greater than $75 \%$ of the rated heating capacity at $47^{\circ} \mathrm{F}\left(8.3^{\circ} \mathrm{C}\right)$, and 2$)$ heating $\mathrm{COP}$ at $47^{\circ} \mathrm{F}\left(8.3^{\circ} \mathrm{C}\right)$ greater than 4.0. The lab prototype using tandem single-speed compressors reached $4.24 \mathrm{COP}$ at $47^{\circ} \mathrm{F}\left(8.3^{\circ} \mathrm{C}\right) ; 76 \%$ heating capacity and $1.9 \mathrm{COP}$ at $-13^{\circ} \mathrm{F}\left(-25^{\circ} \mathrm{C}\right)$, and $2.9 \mathrm{COP}$ at $17^{\circ} \mathrm{F}$ 
Emerson CRADA final report, December 30, 2015

$\left(-8.3^{\circ} \mathrm{C}\right)$, giving an HSPF rating of 11.21 in DOE climate region IV with the minimum DHR line. The tandem design was found to quite robust, maintaining performance very well at higher design heating loads, dropping only $2.3 \%$ and $7.7 \%$ in HSPF with the maximum DHR load lines in regions IV and V, respectively.

Using the same tandem compressors in a breadboard HP, a field investigation was conducted in the past year in an occupied home in Ohio. The field HP ran through 10 months without any failures. During the heating season, the average COP was 3.16 and the HP was able to run down to $-13^{\circ} \mathrm{F}\left(-25^{\circ} \mathrm{C}\right)$ and eliminate resistance heat use. The HP maintained an acceptable comfort level through the whole heating season. During the cooling season, the average COP was 5.2, obtained by running only a single compressor.

Further efforts were made to increase the HP COPs at low ambient temperatures. We developed a "premium" version using tandem VI compressors. The "premium" prototype reached $4.4 \mathrm{COP}$ at $47^{\circ} \mathrm{F}\left(8.3^{\circ} \mathrm{C}\right) ; 88 \%$ heating capacity and $2.0 \mathrm{COP}$ at $-13^{\circ} \mathrm{F}\left(-25^{\circ} \mathrm{C}\right)$, and $3.1 \mathrm{COP}$ at $17^{\circ} \mathrm{F}\left(-8.3^{\circ} \mathrm{C}\right)$, having a $\mathrm{HSPF}$ of 11.84 . Its performance is uniformly $5 \%$ higher than the option using tandem, single-speed compressors. We also investigated coupling an ejector with the tandem, single-speed compressors. However, the laboratory results demonstrated that the ejector didn't work reliably for the CCHP operating in the extensive range of ambient conditions and varying mass flow rates from one to twocompressor operation.

To obtain more capacity and efficiency gains, two-stage compression may be another option to pursue. However, it will require more compressors, complicated system configuration, and potential oil return risk when having compressors in series. Considering that the "simple" configuration using tandem single-speed compressors has already achieved the project goals, with an 11.2 HSPF, the CCHP using two-stage compression will hardly be more cost-effective for residential customers.

\section{References}

Abdelaziz O. A., B. Shen, Z. Gao, V. D. Baxter, and I. Iu. 2011. "Development of a high performance air source heat pump for the US market." Proceedings of the 10th IEA Heat Pump Conference, Tokyo, Japan. CD rom format only.

Abdelaziz O. A. and B. Shen. 2012. “Cold Climates Heat Pump Design Optimization,” ASHRAE Transactions, Vol. 112, Part 1.

Abdelaziz O. A. 2013. "ORNL Cold Climate - Experimental Investigations," presentation at Annex 41, 1st Working Meeting, Purdue University, July 1.

AHRI 2008. ANSI/AHRI Standard 210/240-2008, "Performance Rating of Unitary AirConditioning and Air Source Heat Pump Equipment," Air-Conditioning, Heating, and Refrigeration Institute, Arlington, VA, USA. 
Emerson CRADA final report, December 30, 2015

AHRI 2010-2013. Central Air Conditioners and Air-Source Heat Pumps Historical Data. Retrieved from AHRI website (www.ahrinet.org) in December 2010 and in August 2013).

AHRI 2012. “HVAC\&R \& Water Heating Industry Statistical Profile,” 2012 Edition.

ASHRAE 2010. ANSI/ASHRAE Standard 55-2010, “Thermal Environmental Conditions for Human Occupancy," American Society of Heating, Refrigerating, and AirConditioning Engineers, Atlanta, GA, USA.

Bach C. K., J. A. Braun, E. A. Groll, and W. T. Horton. 2013. "Cold Climate Heat Pumps Performance improvement by modification of compression process and cycle," presentation at Annex 41, 1st Working Meeting, Purdue University, July 1

Bell I. H. 2011. "Theoretical and Experimental Analysis of Liquid Flooded Compression in Scroll Compressors," PhD Thesis, Herrick Laboratories, Purdue University, West Lafayette, IN, USA.

Bell I. H., E. A. Groll, and J. E. Braun. 2011. "Performance of Vapor Compression Systems with Compressor Oil Flooding and Regeneration," International Journal of Refrigeration, Vol. 34, No. 1, pp. 225-233.

Bertsch S. S. 2005. "Theoretical and experimental investigation of a two stage heat pump cycle for Nordic climates,” (Doctoral dissertation, Master's thesis, Mechanical Engineering, Herrick Labs 2005-13P, Report).

Bertsch S. S. and E. A. Groll. 2006. “Air Source Heat Pump for Northern Climates Part I: Simulation of Different Heat Pump Cycles," Proceedings of the 11th International Refrigeration and Air Conditioning Conference at Purdue.

Bertsch S. S. and E. A. Groll. 2008. “Two-stage air-source heat pump for residential heating and cooling applications in northern US climates," International Journal of Refrigeration, Vol. 31(7), pp. 1282-1292.

Bucher M. E., C. M. Grastataro, and W. Coleman. 1989. "Heat Pump Life and Compressor Survival in Diverse Climates,” EPRI Report No. CU-6254, February 1989 (AEP).

Bullock C. E. 1978. "Energy Savings through Thermostat Setback with Residential Heat Pumps,” ASHRAE Transactions, Vol. 84, Part 1.

Bullock C. E., G. C. Groff, and W. R. Reedy. 1980. "Sizing of Air-to-Air Heat Pumps for Northern Climate Residential Heating Applications,” Proceedings of the International HVAC Congress, Berlin, Germany, April 17-18. 
Emerson CRADA final report, December 30, 2015

Caskey S. L., E. A. Groll, and W. J. Hutzel. 2013. "Cold Climate Heat Pump Field Demonstration of Air-Source Heat Pump with Two-Stage Compression and Economizing,” presentation at Annex 41, 1st Working Meeting, Purdue University, July 1.

Caskey S. L. 2013. "Cold Climate Field Test Analysis of an Air-Source Heat Pump With Two-Stage Compression and Economizing,” Master’s Thesis, Purdue University, Ray W. Herrick Laboratories, West Lafayette, IN.

Census Bureau, U.S. 2013. Census Bureau's Characteristics of New Single-Family Homes Reports.

Conti, J., and P. Holtberg. 2011. “International Energy Outlook 2011,” Washington: Independent Statistics and Analysis of US Energy Information Administration.

Department of Defense, U.S., Energy Security Task Force, Office of the Under Secretary of Defense. 2009. The WSTIAC Quarterly, Vol. 9, No. 1.

Department of Energy, U.S. 2011. "Buildings Energy Databook," Office of Energy Efficiency \& Renewable Energy.

Energy Independence and Security Act of 2007. Public Law, (110-140), 2.

Energy Information Administration, U.S. (EIA) 2009. "Residential Energy Consumption Survey,” Tables HC6.8, HC6.9, HC6.10, and HC6.11. Accessed September 2013.

Energy Information Administration, U.S. (EIA) 2013. “Annual Energy Outlook (AEO).” Early Release Overview, Release Date: December 5, 2012, Report Number: DOE/EIA0383ER.

Energy Information Administration, U.S. (EIA) 2013. “Annual Energy Outlook 2013,” DOE/EIA-0383(2013), retrieved September 2013.

Executive Order. 2009. 13514. Federal Leadership in Environmental, Energy, and Economic Performance.

Groff G. C. and W. R. Reedy. 1978. "Investigation of Heat Pump Performance in the Northern Climate through Field Monitoring and Computer Simulation,” ASHRAE Transactions, Vol. 84, Part 1.

Groff G. C., C. E. Bullock, and W. R. Reedy. 1978. "Heat Pump Performance Improvements for Northern Climate Applications," pp. 838-846 in Proceedings of the 13th International Energy Conversion Engineering Conference, San Diego, CA, USA, September. Society of Automotive Engineers. Paper no. 789455. 
Emerson CRADA final report, December 30, 2015

Groff G. C., W. R. Reedy, and C. E. Bullock. 1979. "Recent Investigation of Air-Source Heat Pump Performance in Cold Climates," Paper E1-25 in Proceedings of the 15th International Congress of Refrigeration, Venice, Italy, September 23-29. International Institute of Refrigeration.

Groff G. C. and J. P. Moreau. 1983. "An Investigation of Air-to-Water Heat Pump Performance in New and Existing French Homes,” ASHRAE Transactions, Vol. 89, Part

Groff G. C. and R. E. Ertinger. 1984. "Heat Pumps in the USA - Projections for the Future," Published in the Proceedings of the 1st International Energy Agency Heat Pump Conference, Graz, Austria, May.

Groff G. C., C. E. Bullock, and R. E. Hough. 1984. "An Investigation of Electric Heat Pumps Applied to Commercial Buildings," Published in the Proceedings of the 1st International Energy Agency Heat Pump Conference, Graz, Austria, May.

Hadley A., J. Callahan, and R. Stroh. 2006. "Without strip heat: In-Situ monitoring of a multi-stage air source heat pump in the Pacific Northwest," Bonneville Power Administration.

International Code Council (2006). “2006 International Energy Conservation Code,” International Code Council, Washington, DC. http://www.iccsafe.org

Khowailed G., K. G. Sikes, and O. A. Abdelaziz. 2011. "Preliminary Market Assessment for Cold Climate Heat Pumps," Oak Ridge National Laboratory report ORNL/TM2011/422, August.

Kwon O., D. Cha, and C. Park. 2013. "Performance evaluation of a two-stage compression heat pump system for district heating using waste energy," Energy.and Building

Lannus A. 1993. "Expanding the Limits: Heat Pump Technology and markets in North America,” p. 373-380 in Heat Pumps for Energy Efficiency and Environmental Progress. Proceedings of the 4th International Energy Agency Heat Pump Conference, Maastricht, The Netherlands, April 26-29.

Lapsa M. and G. Khowailed. 2011. "The Evolution of the U.S. Heat Pump Market," Proceedings of the 10th International Energy Agency Heat Pump Conference, Tokyo, Japan.

Lovvorn N., C. C. Hiller, and A. Bartolucci. 2001. "Heat Pump Life in AlabamaRevisited: A Follow-Up Survey 13 Years Later,” EPRI, Palo Alto, CA, and Alabama Power Company, Birmingham, AL: 2001. 1006265.

Lovvorn N. and C. C. Hiller. 2002. "Heat Pump Life Revisited,” ASHRAE Transactions, Vol. 108, Part 2. 
Emerson CRADA final report, December 30, 2015

LBNL. 2012. EnergyPlus Example File Generator, Lawrence Berkeley National Laboratory, Berkeley, CA, USA, http://apps1.eere.energy.gov/buildings/energyplus/cfm/inputs/

Mahderekal I., B. Shen, E. A. Vineyard. 2012. "System Modeling of Gas Engine Driven Heat Pump," Proceedings of 14th International Refrigeration and Air Conditioning Conference at Purdue, West Lafayette, IN.

Mathison M. M., J. E. Braun, and E. A. Groll. 2011. "Performance Limit for Economized Cycles with Continuous Refrigerant Injection,” International Journal of Refrigeration, Vol. 34, pp. 234-242.

Mathison M. M. 2011. "Modeling and Evaluation of Advanced Compression Techniques for Vapor Compression Equipment,” PhD Thesis, Purdue University, Ray W. Herrick Laboratories, West Lafayette, IN.

NEEP (Northeast Energy Efficiency Partnerships), “Cold Climate Air Source Heat Pump Listing”,http://www.neep.org/initiatives/high-efficiency-products/emergingtechnologies/ashp/cold-climate-air-source-heat-pump

NEEP (Northeast Energy Efficiency Partnerships), "Cold Climate Air Source Heat Pump Specification”,http://www.neep.org/initiatives/high-efficiency-products/emergingtechnologies/ashp/cold-climate-air-source-heat-pump

PNNL. 2012. Residential Prototype Building Models, Pacific Northwest National Laboratory, Richland, WA, USA, http://www.energycodes.gov/development/residential/iecc_models

Pientka K. A. 1987. "Heat Pump Service Life and Compressor Longevity in a Northern Climate,” ASHRAE Transactions, Vol. 93, Part 1.

Ramaraj S. 2012. "Vapor compression enhancements for cold climate heat pumps," Master Thesis, Herrick Laboratories, Purdue University, West Lafayette, IN, USA.

Ratts E. B. and J. S. Brown. 2000. “A generalized analysis for cascading single fluid vapor compression refrigeration cycles using an entropy generation minimization method,” International Journal of Refrigeration, Vol. 23(5), pp. 353-365.

Rohm C. W. and M. S. Kim. 2011. "Effects of intermediate pressure on the heating performance of a heat pump system using R410A vapor-injection technique," International Journal of Refrigeration, Vol. 34(8), pp. 1911-1921.

Roth K. W., D. Westphalen, J. Dieckmann, S. D. Hamilton, \& W. Goetzler. 2002. "Energy consumption characteristics of commercial building HVAC systems Volume III: 
Emerson CRADA final report, December 30, 2015

Energy savings potential," Report prepared by TIAX LLC for DOE Building Technologies Program.

Ryan J. D. and G. C. Groff. 2002. North American Market Overview. pp. 26-37 in Heat Pumps - Better by Nature. Proceedings of the 7th International Energy Agency Heat Pump Conference, Beijing, China, May 19-22.

Shen B. and C. K. Rice. 2012. "Multiple-Zone Variable Refrigerant Flow System Modeling and Equipment Performance Mapping," Conference CD of ASHRAE 2012 Winter Conference, Chicago, IL.

Shen B., O. Abdelaziz, and C. K. Rice. 2012a. "Auto-Calibration and Control Strategy Determination for a Variable-Speed Heat Pump Water Heater Using Optimization,” HVAC\&R Research, Vol. 18(5), pp. 904-914, 2012.

Shen B. 2013. "Cold Climate Heat Pump - ORNL System Modeling and Analysis," presentation at Annex 41, 1st Working Meeting, Purdue University, July 1.

Shen, B., S. S. Shrestha, and O. A. Abdelaziz. 2013. “Assessment of Main Strategies for Achieving Performance Targets for Cold Climate Heat Pump,” draft ORNL Report (under review), February, 2013.

Song. 2013. "Modeling and experimental validation of multi-port vapor injected scroll compressor," Master Thesis, Herrick Laboratories, Purdue University, West Lafayette, IN, USA.

Wang S. and A. Majumdar. 2004. "Digital Scroll Technology," ISHRAE Journal, January-March, Issue 2004.

Wang X., Y. Hwang, and R. Radermacher. 2009. "Two-stage heat pump system with vapor-injected scroll compressor using R410A as a refrigerant," International Journal of Refrigeration, Vol. 32(6), pp. 1442-1451.

Xu X., Y. Hwang, and R. Radermacher. 2011. "Refrigerant injection for heat pumping/air conditioning systems: literature review and challenges discussions,” International Journal of Refrigeration, Vol. 34(2), pp. 402-415.

Zubair S. M., M. Yaqub, and S. H. Khan. 1996. "Second-law-based thermodynamic analysis of two-stage and mechanical-subcooling refrigeration cycles," International Journal of Refrigeration, Vol. 19(8), pp. 506-516.

Yang, Bin; Blatchley, Timothy N.; Bach, Christian K.; Braun, James E.; Horton, W. Travis; and Groll, Eckhard A., "Application Of Oil Flooded Compression With Regeneration To A Packaged Heat Pump System" (2014). International Refrigeration and Air Conditioning Conference. Paper 1547. http://docs.lib.purdue.edu/iracc/1547 